\title{
AN INVESTIGATION INTO HOW A GLOBALISED \\ LIFESTYLE, INTERNATIONAL CAPITAL AND AN \\ INTERNATIONAL SCHOOLING EXPERIENCE \\ INFLUENCE THE IDENTITIES AND ASPIRATIONS OF \\ YOUNG PEOPLE.
}

Thesis submitted for the degree of

Doctor of Education

at the University of Leicester

by

Jonathan Gerald Young

School of Education

University of Leicester 


\section{An investigation into how a globalised lifestyle, international capital and an international schooling experience influence the identities and aspirations of young people.}

\section{Jonathan Young}

\section{Abstract}

This research project focussed on the aspirations and identities of students in an international school in Belgium. Aspirations are framed and formed by both macrolevel factors such as social and international capital and schooling and micro-level factors such as well-being, identity, agency, relationships and motivation: in short, via the interaction and interrelationship of self and social context. The originality of this work is in its emphasis on students' own perceptions of the influences on their aspirations, within the geographical space of Belgium and the social sub-culture of a fluid, semi-transient international social context and a local student population. The study explains, from the students' viewpoint, the factors which affect the aspirations of a privileged group of young people. This research indicates convincingly that socioeconomic background and international capital are crucial factors framing and influencing young people's expectations and aspirations. This study also shows us that home is not bound by space and mobility does not limit the participants' sense of selfworth. Also, transience does not threaten nor hinder their stable sense of identity as their relationships with family and friends are strong and bounded by trust. In the worlds of these 'third' and 'fourth' culture young people, identities are not at all 'fragmented', as has been previously claimed. Additionally, the participants are very similar due to their privilege, are not naïve about their own advantage and are not 'blinkered' by their position. These findings could be of great interest to those working in an international school context. This study might help schools maximise on the international experiences of students to reflect on their global citizenship and altruism. This project has the possibility to help international school educators, who are active players in this culturally complex field better support young people in their process of identity formation in a global society. 


\section{Acknowledgements}

Writing can sometimes feel like a solitary endeavour. Yet, it cannot happen without encounters with and support from others. It is difficult to thank all of the people who have, in various ways, supported me in the completion of my thesis. Firstly, I must express my deepest gratitude to my outstanding and patient supervisors, Dr. Joan Smith and Dr. Hugh Busher. I have learned a tremendous amount about education from both of them. Throughout the four years of the doctoral program Joan has been a wonderful coach, mentor, teacher, guide and inspiration to me. Her clear guidance and strong support have made this an enjoyable and rich professional experience. Other people in my life who have moved my thinking forward, helped me and have been with me throughout this journey in one way or another are Mark Silcock, Jonathan Jones, Dr. Phil McCash, Colm O'Connor, Ewan MacDonald, Helen Manning, Jill Young, Dr. Lee MacLean, Jim and Jeanne Dorie, Dr. Katy Vigurs, Maria Scalise, Jeffrey Blucher and Stephanie Cooper, Tim Nichol and Sandra Strigel, Gil Paelinck, Walter and Mary MacDonald, Mark Deen, Dr. Ron McCarville, Janet O'Brien, Steven Bainbridge, Tineke de Regt, Hubert Jacobs, Anthony Howard, Dr. Richard Pearce and The European Council of International Schools. E.C.I.S. recognised my work when they awarded me The E.C.I.S. Fellowship Grant Award in 2012. All of the above mentioned persons' intellect, support, friendship, encouragement and insight are admirable, inspiring and enabled me to complete the thesis. Lastly, my thanks go to the young people who gave up their time to share their life stories with me. They generously offered their insights, thoughts and musings to me. I hope I have represented their voices in a way which does them justice. I wish them well in their future transitions and I hope that they realise their aspirations. 


\section{Preface}

I am a Canadian, born to two Canadian parents. I still hold a Canadian passport although I have not lived there in 18 years. I lived in the same small town where I was born in Canada until I was 18 years old, at which point I went to university only two hours away in a neighbouring province. During my childhood I only moved house once and that was around the corner in my same hometown in Nova Scotia. I would not say that my family was privileged and travelling was a special treat for me during my childhood and young adulthood. After completing my Bachelor of Education and spending one year supply teaching in Canada, my international teaching experience began in 1997 at the age of 25, when I moved to South Korea to teach English, and began living outside of Canada for the first time in my life. I then spent two years teaching third grade at a small international school in Ukraine and since 1999 I have lived and taught secondary students in international and European schools in Belgium. My teaching experience has predominantly been with young people of affluence and from a high social economic status and background. Recognising some of the gaps between my life-world and the life-worlds of my students, whilst at the same time recognising certain similarities, I found myself fascinated by their lives, their sense of

who they are and where they hope to be going. This is the story of my research with a special cohort of my own former international school students. I am grateful to them for their sharing their life stories with me. I do hope the experience of participating in the study allowed them to reflect on their own lives.

The journey of a research project includes selecting a research design, choosing methods, thinking about validity and ethics and writing up results (Wolgemuth et al 2015: 352). This thesis begins with an introduction to and rationale for the study. I discuss the keys issues surrounding the study and its context and reveal the research questions. In Chapter Two I explore the literature around this study and categorise the readings by theme. In Chapter Three I explain the methodology of the study and discuss how the data was collected, organised and analysed. In Chapter Four I report and analyse my findings in themes and incorporate the headings of the research questions as they relate to the themes. In Chapter Five I summarise the key points I make in the thesis, state my original contribution to knowledge, discuss the 
professional relevance of the work, and outline recommendations for practice and further research. I conclude the thesis with a personal reflection of the doctoral study experience. 


\section{Table of Contents}

$\begin{array}{lr}\text { Abstract } & 2\end{array}$

$\begin{array}{ll}\text { Acknowledgements } & 3\end{array}$

$\begin{array}{ll}\text { Preface } & 4\end{array}$

$\begin{array}{lc}\text { Contents } & 6\end{array}$

$\begin{array}{ll}\text { Chapter One -Introduction } & 10\end{array}$

$\begin{array}{ll}1.1 \text { Rationale for the Study } & 10\end{array}$

Adolescence and Aspirations 12

Youth Identity in the Present Day 15

$\begin{array}{lr}\text { Student Voice, Belonging and Self-Exploration } & 17\end{array}$

1.2 Research Questions 22

1.3 Context and Background of the Study 22

$\begin{array}{ll}\text { An Elite Education } & 23\end{array}$

Globalisation and Privilege $\quad 28$

$\begin{array}{ll}\text { 1.4 Summary } & 35\end{array}$

$\begin{array}{ll}\text { Chapter Two -Literature Review } & 37\end{array}$

$\begin{array}{ll}2.1 \text { Introduction } & 37\end{array}$

$\begin{array}{ll}2.2 \text { Aspirations and Identity Formation } & 38\end{array}$

The Shaping of Aspirations 38

Identity Formation and Agency 45 
2.3 International Capital and International Schooling

The Importance of Relationships Formed in International Schools 
5.4 Professional Relevance to International Education

and Implications of the Study

5.5 Recommendations for Further Research 155

5.6 Personal Reflection 158

\section{Appendices}

Table One: Issues and Themes from the Pilot Study

Table Two: The Participants of the Main Study 
Table Six: Other Themes Mentioned in the Main Study

Further Evidence from the Participants' Interviews

References

List of Tables

Table One: Issues and Themes from the Pilot Study

Table Two: The Participants of the Main Study

Table Three: Issues and Themes from the Main Study

Table Four: Categories of Aspirations

Table Five: Categories of the Participants

Table Six: Other Themes Mentioned in the Main Study

\section{List of Figures}

Figure 1 'Holiday' 


\section{Chapter One}

\section{Introduction}

\subsection{Rationale for the Study}

The aim of the study was to gain rich insights into young people's perceptions of the factors that influence their current and evolving aspirations and how they see their present selves and envisage their future selves. This is a study of the sense I make of the sense young people make of their experiences. The originality of this work is in its emphasis on students' own perceptions of the influences on their aspirations, within the geographical space of Belgium and the social sub-culture of a fluid, semi-transient international social context and a local student population. The implications of these insights can inspire positive practices in international schools that seek to support students' abilities to define their own futures and develop ethically and socially responsible citizens.

The international school is a rich site for sociological inquiry in global times (Tarc and Tarc 2015: 34). My particular interest in aspirations and identity formation arose from my 18 years teaching internationally; in South Korea, Ukraine and Belgium. It fascinates me how young people see their present selves and envisage their future selves. The children I have taught have generally come from advantageously situated socio-economic groups in their home societies and have significant amounts of capital invested in them.

An over-looked global educational development has been the growth of international schools (Bunnell 2015a: 1). Today, most major cities in the world have at least one international school (Brummitt and Keeling 2013: 25). International schools represent a phenomenon worthy of academic research as they are a market force which is driving education globally (Tarc and Tarc 2015: 34; Brummitt and Keeling 2013: 25). The International Baccalaureate's (I.B.) reputation targets academic high achievers aiming for university entrance. The I.B. is the secondary school two year degree program which most international schools offer and is a globally recognised brand 
name and logo (Bunnell 2008: 158). In November 2014 there were 2,626 schools in 139 countries offering the I.B. Diploma Programme (Bunnell 2015b: 388). The I.B. anticipates serving 2.5 million children in 10,000 schools by 2020 (Bunnell 2011: 268). International education, a term without a circumscribed meaning (Pearce 2013a: xii), raises sociological questions pertaining to globalisation, social class, multiculturalism and identity formation (Resnik 2012: 292). Though international schools existed before the term 'globalisation' was coined, mobility and transience were influential factors in the creation of international schools (Hayden and Thompson 2013: 4). Today, schools designating themselves as international can no longer be considered a peripheral dimension of educational provision (Bunnell et al 2016: 2).

A global internationally minded citizen is someone who espouses the values of empathy, collaboration and compromise, is committed to the recognition of basic human rights and their own responsibility to reduce the inequalities and injustices in the world. Interculturalism asserts that teachers and students ought to recognise oppression by promoting education for empathy (Faas et al 2014: 306). The five tenets of injustice are that: elitism is efficient, exclusion is necessary, prejudice is natural, greed is good and despair is inevitable (Dorling 2011: 1). Empathy has the capacity to generalise positive perceptions from those directly involved in the interactions to the groups of which they are each members (Hughes et al 2013: 762). Schools should aim for children to understand others, apply and defend human rights and have children feel like they are part of a community (Dorling 2011: 311). As one of the most useful facilities for young people in the modern world is accepting difference in one's world, there exists an opportunity for international schools to further practise perspective taking about respectful living with each other and to place the good of the whole beyond their own needs (Murdock et al 2014: 132; Bruhlmeier 2010: 18). A society must organise itself around the norms and rationality of love, care and solidarity (Apple 2013: 16) and international schools are an appropriate starting point to create such a society.

This study attempts to advance the idea that embracing diversity and the recognition of the many forms of national identities can lead to improved social cohesion (Keddie 2014a: 4). Exploration and identity formation are primary developmental tasks during 
adolescence and the transition to adulthood (Malanchuk et al 2010: 97). For young people in the circumstances explained here, identities are rooted in transience in space and social relationships which yet remain stable in terms of family, social capital, privilege and trans-generational aspiration. These young people are making the best out of their cosmopolitan condition and using the resources they have at their disposal, given the social arena they are engaging in (Weenink 2008: 1103). In order to better serve and empower their students, those working with them in the international schooling environment have an opportunity to improve upon the practice of listening to and working with this unique group of first world citizens so that they can embrace life in all its fullness. It is imperative that cultural aspects be considered when developing mentoring and guidance programs so that all students are more fully informed as to their options of what they want to do in life (Kochan 2013: 412). The international educator must recognise the importance of the pedagogical relation which is based on openness and trust, which in turn encourages every unique individual to share and question who they are (Adami 2014: 301). This can in turn help young people develop the capabilities necessary to flourish as human beings (Glassman 2011: 162).

\section{Adolescence and Aspirations}

In order to understand the individual it is necessary to understand the social situations in which the individual exists (Wertsch 1993: 25). It is not enough to know what young people are doing, but how they make sense of the world and understand life (Vornanen et al 2009: 401). With the capacity for abstract thinking, adolescents begin identity exploration, facing the critical questions of 'who am I?' and 'what will I amount to?' (Luthar et al 2013: 1536). There is a growing interest in how adolescents are building and defining identities, the fundamental and core developmental task during this time of life (Gee 2000: 120; Crocetti et al 2008: 983; Crocetti et al 2014: 1818). Young people between 11 and 15 face many pressures and challenges, including academic expectations, changing social relationships with family and peers and the physical and emotional changes associated with maturation (World Health Organisation 2012: 2). Adolescence consists of compelling and stressful life stories not only for the personal aspect but also for educational and career development aspects 
(Erden and Ummet 2014: 72). In the era of modernity where young people feel increasing risk, the identities of young people are subject to tremendous change (Stahl 2014: 88).

Education and whole school improvement should be based upon or at least be informed by the best available evidence and research (Biesta 2014: 19; Mincu 2015: 253). Teachers who engage in and with research 'will incline towards a reflexive disposition' (Leat et al 2015: 271). Sustained, enquiry-oriented learning is part of the research world's traditional approach to supporting continuing professional development for teachers (Cordingley 2015: 249). To my knowledge, no such qualitative study, in which students in international schools have been interviewed, has been conducted in Belgium. I chose not to explore young people's aspirations longitudinally but rather to forefront a snap-shot in time, this very particular time of young people's lives as they experience adolescence.

One main argument of this study is that transience does not threaten the stability of the identity of this cohort of young people due to their strong familial ties and international capital. Additionally, the data clearly show that cultural, international and social capital are the keys to the participants' agency and have a direct impact on their aspirations. This project adds to the body of research completed on student voice and it offers the potential to inform practice in international schools. This practice includes guidance, developing close and nurturing relationships with students, introducing or exposing young people to options and possibilities in their lives, recognising and encouraging talents in young people, and advising on the most appropriate goals to which young people can aspire.

Aspirations provide an interesting focus for sociological analysis, as they can allow us to explore the intersection of identities and inequalities within young people's lives (Aspires 2013: 8). Aspiration has been described as the various desires, dreams, choices, hopes and ambitions held by young people about their futures (Kintrea et al 2011: 12; Unterhalter et al 2014: 133; Kintrea et al 2015: 666). Aspirations occur within a social context, rather than only in isolation. Aspirations are formed from both macro and micro level factors. St. Clair and Benjamin (2011: 507) explain that 
aspirations are formed from the resources available in four domains: place, school, family and individual. They are multidimensional in nature; from careers to education to financial, familial and social. Aspirations are personal, subjective, continuous, intensive, and they evolve with the passage of time. Aspirations can also be perceived as an emotional state to be affected, as Brown (2011: 9) explains: aspiring to become something, aspiration as an emotional disposition, an emotional state that can be affected and an emotional state that affects other emotions. Emotions are feelings connected to ideas and perceptions of our social and cultural contexts (Miller 1997: 8). These emotions even reveal themselves in the case of social class (Tyler 2008: 19). A desire to stay in school and attend university, and to aim for a job which requires qualifications and skills is seen as possessing high aspirations, while aiming to leave school early and take a low skilled job is taken to mean one has low aspirations (Kintrea et al 2015: 667).

Childhood has a profound effect on our lives. Growing up can be a tough time in one's life. Adolescents are faced with a multitude of factors and influences which dynamically shape their choices (Albert and Steinberg 2011: 211). Aspirations shift from fantasies in early childhood to tentative explorations of personal interests, abilities and values in adolescence (McDevitt et al 2013: 532). Young people have no shortage of aspirations and those aspirations they hold have come to be considered an important influence on their ultimate achievements (Rose and Baird 2013: 170; St. Clair et al 2013: 1). Quaglia and Cobb (1996: 130) offer a clear definition of a student's aspirations as their 'ability to identify and set goals for the future, while being inspired in the present to work toward those goals'.

Human beings are complex organisms and the development of the self is a life-long process in which adolescence is seen as a particularly important period (Michalos 2008: 347; Murdock et al 2014: 122). According to Havighurst (1953: 111) adolescence spans the period from 12-18 years of age. This period of intense change impacts the interaction between individuals and their environments (Vera-Estay et al 2015: 17). Adolescents spend more time with their friends as they gravitate towards their peers and away from their parents (Jager et al 2015: 515). Adolescence is a developmental 
period of storm, unpredictability, exploration, dreaming, planning and stress when future thinking becomes increasingly salient, especially in the domains of education and occupation (Arnett 2006: 186; Beal and Crockett 2013: 219; Flouri and Panourgia 2012: 14; Prince 2013: 1).

\section{Youth Identity in the Present Day}

Youth must often test extremes in their identity formation, before settling on a considered course (Erikson 1962: 7). Some of these fearless teenage habits and behaviours are dampened with age and experience (Molloy 2015: 468). However, extreme behaviours in adolescence might involve crime, smoking, drinking, drug use and other unhealthy activities which have the potential to play out over a lifetime if not changed during adolescence (Reyna and Farley 2006: 1).

The number of children and young people with mental health problems such as anxiety and depression has increased in the Western world in the last 25 years (N.H.S. England 2008: 2). Over half of mental health problems in adult life (excluding dementia) start by the age of 14 (N.H.S. England 2015: 9). Children with mental health problems are more likely to be excluded from school than their peers (N.H.S. England 2008: 4).

In the last few decades, the disciplines of philosophy, psychology, anthropology, cultural studies and the social sciences have all contributed to studies on identity formation and the construction of self (Pizzorno et al 2015: 196). The period of adolescence is an important time of identity development, characterised by tension between an increasing need for autonomy and an increasing conformity to societal expectations (Barni et al 2011: 106). As children grow and make their complex passage into adulthood, they are faced with a multitude of choices that affect not only their own wellbeing, but that of their families and communities and unhealthy choices take tolls on healthcare costs and property damage as well as less measurable costs on human misery and lost potential (Settersen Jr. and Ray 2010: 19; Goldin et al 2014: ix; Reyna and Farley 2006: 2). Adults such as teachers should understand emotional and mental health in young people and know how to help those in need of care (N.H.S. England 2015: 11). 
There are over 3.5 billion people under the age of 25 in the world today. The estimated 1.8 billion youth who are between $10-24$ on the planet today represent the largest youth generation in human history (Goldin et al 2014: 2). The largest group of people between the ages of 0-14 live in Asia (Alipio et al 2015: 255). The so-called Generation Y, born between $1980-2000$ is stereotyped as being overly pampered, narcissistic and lacking commitment while young people born since 2000 (Generation Z) are the first generation to be born into a world of unprecedented communicative technology, the consequences of which we are only becoming aware (McGregor 2013: 3; Hayden and Thompson 2013: 13). Media plays a salient role in the identity formations and constructions of young people (Sihvonen 2015: 171). A life without television, the internet, gaming and mobile phones is very uncommon in Western countries (Sihvonen 2015: 171). Media consumption has become an alternative way of spending leisure time (Sihvonen 2015: 182) and whilst electronic media has some positive effects, there are concerns about decreased attention and excessive use amongst young people (N.H.S. England 2015: 38).

The image of young people as tech-savvy, narcissistic digital natives who take photographs on their phones and share them on social media, among other things, in sharp contrast to older generations, has become almost something of a cliché, and characterises much public discourse around young people today (Beavis 2013: 39). These technological developments, coupled with increased mobility, have facilitated continuous exposure to linguistic and cultural diversity, in professional and personal contexts, abroad and at home (Messelink et al 2015: 64). Technological change can lead to aspirational shifts, new expectations and new desires as young people are exposed to more and more of the world (O'Reilly 2012: 74). Technology and social changes make Generation Z's future complex and shifting (Hooley et al 2015: i).

Young people appreciate opportunities to tell their stories to empathetic listeners (Wolgemuth et al 2015: 353). There is a new emphasis on the child and youth centred study of children and young people, taking their own priorities, thoughts, understandings and concerns as starting points for social enquiry (Hemming and Madge 2011: 39; Mazzoni and Harcourt 2014: 257). A school is a learning community where the active involvement of all members is vital (Martinez et al 2015: 45). If we 
consider children endowed with agency and autonomy, able to express their points of view and priorities, then all school pupils have a right to have their voices listened to (Ballet et al 2011: 22; Mclntyre et al 2005: 150).

Experiencing the present is simply not as meaningful as mentally transporting oneself to the past or future (Waytz et al 2015: 350). Skrbis et al (2011) recognised the growing emphasis on the reflexive self, where individuals determine their future pathways (Skrbis et al 2011: 63). We should not underestimate the ways in which the past and present shape aspirations for the future (Smyth and Wrigley 2013: 47). Academic research suggests that all people are capable of engaging in self-reflection about their future and that self-reflection is beneficial (Maxwell and Aggleton 2013: 8; Wolgemuth et al 2015: 358).

All people are constantly undertaking a process of self-authoring where issues such as social class and the positions imposed by self and others are significant (Cahill 2011: 29). In adolescence, remembering the personal past and understanding what kind of person one is intertwine to form a story of one's life (Habermas and Hatiboglu 2014: 29). Looking back not only enriches our lives, it can help us to see what lies ahead. Voices of children need to be included in research which considers aspirations as children know more than anyone else what their lives are like and the human being is the only animal that thinks about the future (Pimlott-Wilson 2011: 111; Amplify et al 2013: 5; Goldin et al 2014: xii; Waytz et al 2015: 351). Qualitative research now includes the insights of participants' voices which have been excluded from telling their stories in the past (Gitlin 2008: 627).

\section{Student Voice, Belonging and Self-Exploration}

Teachers can use students' ideas to develop their teaching in ways in which both they and the students believe are important (Mclntyre 2004: 88). Linking democracy to education is nothing new but is becoming more and more important (Strajn 2014: 587). Although meaningful student involvement strengthens a commitment to democracy, students' perceptions of the learning environment in schools are not often valued or taken into account (Fletcher 2005: 5; Hopfenbeck 2013: 179). The pivotal feature of involving children in research is educative, creating a space where they can 
not only express their ideas but reflectively develop their own values (Sternberg 2001: 238; Mazzoni and Harcourt 2014: 256). Individuals are agentic in the construction and reconstruction of themselves (Gale 2013: 4), and encouraging a reflective selfnarrative helps to bring a young person hope for the future, for a failure to project a future hopeful story can result in a present life of unhappiness (Polkinghorne 1988: 107). Therefore giving students a space to express a view acknowledges their right to be listened to (Mazzoni and Harcourt 2014: 257). Working in more collaborative ways with students goes further toward developing trusting relationships in schools between teachers and students (Mclntyre 2004: 90).

Education has been described as an institutional transmitter of knowledge and as a contributor to the development of cultural competence (Hannerz 1992: 83). Students should be citizens and not subjects of their own schools (Bradshaw 2014: 3). Schools should teach young people about democracy and develop students' capacity to exercise citizenship when they leave school (Sohl and Arensmeier 2015: 133). Schools are social institutions and networks of sustained relationships and education can play a pivotal role in building a society where people trust and care about each other (Bryk and Schneider 2002: xiv; Murphy-Graham and Lample 2014: 61; Pearce 2013a: xiii). Feeling connected to school and valued by those within it develops a sense of agency in young people (McLaughlin and Gray 2015: 3).

International understanding is a central aim of international education. International education exposes young people to a complex world and the successful student will develop a complex understanding of it (Pearce 2013b: 78). There is a bewildering degree of diversity on our planet and a global culture is a developing phenomenon (Karim 2012: 138; Resnik 2012: 294). This global culture brings with it an exposure to and experience with other cultures. People in the United States tend to express less trust in their fellow citizens if they live in ethnically diverse areas, whereas, in contrast, the ethnic composition of neighbourhoods in the Netherlands is not systematically related to social trust (Ziller 2015: 1213). Educational research is distinguished as the creation of valid forms of knowledge that can explain the educational influences of individuals in learning of others (Whitehead 2008: 105). 
Social and physical contexts like schools instruct youth about who they might eventually become (Prince 2013: 6). International schools are growing in number and research into them has come in from the 'margins' of educational research to attract now greater interest from researchers and has become a promising field of inquiry (Dolby and Rahman 2008: 676; Resnik 2012: 291). This study aims to inform the understanding of how this type of independent and elite education shapes the experience and future orientations of students (Hayden 2011: 214; Maxwell and Aggleton 2013: 9). The study of this sort of 'elite' institution has a lot more ground to cover in scholarly research (Kenway and Howard 2013: 1210).

Nations consist of a group of people united by traditions, history, and political and geographical interests. People need to feel part of a larger group within which they have something in common with the other members in the group. Notions of home and family belonging have been central to the debates about transnational social spaces and cosmopolitan identity (McLeod and Burrows 2014: 369). Belonging has been defined as a personal, intimate feeling of being at home in a place (Antonsich 2010: 245). Individuals' backgrounds, relationships and length of settlement all play a part in people's ability to develop attachments and feelings of 'being at home' (Antonsich 2010: 247).

The feelings of emigrants contemplating departure are those of hope, heartbreak, fear, exhilaration and expectation (O’Tuathaigh 2014: 9). Children interact with transnational migration in many ways and through varying magnitudes of agency (Alipio et al 2015: 260). Although young people are significantly affected by globalisation in many ways, there is room for further study of its impact on their identity development (Jensen 2011: 62; Thompson 2012: 187). Although the interplay of culture and self has been one of the most active areas of research in self and identity (Kashima et al 2011: 12), it has been recognised that more detailed research is needed into the contextual specificity of transnationalism and the reproduction of elites (Power et al 2013: 578). For the purposes of this study 'transnationalism' is first and foremost about people: the social spaces they inhabit and the networks they form (Clavin 2005: 422). Elites possess vast amounts of economic, social, cultural, political 
and knowledge capital (Khan 2012: 361). It will be argued that international schools are one aspect in achieving social reproduction of the elite.

Teaching can profoundly shape the developing brain of an adolescent and education can contribute to the building of aspirations (Blakemore and Mills 2014: 9.14; Rao et al 2015: 1). Education has long been considered as playing a key social role in the construction or formation of self, identity, the recognition of capabilities and human flourishing (Seery 2010: 63; Alexander 2013: 488; Apple 2013: 20; Glassman and Patton 2014: 1353). Although mobility causes a change in a young person's social environments, it is also seen as an effective means of increasing intercultural understanding amongst young people (Messelink et al 2015: 62). These journeys of the mobile student thread together these varied social encounters which make up their lives. As education enlarges horizons and perspectives, blurred boundaries between groups form and these various forms of multiple belonging are important elements of modernity (Richter and Nollert 2014: 458). With globalisation and the movement of people and knowledge across the world, new opportunities, possibilities and aspirations are generated and identities redefined (Rao et al 2014: 849; Sellar 2013: 31-32).

International schools celebrate the number of nationalities represented in their student body and teaching staff as those people bring a 'multiplicity of cultural contributions' to the schools as well as adding to the colours, shapes and sizes of the young people's social worlds (Pearce 2011: 155; Cook 2015: 4). Examining the discourse surrounding international schools, Pearce (2013b), claims there exists a primitive portrayal of identity of the people within them (Pearce 2013b: 78). Arrington (2000: 104) writes that young people are engaged in a daily task of forming a firm selfidentity and guidance is a means to meet the need for self-exploration. Youth is an assemblage of multiplicities combining in radical and different ways to form a 'becoming-youth' (Riddle 2013: 45). Young people face choices in the areas of education and friendship and these choices may be solid and sustainable or misguided and harmful (Vornanen et al 2009: 403). Part of this self-exploration and decision making can be facilitated and guided by the people they are in contact with in international schools. Having a clearer understanding of how adolescents strive to 
meet goals and what goals they aspire to will assist those who help adolescents manage their goal striving strategies (Sawitri and Creed 2015: 1). Every school should develop the linguistic, social, logical, physical, creative, moral, personal and spiritual faculties of young people and to help them know who they are (Smith 2008: 561).

Children are entitled to an education that has their best interests at heart and develops their talents and skills to the full. Turok et al (2009: 44) found a sense among school staff that raising aspirations was a good thing and they observed projects and services taking place within the three schools they visited which were designed to support children to aspire. Sinclair et al (2010: 18) recommend that schools show themselves to be valuable by helping young people to reach the status to which they aspire. Borgen and Hiebert (2006: 398) conducted a study on careers guidance and concluded that programs should focus on the needs expressed by young people and they should have a say in the design of such programs.

It is an illusion that the education system is anything like a level playing field (Smyth and Wrigley 2013: 195). The reproduction of the dominant culture and the maintenance of the 'social order' (Bourdieu 1984: 387) are the precise functions of an institutional education system and some would argue that education is as much about social privilege as it is about training the mind (Findlay et al 2012: 118). The different school types prepare students for different occupational fields that are associated with different social classes; they shape youths' careers aspirations (Wicht and LudwigMayerhofer 2014: 298, 305). Taking Gorard's (2010: 62) claim that the type of school attended affects occupational aspiration further; he writes that schools can be precursors to the kind of society we wish to have, rather than just a reflection of society. Gorard reflected on a series of findings over the ten years prior to the writing of his paper which dealt with equity of school intake in eight countries worldwide. He concluded that specialist schools can only lead to segregation and challenges schools to concern themselves more with the kind of people they want their students to be (Gorard 2010: 62). In addition, by recognising that students have a legitimate voice in their schooling, educators can reflect upon this feedback and improve practice. 


\subsection{Research Questions}

The main research question for the study was:

How do a globalised lifestyle, international capital and an international schooling experience influence the identities and aspirations of young people?

The subsidiary research questions for the study were:

1. Is there evidence of a link between these students' first world citizenship privilege and the nature of their aspirations?

2. To what extent do parents influence aspirations?

3. To what extent do:

i. Globally nomadic experiences and

ii. International Schooling

influence the identity and aspirations of young people?

4. How do young people of this transnational class:

i. Define success and

ii. View their future selves?

\subsection{Context and Background of the Study}

The context for the study was a fee paying international school in Belgium, where, at the time of the study, there were approximately 800 students enrolled and over 50 nationalities represented. Belgium is home to the capital of Europe and is one of the most egalitarian of rich nations (Dorling 2011: 153), meaning people are generally seen as equal and are treated fairly. Belgium, with a population of nearly 11 million people, has three official languages; French, Dutch and German. Belgium is linguistically and politically divided into two regions, Flanders and Wallonia, where the predominant languages spoken are Dutch and French, respectively. Historically a Catholic country, Belgium welcomes a permanent flow of newcomers, a society of immigrants if you will, who bring with them diverse cultures and world views, creating a multicultural web of relationships among them. In Flanders, the Dutch speaking part 
of Belgium, socioeconomic segregation in schools is very high compared to other Western countries (Belfi et al 2015: 33).

\section{An Elite Education}

Located in a residential suburban setting in Belgium, the international school in this study is co-educational and serves students between the ages of 2-18. The school is owned by a religious order and is ecumenical in its outlook, with children of all religious beliefs welcomed and represented in the student body. The school advertises its values as 'companionship, integrity and respect'. The school could be argued to be intensely cultivating a particular privileging habitus with its long school day, an academically focussed curriculum and the wide range of extra-curricular activities, exchanges and trips on offer (Forbes and Lingard 2015: 116-117). Fees for one academic year in the school run in the area of 30,000 euros per year, per student.

Short-term mobility represents the bulk of cross-border movement of people (Mau et al 2015: 1193). International schools are diverse institutions serving mobile students whose average length of attendance is $2-3$ years, so at any one time these students are undergoing adjustments. The world of international schools is expanding, fuelled by globalisation and the ease with which people can relocate (Hrycak 2015: 29). The number of international schools has been increasing for many years and the international teaching market is larger than most people realise (Hrycak 2015: 30). By the end of this decade the number of international school teachers will reach 500,000 and in this group there is a rapid and extensive turnover of teaching staff in international schools where they teach (Tarc and Tarc 2015: 35; Bunnell et al 2015: 14; Odland and Ruzicka 2009: 7). International staffrooms include a mix of teachers from different backgrounds and personal circumstances (Hrycak 2015: 37). Within these staffrooms are larger numbers of 'host country teachers', which can diminish the need to appoint the 'overseas hire' teachers (Hayden and Thompson 2013: 9).

International schools could be argued to be an accidental space, responding to the demands of the elite in unique circumstances. International schools are in many respects a well-kept secret, with the majority worldwide completely unaware of their 
existence (Hayden and Thompson 2013: 3). The arena of international schooling, although growing rapidly, is still a peripheral and little-discussed one (Bunnell 2015a: 4). Suffice to say that since no international body has the authority to adjudicate on whether or not a school may describe itself as an international school, the 'international school' label can also be self-awarded and has to be interpreted cautiously (Hayden and Thompson 2013: 4). In this connection Bunnell (2006: 156) argues that international schools may not share an underlying educational philosophy and are, like an adolescent, in a permanent identity crisis (Pearce 2013a: xii). The arena of international schools has never been a system, with a coherent sense of standards, rules, practices or procedures (Bunnell 2015a: 5). MacKenzie (2009: 330) explains that international schools are hard to define but have common characteristics such as: they are mostly established to meet the needs of expatriate communities, they have volunteers on their boards, and the language of instruction is predominantly English. In fact it can be argued that the only characteristic that all international schools have in common is that the curriculum offered is not of the home country (Hayden and Thompson 2013: 9). This resonates with Jones' (2011: 312) description of international schools as catering to elite professional families who have high aspirations for their children and Hayden's (2011: 211) observation that aspiring middle class parents seek a competitive edge for their children in a globalized market.

'A public fascination with a family possessing incalculable wealth should itself signify an interesting academic puzzle' (Billig 1992: 14). Elites are those with vastly disproportionate control over or access to a resource (Khan 2012: 361). In this context, the elite have an access to wealth which separates them from an established middle class (Savage et al 2013: 220). An international school education is an elite education, paid for by the top income groups in society, and an elite education tends to be a very expensive education (Bray and Yamato 2003: 62; Dorling 2011: 71). International schools can be classified as 'elite' in that they are financially selective (Kenway and Koh 2015: 1). International schools are private and are both academically and socially elite (Bunnell 2010a: 474). Privileged parents transmit social advantage through the family (Gracia 2015: 290) and these parents make great sacrifices for accessing good-quality education, seeking to ensure their children gain entrance to elite universities and 
possess an ability to become part of an international mosaic of a world that accepts a global identity (Kenway and Fahey 2014: 182; Hasanen et al 2014: 549; Rao et al 2015: 2). These wealthy elites are removing themselves from the rest of the population as they move through these close social networks and access elite education for their offspring in order to secure their future success and financial positions (Hansen 2014: 458-459). The most high-end international schools serve the very rich and often very famous from around the world (Koh and Kenway 2012: 335).

The school on which this study focuses caters for a globally mobile student population whose parents have left their countries of origin for the purposes of high-end employment and a local student population whose parents see the school as an alternative to the national school systems. So, in effect these schools are dealing with two groups of people, the global nomad and the local student. These class actors are both expatriate and local, linked by their social ties across a number of registers of economic, political and social difference (Tarc and Tarc 2015: 37). Bates (2012: 265) clearly explains these two groups in his critique of the concept of global citizenship. Bates writes that the first "tier" consists of a transnational elite who hold an abstract notion of citizenship, not connected to any territory per se and imagine themselves as close to a cosmopolitan ideal. They travel internationally, function within multiple settings and provide part of the client base for international schools (Guy and Beaman 2003: 993). These people, as O'Reilly describes, move away from their nation, state, family and friends when they sometimes do not have to (O'Reilly 2012: 74).

The second tier, as Bates (2012: 265) puts it, seek to enhance their national or local citizenship by chasing perceived positional advantage through private education. This resonates with Roberts' (2012: 73) description of the host country family, usually paying the fees to the school themselves, as they are often from a particular social and economic class. The international school then responds to the perceived absence of desired educational values in host country local schools. As of 2013 , local students filled up $80 \%$ of international school places worldwide, a complete reversal of 30 years ago, when $80 \%$ were taken up by expatriate children (Brummitt and Keeling 2013: 29). These locals are wealthy parents who perceive the national education systems as 
inadequate for the new global age and are seeking out alternative paths to purchase a kind of education and credentials that will ensure their children a secure pathway in the global market place (Resnik 2012: 294; Bailey 2015a: 85). This elite class mostly and proudly chooses the elite English medium school which, unlike their state-run and non-elite counterparts, charge a high fee structure to provide a 'Western' atmosphere and 'modern' standards of education. Not surprisingly, the same standards completely exclude the working class and most of the members of the middle class from this elite educational circle (Dildar et al 2015: 2).

It has been argued that hard work and self-belief are messages which the elite convey as being the reasons for their success and privilege and recommend these as the route for others to follow (Littler 2013: 67). These privileged families could be attempting to distance themselves from the majority of the host country population and thereby gain perceived advantages for their children from following such an education. In essence, one group attempting to solidify its membership in the global transnational elite by following international education in international schools and another which seeks its own membership into the club. The Belgian student population of the international school under study stood at $25 \%$ at the time of the study. As consumers in a democratic nation, it is up to individual parents to decide to send their children to local or international schools (Song 2013: 147).

I found seven studies conducted since 2006 which related to local students attending international schools in their home countries. MacKenzie (2009) and Ezra (2007) both wrote of parental choice of and attraction to international schools in Japan and Israel, respectively. MacKenzie interviewed and sent questionnaires to parents of Japanese students who attended six international schools in Japan. He concluded from the findings that parents wanted their children to be educated in English, experience an exposure to other cultures and see a world beyond their home country (Mackenzie 2009: 344). Ezra (2007) surveyed and interviewed parents of Israeli students about their reasons for opting out of the local school system in favour of international schools. Problems such as school violence, lack of discipline, poorly trained teachers, and large classes in the local school environment were given by parents (Ezra 2007: 
259). Ezra concludes that the parents surveyed and interviewed saw the local school system in a state of decline. Surveys of parents in Singapore conducted by Vidovich and Yap (2008) found that international schools offered a broad education which was different from local schools (Vidovich and Yap 2008: 220). In a qualitative study of the reasons why parents in Hong Kong chose international schools over the local alternatives, $\mathrm{Ng}$ (2012) found that parents had lost confidence in the local education system and saw international schooling environments as more 'open and positive' ( $\mathrm{Ng}$ 2012: 128). Whilst all of these studies have their obvious contextual and cultural considerations, none of them solely focussed on the students attending these schools.

While Kanan and Baker (2006: 253) did not solely focus on aspirations they instead examined the influence international schools in Qatar have on local students' identities, career aspirations and university choice. In their findings however, they recommend that an investigation be conducted examining the influence international schooling has on the aspirations of local students. In an investigative study into the careers aspirations of Thai children who attended an international school in Bangkok, McDevitt et al (2013) found that students aspired to a range of careers and viewed their own abilities and interests as being of importance in choosing a career track (McDevitt et al 2013: 531). More recently, Bailey (2015) conducted a small-scale study of host country nationals attending an international school in Malaysia. She interviewed eight Malaysian students with the hopes of gaining insights into their experiences of an international education and found that the local students expressed an interest in gaining an education that would allow them to do well professionally and would enable them to succeed in higher education overseas (Bailey 2015a: 95).

Bagnall (2012) conducted in-depth interviews with nine expatriate international school students, aged 15-19 in Brazil. In the interviews he asked the participants questions about their nationalities, their sense of belonging and their thoughts about the future. In his findings he grouped the participants into three categories: those who knew where they came from, those who were not sure and those who felt an attachment to a global rather than national identity (Bagnall 2012: 177). Pearce (2011) in his work on identity formation of expatriate children, interviewed students aged 9-11 and 14-16 who had recently moved to the Netherlands and entered international schools and 
found that national identity gives students a sense of belonging at a time when familiar social markers may be missing (Pearce 2011: 168-169). He recommended further investigation in order to understand the complex value-systems of mobile children.

\section{Globalisation and Privilege}

There is an 'insatiable demand for English', the global business language (Tarc and Tarc 2015: 36). It was estimated that by 2015 approximately half the world's population would either speak or be learning English (Hayden and Thompson 2013: 15). The use of English in schooling causes the mind-sets of students to lean toward a whole range of foreign cultural values (Hasanen et al 2014: 548). Canada, Australia, New Zealand, South Africa and other countries have provided many teachers at international schools and some international schools still prefer their staff to be mother tongue speakers of English (Pearce 2013b: 66). In South Korea, for instance, English-medium international schools, initially established for foreign residents, have recently transformed themselves into private providers of global education for South Koreans (Song 2013: 136). It is likely that international schools will continue to recruit teachers from overseas to meet demand (Hrycak 2015: 38).

Student mobility is and has always been one of the most significant sources of intercultural awareness and one of the most productive contexts for language learning (Kinginger 2015: 7). Globalization is the process of international integration arising from the interchange of world views, products, ideas and other aspects of culture. It refers to the process which sets the stage for the exchange of values and ideas and is seen as a complex process of negotiation between local and foreign identities (Hasanen et al 2014: 543-546). In the present day there exists a growing population of people who live, work and converse in multiple cultures, countries and communicative contexts. To a young child, there is no difference between the USA and Japan (Minoura 1992: 312) and a person who adopts a global identity embraces the international experience and is open to engage with others and their ways of looking at things (Hasanen et al 2014: 543). Adolescence is a time of life with a pronounced openness to diverse cultural beliefs and behaviours (Jensen 2011: 64). Children are 
influenced directly and indirectly by changes in cultural values, beliefs and practices of other people, institutions and social interactions that occur within social ecologies which are altered by processes associated with globalisation (Jensen 2011: 62; Thompson 2012: 188).

Globalization and migration mark the rhythm and the tempo of the fluid contemporary modern society (Kuo 2014: 16). Globalization itself has a history spanning many centuries. The first period involved pre-state Asian, African and European trading empires. The second occurred during the period of 1600-1800 and involved European colonization and slave plantations. Modern globalization spans the period of 1850 to 1950, involving industrialization, economic interdependence and organizational internationalisation. In the past two decades the world has changed so much that we take these changes for granted (O'Reilly 2012: 59). Postcolonial globalization is the present period where the internet, global media and popular culture are significant (Barbalet 2014: 200). This 'third era' of globalization is a period of intense cross-border transactions (Mau et al 2015: 1193), where individuals collaborate and compete globally (Hayden and Thompson 2013: 14).

With the competition for jobs no longer sitting within national boundaries, there is a need to give consideration to the nature and context of international education (Myers 2010: 153; Weis 2014: 312). Globalisation has been seen as a transition from a Fordist workplace orientation to internationalised trade and consumption (Sahlberg 2004: 65). Globalisation has led to many international schools being established in Belgium over the last sixty years. Globalisation provides the client families and thereby the funding, through their salaries, for the operation of international schools. International schools serve families who are deployed to new locations due to their employment.

Many schools call themselves international and many others also cater to both expatriate and local families who seek what Bunnell (2005: 49) would describe as a 'more quality assured product within the host country'. Some parents are seeking an alternative to the national curriculum and see the international school as their preferred choice. Brussels is also a significant locale; being home to the European 
Commission and named the Capital of Europe. As the global mobility of some professionals and their families becomes increasingly commonplace, Hayden and Thompson (2000: 107) describe how more and more schools respond to the need to provide an international education to children in such circumstances. These 'elite' schools are selective; either through fees, interviews or examinations (Kenway and Fahey 2014: 181). The fee paying school in focus has catered to both foreigners and local Belgian students for over 50 years.

The meaning of globalization depicts a borderless, mobile world and lies in the process of enabling financial and investment markets to operate internationally, largely as a result of deregulation and improved communications (Walsh 2014: 598; Cantle 2011: 5). There is a clear increase in the mobility of goods, capital, services, information and people (Mau et al 2015: 1193). Capital-accumulating multinational corporations gain technological and managerial capacities by 'going global' (Zipin et al 2013: 2).

Globalization simultaneously both integrates and segregates as the narrowing of the social world during expatriation makes the school more salient than at home in the lives of the children (Pearce 2013a: xiii; Sahlberg 2004: 66). Globalization has created an area of 'super diversity' in which most western societies have become far more dynamic, complex, and fluid than ever before (Cantle 2011: 3). This contributes to a 'decrease' in size of the world as it takes far less time to move goods, money, images and people around (Carmo et al 2014: 340). In this complexity is a single world of deep interconnectedness in all aspects of social life (Held et al 1999: 2).

Lifestyle means 'how one lives' and includes values, interests and activities (Sihvonen 2015: 175) and there exists a public resentment for the present day lifestyles of the rich. By the 'rich' we can mean millionaires, celebrities and people running large businesses (Wilkinson and Pickett 2010: 181). Today the rich earn more, both in absolute terms and relative to the rest of the population (Oxfam 2014: 30). The rich have become much richer, they work much less, they have longer holidays, they travel more, they live longer, and they are healthier, but they are no happier (Layard 2003: 14). This leisure time spent together with their parents allows the children of the rich 
to acquire an 'embodied cultural capital' which includes cultural knowledge and language skills (Gracia 2015: 291).

It is an interesting context in that, whilst the students who attended are exposed to many different cultures in their school, most if not all of the children attending are from privileged backgrounds. Although the do not share a common culture in the traditional sense, they do share much of the benefits of privilege and social class.

Privilege describes a specific kind of power (Twine and Gardener 2013: 9) and has been understood as something individuals have or possess, rather than who they are (Howard et al 2014: 6). The term privileged in this context is defined by Nette and Hayden (2007: 436) as being afforded relative affluence through opportunities for travel, first-hand experience of different locations and forming relationships with people from numerous cultural backgrounds due to their parents' occupations as diplomats or employees of multinational organisations. Also in this instance, privilege is understood in relation to those who do not have the financial wealth to afford an exclusive or 'elite' education (Kenway and Koh 2015: 3; Vorhaus 2014: 188). Children from more privileged backgrounds attend better schools and have better experiences within any given school than do less privileged children (Jennings et al 2015: 58).

The role of consumption and possession has been of great interest to researchers for some time (Sihvonen 2015: 174). Capitalism's underlying principle is the endless accumulation of capital (Griffiths and Arnove 2015: 101). This 'new elite' consume anything from the finest creation of high culture to the most unremarkable product of popular culture (Caletrio 2012: 146). The globalisation of production and the extensive enlargement of capitalism constitute the material basis for the process of transnational class formation (Robinson 2005: 563). It has been put forth that this privilege has led to the formation of an emerging 'transnational capitalist class' (Murray 2014: 230). This group has been seen to have four fractions: transnational capital executives and their local affiliates, globalising bureaucrats and politicians, globalising professionals and merchants and the media (Sklair 2001: 7). This class includes those who possess 'flexible citizenship' and 'transnational social capital' by virtue of possession of high status knowledge - those who can transcend both cultural 
and national boundaries with their cultural and intellectual capital (Caletrio 2012: 147; Weis 2014: 311; Kenway and Fahey 2014: 190). These experiences and credentials have considerable value in the global job market and are highly transferable internationally (Liu 2014: 18). This creates a world ruling class; an international collusion of national bourgeoisies and their resultant international coalitions (Robinson 2005: 563). Generally, it is the citizens of rich countries which have gained more 'mobility' rights in the last 40 years, creating a 'global mobility divide' (Mau et al 2015: 1192).

At the same time this transnational capitalist class moves freely about, developed nation states are attempting to increase their sovereignty and security with 'antiterrorist and security fences', as some see multiculturalism as contributing to the growth of terrorism and extremism (Bal and Willems 2014: 250; Vertovec 2010: 83). This kind of prejudice may be expressed openly and directly (Zick et al 2011: 30). In 2011, Anders Brievik, a Norwegian born citizen, carried out a series of bombings and shootings and killed 77 people in his home country. Another glaring example of this racism exists in Sweden, where hate crimes against Roma peoples have been recently investigated and documented (Wigerfelt and Wigerfelt 2015: 1). Cook (2015) reported on the 30,000 South American children who fled to the United States in 2014 and this influx being seen by some in the U.S. as an 'invasion' and 'pollution', which would lead to the 'collapse of the nation' (Cook 2015: 3-4). Since the early 1990s, South Korea, which now hosts 1.5 million 'foreign-origin' residents, has experienced growing public debate about migrants and minorities ( $\mathrm{Yi}$ and Jung 2015: 985). It has been put forth that larger foreign-born concentrations of people increase perceptions of threat among native-born peoples in receiving countries (Dewaard 2015: 1041).

In addition, political parties such as The U.K. Independence Party in Great Britain and the Front National in France give voice to feelings of nationalism over globalism and have strong views on immigration in their respective countries. In 2010 the leader of the Front National compared Muslims praying on French streets to the Nazi invasion of France in World War Two (Hafez 2014: 485). This kind of thinking blames all Muslims for terrorist attacks carried out by radical minorities or individuals and treats them as 
'foreigners' regardless of their place of birth (Zick et al 2011: 30, 41). The messages by these political groups, regarding Muslims and extremism, can be linked back to the events of $9 / 11$ and the subsequent attacks in Europe in the 2000s (Abbas 2015: 1).

In many European nations there is a growing 'accepted racism', initiated by far-right extreme political parties who aim to flesh out a kind of 'us' and 'them' political debate and tap into worries over the slow demise of national identities in the face of multiculturalism and globalisation (Hafez 2014: 479, 482, 484). These political parties have gained prominence in Denmark, Germany, Belgium, The Netherlands, Austria, France, Great Britain and Sweden, to name a few (Hafez 2014: 483, 485). It has been put forth that despite these parties' not having fully implemented their radical right policies in their respective countries, they have had some political impact on some positions of the 'mainstream' political parties (Han 2015: 557). In most countries, men are more likely to vote for parties of the radical right than women (Harteveld et al 2015: 103).

It has been put forth that economic affluence and immigration are positively related to protest activity (Dodson 2015: 26). Survey data collected in France, Great Britain, Poland, Portugal, Germany, The Netherlands, Hungary and Italy in 2008 found that about half of the respondents believed there were too many immigrants in their country (Zick et al 2011: 13). This is important because part of identity formation is shaped by how the host country members view immigrants (Choi 2015: 241). Even the press has an important role to play in its depiction of immigration in Europe. In a quantitative study which examined how newspapers in Italy, France and Great Britain framed immigration and migrants, it was found that immigration of securitisation and the economy were prevalent topics in the press (Caviedes 2015: 912).

There is a need for education systems to focus on preparing critical citizens with welldeveloped ethical commitments and empathetic qualities of tolerance and respect (Griffiths and Arnove 2015: 101-102). Schools with an international mind-set might offer global or international values or goals rather than a locally oriented curriculum (Yemini 2012: 153). Some of these values include positive attitudes towards peace, international understanding, and responsible world citizenship so that people can 
adapt to a rapidly changing, more flexible and fluid global world (Cambridge and Thompson 2004: 164). The term international mindedness relates to individuals who favour a world view of the problems of mankind and involves a study of issues which have application beyond national borders, ultimately striving for a peaceful coexistence of the human race (Hill 2012: 260). This concept of being internationally minded could have significant effects on young people and their sense of where they belong, their identity and their assumed 'responsibilities' as global citizens. The school where the study was undertaken aims to provide an English-language education based on solid values, demanding personal excellence and stimulating individual responsibility within a culturally diverse environment. Over the last 45 years the market share of religious schools in Europe has remained largely unchanged (Merry 2015: 133).

Few words in the English language are more complex than 'culture' and all the assumptions and politics which come with the idea (Ferrare and Apple 2015: 43 44). A culture comes from the beliefs, traditions and practices which a group of people hold dear and important to them over time. However, cultures are not static and evolve and modify from interactions with people from other cultural backgrounds (Martin 2012: 3).

Educational aims for societies comprising multiple ethnic, cultural and racial groups should involve three different values-recognizing difference, national cohesion and equality (Blum 2014: 332). A culturally responsive organisation allows individuals to honour different values and beliefs, whether those cultural differences are global or domestic (Bennett 2011: 4). Although cultural values are socially developed in the family, international schools teach about culture yet try not to replace the cultures of their students.

The young people attending the school in this study are learning to coincide peacefully with people of many different cultures and find unity in diversity; in a world rife with conflict, fear and ignorance of 'foreigners'. The challenge for schools is how they articulate their vision and ethos and for teachers the challenge is how to prepare students for citizenship in a diverse society grounded in faith-based values 
(Dallavis 2013: 282; Green 2014: 285). It is true of both young people and schools that having good friends and good values are conducive to achieving good success (Pike 2009: 143). Enabling students to think about their relations with others that are not their family members might be a first step in seeing oneself as a member of a global, interconnected family (Murphy-Graham and Lample 2014: 61).

\subsection{Summary}

The main research question of this study was How do a globalised lifestyle, international capital and an international schooling experience influence the identities and aspirations of young people?

The aim of the study was to gain rich insights into young people's perceptions of the factors that influence their current and evolving aspirations and how they envisage their present and their future selves. This is a study of the sense I make of the sense young people make of their experiences. Overall, this thesis seeks to bring together readings and current debate regarding identity formation during adolescence, aspirations, the international schooling experience and international capital with an analysis of the testimonies of the participants. The originality of this work is in its emphasis on students' own perceptions of the influences on their aspirations, within the geographical space of Belgium and the social sub-culture of a fluid, semi-transient international social context and a local student population. The implications of these insights can inspire positive practices in international schools that seek to support students' abilities to define their own futures and develop ethically and socially responsible citizens.

In this introduction, I presented the central issues relating to the study. These include elite schooling, identity, aspirations, adolescence, migration, mobility, racism, privilege, inequality, globalisation and capitalism. I also offered a brief background of international schools and a description of the clientele who attend them: expatriates and local elite families. I presented a brief description of the case study school in which the study took place, which was also my place of work at the time of the study. 
The claim to be an 'international school' appears to be a title which any school can award itself. They are growing rapidly in number worldwide, as the elite of the world demand this perceived privileged education. International schools could be argued to be an accidental space, responding to the demands of the elite in unique circumstances and are in many respects a well-kept secret. What is interesting about these schools is that adolescents, who are experiencing their journey of identity formation, are doing so alongside others from diverse cultural backgrounds. At the same time, these young people share a common privileged socio-economic status.

In the next chapter, Chapter Two, I discuss the relevant literature surrounding the key issues of this study. In doing so, I revisit the topics presented in the introduction to the thesis. I draw upon literature which explores aspirations and identity formation during the salient period of adolescence. I also explore research which has examined the importance of relationships in schools and international capital and the roles they both have to play in the formation of adolescents who find themselves growing up in such unique circumstances.

In Chapter Three I discuss the methodology of the study in detail. In particular, I consider the interpretivist paradigm and how it is well suited for this study. The interview methods are discussed, as well as the methods of data collection and analysis. Finally, ethical considerations and the limitations of the study are presented.

In Chapter Four I present the findings of the study. I offer a link between the themes I extracted from the data and the research questions. I share the participants' voices through extracts of their narratives and discuss the findings.

In the final chapter of the thesis, Chapter Five, I conclude the thesis with a discussion of the findings, the originality of the study, implications for international schools, proposals for areas of further research and a personal reflection of the doctoral study experience. 


\section{Chapter Two}

\section{Literature Review}

\subsection{Introduction}

The main research question of this study was How do a globalised lifestyle, international capital and an international schooling experience influence the identities and aspirations of young people?.

The overall aim of this study was to gain insights from young people who attend an international school as to what they feel influences their identities and aspirations. This is a qualitative study based on data collected from interviews with students. The responses are based on how the participants perceived their lives. In this chapter I examine the related literature. The aim of this chapter is to explore how the topics of identity, aspirations and international schools have been researched. The literature reviewed informed my research questions.

The main research question for the study was:

How do a globalised lifestyle, international capital and an international schooling experience influence the identities and aspirations of young people?

The subsidiary research questions for the study were:

1. Is there evidence of a link between these students' first world citizenship privilege and the nature of their aspirations?

2. To what extent do parents influence aspirations?

3. To what extent do:

i. Globally nomadic experiences and

ii. International Schooling

influence the identity and aspirations of young people?

4. How do young people of this transnational class:

i. Define success and 
ii. View their future selves?

Importantly, I scope this literature review to the educational perspective. I review the available literature on aspirations and their formations, particularly in the period of adolescence. Secondly, I consider the literature surrounding identity formation and agency. Thirdly, I review the literature on relationships and mentoring in schools. Finally, I analyse the literature on international capital and international schooling. I offer a brief history of international schools and how they have been classified and described. I construct themes which are drawn from the literature reviewed up to December 2015, focussing on international schools, international capital, identity and aspirations. I offer two themes from the literature: 'Aspirations and Identity Formation' and 'International Capital and International Schooling'. I then break these down into four subthemes of 'The Shaping of Aspirations', 'Identity Formation and Agency', 'The Importance of Relationships in International Schools' and 'International Schooling and International Capital'.

\section{$\underline{2.2 \text { Aspirations and Identity Formation }}$}

The Shaping of Aspirations

Let me outline the impressions I have from my review of the literature on aspirations. Firstly, aspirations are personal, variable and possibly emotional states of thought or being. Secondly, aspirations change over time and are affected by personal circumstances, which evolve as life goes on. Thirdly, it is presumed all of us, regardless of class or gender, should or do have aspirations and that it is in our interest and benefit to have goals to which to aspire. Fourthly, it is generally recognised and agreed upon that schooling has some impact on children's aspirations, although parents tend to be the major influence on future aspirations of their children. There is a growing interest in the concept of purpose and what it means for individuals to have purpose in life (Malin et al 2013: 1). For the purposes of this study, I drew upon the already large volume of work on aspirations and young people.

The Latin root of the word 'aspiration' is 'to breathe'. Having space to breathe is an aspiration and with breath comes imagination and possibility (Ahmed 2010: 120). 
Aspirations reflect what someone would like to achieve rather than what they think they will achieve (Flouri et al 2015: 71).

Aspirations are complex understandings of the future pathways available to people (Bok 2010: 164). Aspirations are shaped by relations of power and by discourses within schooling, family and popular cultures (Mendick et al 2015: 4). Possessing 'aspirational capital' means one has an ability to maintain hopes and beliefs for the future (Yosso 2005: 77). As human behaviour is fundamentally goal directed, aspiration has been described as 'the goal that an individual sets for himself in a task which has intense personal significance for him' (Kalita 2014: 118). Personal goals are dynamic in that they may be accomplished, pursued, deferred or abandoned (Klug and Maier 2015: 37). Aspiration as a formative process entails capacities of human agency to desire, imagine, articulate and pursue alternative futures people have reason to value which exclude the possibility of desiring the impossible (Bourdieu 1990a: 54; Hart 2012a: 79; Zipin et al 2013: 4). As individuals strive for personal goals, they form aspirational visions of themselves and form expectations as to whether they will attain these goals (Rutherford 2015: 69).

Aspirations are not hierarchical, linear or constant (Hart 2012a: 180). Aspirations are complex, especially in a time of identity formation for young people. Relationships and networks created where trust and support are evident help to develop young people. Accepting that the young person's own perception is the young person's reality enforces acceptance and respect for the young person. To be asked to engage in searching dialogue about aspirations encourages critical reflection (Doncaster and Thorne 2000: 396).

The process of aspiring can be constructed as an active endeavour undertaken through abstract thinking and developed through forms of creative and physical expression (Hart 2012a: 79). There is a body of research which puts forth that young people have no shortage of aspirations and high aspirations know no ethnic, gender or class boundaries (St. Clair and Benjamin 2011: 502; Rose and Baird 2013: 170; Baker et al 2014: 539; Teney et al 2013: 587). However, aspirations are contextual and should be understood in relation to the agents' socio-economic and cultural environments 
(Stockfelt 2015: 6). It is well documented that social background is associated with aspirations for education and occupational aspirations (Schoon and Parsons 2002: 264). Economic and occupational aspirations are an important predictor of future success (de Vries and Rentfrow 2016: 33). For young people coming from low income families, the issue is more to do with the absence of opportunities and the conditions for them to be realised than of the issue of aspirations (Baker et al 2014: 539). Those in poverty are not deficient nor are they lacking in aspiration (Zyngier 2014: 2).

Adolescents are capable of achieving their goals through rational decision making (Reyna and Farley 2006: 1). Adolescence is a critical period in a life course when aspirations tend to be high as young people take greater control of their lives, constructing their own life courses through the choices and actions they take within the opportunities and constraints of the social and institutional structures in which they live (McDonald et al 2009:24; Flouri et al 2015: 71; Cook 2015: 3). Aspirations are shaped through interactions with significant others, friends, family, teachers, school, popular culture and resources (Hauser and Anderson 1991: 246; Wrench et al 2012: 2; Baker et al 2014: 538). Aspirations, like other attitudes, operate within a field of opportunities; they grow or shrink partly in response to the perceived possibilities of a successful outcome (Smyth and Wrigley 2013: 120). Aspirations are of sociological interest as they are socially constructed phenomena that provide means for examining the interplay between agency and social structures within young people's lives (Archer et al 2013: 2). An individual's sense of their own future is framed by their social location in the world.

One of the most salient and significant dimensions of human experience and emotional life is happiness (Lyubomirsky 2001: 239). Happiness can be expressed as 'living well and doing well' (Michalos 2008: 348). Happiness is the main goal in present day Western society and the pursuit of happiness determines the thoughts and actions of every person (Veenhoven 1994: 102; Klug and Maier 2015: 37). Measuring the feelings of happiness in life has become steadily important in recent years as an indicator of how people are developing, with an eye toward success (Pendery 2015: 1). Happiness can to some extent be considered both a trait and a state and includes internal factors such as good feelings about life, satisfying and positive relationships 
with family and friends and hope for the future (Diener 1984: 550; Pendery 2015: 3). In this vein, happiness is a wholly subjective issue (Seligman 2011: 239).

Where we find happiness teaches us what we value rather than simply what is of value (Ahmed 2010: 13). Happiness theory claims that the way we make choices is to estimate how much life satisfaction will ensue, then people follow the course that will maximise future happiness (Seligman 2011: 25). If success precedes happiness, then every positive outcome should bring with it satisfaction, but this is not always the case as our goalposts of success get pushed out wider and wider with each 'victory' (Bayramoglu and Sahin 2015: 154). This approach to happiness seems to regard happiness as some kind of 'achievement' on the part of the individual rather than a 'state of mind' (Smith 2008: 560).

Recent research has suggested that happiness is the initiator of success and happiness and optimism affect performance (Bayramoglu and Sahin 2015: 154). In Raco's (2009) analysis of welfare reform in Great Britain, he claims that human happiness is seen to be achieved through material acquisition and enhanced consumption (Raco 2009: 439). Happiness-seeking via consumption, otherwise commonly known as materialism, has become a modern day symbol of status (Belk 1985: 265). Materialism is commonly defined as the importance consumers place on material goods as a means of achieving goals (Richins and Chaplin 2015: 1334). These same researchers found that adults who receive material rewards during childhood will likely continue rewarding themselves with material goods when they are adults themselves (Richins and Chaplin 2015: 1352). However, Belk (1985: 267) asserts that it is unclear whether or not buying things for oneself acts successfully in the service of self-esteem and more recently Shin (2015: 18) puts forth that despite decades of debates and research on the topic, there is little consensus on the exact nature of the relationship between income and happiness. Material life must be harnessed to attain happiness, which is a positive mood in the present and a positive outlook for the future (Pendery 2015: 3; Achor 2010: 39).

Emotions are cognitive events, possess a component of 'feeling' and are reactive rather than active (Morgan 2015: 293). Aspirations are also emotional dispositions 
which can both affect other emotions and be affected by other emotions. These emotions shape our lives and the things we do with our lives as well as the general feeling of where we want to go with our lives (St. Clair and Benjamin 2011: 502; Brown 2011: 9; Ahmed 2008: 12). Intense emotional experiences can affect and raise one's aspirations (Brown 2011: 14).

There are two types of aspirations: intrinsic, which provide relatively direct satisfaction of basic needs and extrinsic, which are more related to obtaining external signs of worth. Examples of intrinsic aspirations are affiliation, personal growth and community contribution, whilst examples of extrinsic aspirations are wealth, fame and image (Ryan and Deci 2012: 24). To explain further, 'doctor' may be an extrinsic goal if the motivation is the high status and public prestige which goes along with being a doctor, but intrinsic if the motivation is to help those in need (Flouri et al 2015: 78).

However, aspirations have also been categorised as 'doxic', 'habituated' and 'emergent' (Zipin et al 2013: 5). Doxic aspirations are the aspirations with which students often respond when asked: "What do you want to be when you grow up?" and they are the responses the students know they should give and which carry the most value in society (Gale and Parker 2015: 85). Habituated aspirations are derived from one's familial and sociocultural group and bring with them a desire for occupations with the same or of similar importance as their parents' (Gale and Parker 2015: 85). Emergent aspirations are not primarily grounded in past-made-present, but are emerging among young people as their lives apprehend the present becoming future (Zipin et al 2013: 10).

Aspirations are formed in childhood, evolve over time as social and personal circumstances change and will shift considerably throughout an individual's life course (Hart 2012b: 35; Kintrea et al 2011: 13; Hegna 2014: 594). Quaglia and Cobb (1996: 130) offer a clear definition of a student's aspirations as their 'ability to identify and set goals for the future, while being inspired in the present to work toward those goals' (agency). At ages 9-13 young people become more pragmatic about their educational and professional aspirations (Dupriez et al 2012: 505). In their 'becoming' status (Cook 2015: 3), they begin to evaluate what is desirable, and realistic, for people 
like them, and start to think about the effort required for and likelihood of achieving desired outcomes (Rose and Baird 2013: 160). Between the ages of 11 and 15, students make decisions about staying in school (Hattie 2012: ch.1). In the eighth grade students' attention to occupational aspirations is only beginning to surface (Farmer 2001: 162).

Career interests formed and choices made during this period influence postsecondary educational pathways (Chow et al 2014: 1102). For populations living in poverty, schooling becomes a means of realising ambitions for social mobility (Boyden 2013: 580). Atherton et al (2009: 59) ask if educational aspirations remain high as young people become more aware of their capabilities. This is supported by Gutman and Akerman (2008: iii) who claim that in general, children's aspirations decline as they mature and their understanding of the world increases, and Ferrante (2009: 559), who recognizes that individuals learn from experience and revise their aspirations. For instance, Mann et al (2013: 8) found that the single most popular job among 13-14 year olds is an actress and by the age of 17-18 this preference falls out of the top ten. This supports the notion that aspirations change over time.

Influences on aspirations are wide ranging, including peer-group, schools, class, ethnicity and family (St. Clair et al 2013: 3). Parents are seen as the most important others in shaping aspirations as they provide the opportunities and support for their children, are powerful inculcators of values and aspirations, and are a constant influence on their children (Strand and Winston 2008: 250; Osborne and Guenther 2013: 90). Adolescents' opinions and beliefs are influenced by their parents' values. Adolescents who report to have very close and supportive family relationships adopt their values from these significant others (Crocetti et al 2014: 1819). A good relationship with at least one parent contributes positively to enrolment in postsecondary education (Orthner et al 2009: 258-259).

Trust and security are created in close relationships with caregivers (Vornanen et al 2009: 402). Studies on emotionally stable children illustrate that they have had parents who have encouraged and supported them to be independent (Vornanen et al 
2009: 404). One of the research questions posed in this project concerns the impact parents have on young people's aspirations.

Parental career expectations are likely to motivate young people to have higher career aspirations and to engage more in career planning (Sawitri et al 2015: 558).

Occupational aspirations refer to decisions made by students on their future work, occupation, career or profession (Kalita 2014: 118). In early adolescence, young people are influenced by gender, race, class and social valuation, all of which impact on later career development (Orthner et al 2013: 28). It has been claimed that girls choose more 'female' service professions, whilst boys opt for career paths related to science, technology, maths or engineering (Hadjar and Aeschlimann 2015: 22). Cuiting and Kerpelman (2007: 107), who conducted a study on young women's career aspirations, were particularly interested in how parental relationships affected certainty about future careers. Extensively citing previous literature on the issue, the authors concluded that the familial factor remains evident, as parents often communicate ideas and views to their children.

The influence of family has been described as the solidification and intensification of the father-mother-child relationship (Foucault 2003: 327). The atmosphere in the family and the relationships between children and parents play an important role in children's health and development (Vornanen et al 2009: 404; Tinnfalt et al 2015: 429). Being connected with the family as household is a social investment and a social reproduction project (Bourdieu 2005: 21). Family studies deals with private matters; focussing on personal life, intimacy, relationships and kinship (Gilding 2010: 757; Edwards and Gillies 2012: 63). Family networks may include step-relations, close friends, same-sex partners, ex-partners and relatives (Williams 2005: 18). The impact of parenting style, involvement and expectations upon children's educational and career choices is strong, and familial participation is needed to achieve a positive educational atmosphere (Garg et al 2002: 88; Kirk et al 2011: 89). Parenting practices during middle school have positive associations with aspirations and school engagement (Hill and Wang 2015: 232). Different classes emphasise different values and have different parenting styles and in order for parents to sustain and help fulfil their child's aspirations, they must provide them with the required resources and 
skills, which the more economically affluent family possesses (Khattab 2015: 4). Skills give agency to people to shape their lives, create new skills and to flourish (Kautz et al 2014: 5).

Social class is shaped by an individual's material resources which include wealth and education (Kraus et al 2012: 546). A family's social class ensures that children adopt knowledge strategies that pay off (Kenway and Hickey-Moody 2011: 161). It goes without saying that the lives of the rich and the poor are not the same (Kraus et al 2012: 546). Classes or groups who have different levels or types of 'cultural capital' would shape child-rearing differently and facilitate different levels of educational success (Khattab 2015: 5). This can be achieved by exposing children to culture, helping them with schoolwork, transferring certain ways of thinking and talking, instilling an attitude toward education and employment and actively supporting the education of their children beyond time spent in school (Khattab 2015: 5). These students are then likely to be high achievers, as they have open opportunities and facilities, and therefore hold high aspirations as part of their cultural capital (Khattab 2015: 5; Shaheen and Gul 2014: 165). In addition, this stable and comfortable environment is likely to lead children from more advantaged homes to be more socially confident (de Vries and Rentfrow 2016: 34).

Educational aspiration is an attitude and is the desire to achieve conventional notions of educational success, particularly a university education (Kenway and Hickey-Moody 2011: 152). Sheng (2014) found that working class parents also have high expectations of their children's higher education but their lack of cultural, economic and social capital firmly restricts their ability to realise their expectations effectively (Sheng 2014: 573). This is important to the context of this study involving privileged young people and how they perceive their educational and occupational futures.

\section{Identity Formation and Agency}

Identity has been defined as the individual's dynamic self-understandings and selfdefinitions used to structure, direct and give meaning to and present the self and which are negotiated over time within sociocultural contexts (Schachter and Rich 2011: 223). The notion of identity involves history, culture, tradition, community, class, 
beliefs, language and behaviour and becomes more complex for people caught in between or experiencing many cultures (Choi 2015: 240).

Identity is something all people have, or ought to have and it is something people can have without being aware of it; therefore it is something to be discovered (Brubaker and Cooper 2000: 10). These same authors identify five key ways in which identity can be discussed: as a ground for political action, as a 'collective' discussion, as a core aspect of the individual self, in a context of solidarity or group-ness and as a product of the multiple or fluctuating nature of the contemporary self (Brubaker and Cooper 2000: 6-8). It is from this last perspective that I would like to situate my approach to identity formation in the context of this study.

Individuals have multiple, overlapping personal and collective identities that change in content, salience and centrality in different situations and over time (Eccles 2009: 79). Gee distinguishes between the 'socially situated' and 'core' identities, where the former are the multiple identities we take on in different practices, while the latter refers to a fixed sense of self beneath shifting identities (Gee 1999: 39).

Lamenting the lost part is therefore understandable but pointless (Baggini 2007: 41). If they are not to fail, individuals must plan for the long term and adapt to change; possessing tenacity, initiative and flexibility (Beck and Beck-Gernsheim 2002: 4). After all, the willingness to learn and adjust is necessary when one moves to a new context, especially when the move takes place between societies with differing cultures (Zhang and McGrath 2009: 185).

Home is sometimes a state of mind (Bunske 2004: 94). Before coming to one country, one has had to leave another (Maalouf 2000: 38). Migration cuts to the very heart of who we are and to the very notions of home, identity and belonging (O'Reilly 2012: 1). There is a complex range of feelings that emerge as a consequence of mobility, which challenge the sense of self and shape social relations (Zembylas 2012: 166). The globally nomadic children shuttle back and forth between nations, languages, cultures and loyalties (Eidse and Sichel 2004: 1). 
Terms such as 'nation', 'class', 'community' and 'tradition' are associated with identity (Brubaker and Cooper 2000: 4). The concept of identity is also used to persuade people to understand themselves and their interests in a certain way, to persuade them that they are 'identical' with one another (Brubaker and Cooper 2000: 4-5). There is an immediate relationship between individuals and their nation and there are daily reminders of 'who we are', from national newspapers speaking for the 'nation' to calls to support the nation in sporting events (Calhoun 1997: 125; Billig 1995: 6). However, many people now claim multiple identities, generally a mixture of faith, nationality, ethnicity and place of residence (Cantle 2011: 8). While migrants continue to feel bound to their homelands, they are now more able to maintain and enhance these feelings whilst at the same time being quite capable of developing new lives and social ties in new places of settlement (Vertovec 2010: 93). These transcultural and transnational identities allow for their comfortable circulation amongst different worlds (Zhang and Guo 2015: 210).

Every individual possesses a composite identity which is complex, unique and irreplaceable, not to be confused with any other (Maalouf 2000: 20). Identity has become a popular concept in many disciplines, as well as the notion of changing and fluid identities. The notion of identity means different things to different people and measuring it is complicated as each individual is a meeting ground for different allegiances which gives them their complex identity (Herrmann and Brewer 2004: 4; Maalouf 2000: 4). Hence, identity is riddled with ambiguity and riven with contradictory meanings (Brubaker and Cooper 2000: 34). People can belong in many different ways and to many different objects of attachments (Yuval-Davis 2006: 199). The spaces of citizenship in the contemporary world are increasingly notable for their adaptive fluidness (Cottrell-Studemeyer 2015: 565). It is then clearly possible to belong in many different ways at many different scales and to incorporate into our lives the countless ingredients that come to us from the world's cultures (Mee and Wright 2009: 772; Maalouf 2000: 120). In this vein, these multiple and shifting identities do not necessarily have to be 'reconciled' (Faas 2009: 303).

The self has been described as the set of a person's core commitments, traits, aspirations and ideals that are most central to him or her (Kristjansson 2010: 5). 
Education has long been considered as playing a part in the construction or formation of self and identity (Seery 2010: 63). In adolescence crucial learning with regard to selfidentity is taking place and what it means to be a certain kind of person. This age is marked by a great deal of transience, confusion, rupture, change, self-obsession, melodrama, conflict, emotional stress, social transition and disappointment (Smith 2009: 280; Riddle 2013: 45; Blakemore and Mills 2014: 9.1). During puberty, young adolescents experience more rapid and dramatic changes than at any other period in their life, often creating feelings of stress and insecurity for the adolescent (M.Y.S.A. 2008: 1). As children enter early teen years, their ability to hold multiple representations of self and the conflicts between these possible selves can become a problem (Rutherford 2015: 71). This unique time period of life produces immense change and can be argued to be a state of being in-between (Jackson 2013: 116). Between the ages of 9-13, children enter a stage where the more abstract concept of social class becomes an important determinant of behaviour and by age 14, young people become more attuned to their internal feelings and capacities, often referred to as the adolescent identity crisis (Gottfredson 1981: 549).

There are ways to view identity, as explained by Gee (2000: 102), which are nature identity, discourse identity, affinity identity and institution identity. Nature identity is developed from forces in nature over which no one has any control; such as being a twin. Discourse identity is recognised in the dialogue with rational individuals with an aim of being recognised in a certain way. Gee calls this "fashioning" oneself (Gee 2000: 104). Affinity identity deals with experiences shared in the practice of affinity groups people choose to join, sharing an allegiance to, access to and participation in specific practices that provide each of the group's members the requisite experiences (Gee 2000: 105). Institution identity involves a position authorised by authorities within institutions, such as schools (Gee 2000: 100).

The Plural School, a concept conceived by Montaigne over 400 years ago, is one which strives to respond adequately and appropriately to the diverse needs of students in a single class in terms of their personal histories. Its policies are formulated within the idea of identity development and knowledge being understood in a global sense (Vasques de Miranda 2007: 65). There is an underlying philosophy of a more 
democratic, broader school, open to cultural differences and communities (Vasques de Miranda 2007: 69). This model could prove valuable to teachers in international schools as a plural pedagogy is one which gives high priority to the individualisation of teaching in response to the differing cultural needs of students in a single class (Pearce 2005: 276-278). International school students are seen as having to adjust to moves by identity development whilst acquiring new values through various global cultural influences (Pearce 2011: 154).

Children spend a very large part of their lives inside buildings we call schools, where they come to grips with authority relations (Apple 2013: 20). With regards to institution identity, power dimensions within adult-child relationships are heightened in schools where adults involved hold posts of responsibility and authority in relation to students (Robinson and Taylor 2013: 33). Within this adult dominated power structure of the school students exercise agency in their interpersonal relationships (Larkin 2013: 3). The capacity of the individual to take action and keep their narrative going within the constraints of the social context, in this case schools, is discussed by Giddens (Giddens 1984: 15; Giddens 1991: 54). Giddens writes that the individual agent is powerful, able to take action, create their lived environment and to change social structures. The idea of agency has been central to educational thinking and practice at least since the Enlightenment, where Kant argued that human beings could only become human through education as they become capable of independent judgement (Biesta and Tedder 2006: 4).

Possessing agentic qualities has been seen to be instrumental in acquiring status (Carrier et al 2014: 348). Agency refers to people's ability to make choices, take control, pursue goals, have free will, get ahead, act according to their own wishes, transform themselves and has been defined as 'the capacity to make a difference' (Carrier et al 2014: 347; Duff 2012: 413; Giddens 1984: 14; O’Reilly 2012: 14). Agency has a role to play between external forces and internal motivations and people in positions of influence can affect agency. Agency is also used to refer to how young people relate to society (Coffey and Farrugia 2013: 3). Agency has been described as the capacity of a socialised body to construct a social reality within a space (Bourdieu 1985: 724; Bourdieu 2000: 137). However, adult dominated power structures, such as 
those in schools, mean that children's agency may be affected by multiple relations of domination, exploitation and subordination as children learn to deal with authority (Apple 2013: 23).

Human agents are historical animals who carry with them acquired sensibilities and categories that are products of their past social experiences (Wacquant 2011: 82). Social networks increase people's agency by providing access to information and opportunities (Oosterlaken 2015: 157). Human agents can understand the social conditions they find themselves in, can try to make sense of them and act accordingly (O'Reilly 2012: 15). To be a human being is to be a purposive agent, who both has reasons for his activities and is able to elaborate discursively upon those reasons (Giddens 1984: 3). Empowering the individual through self-awareness, self-knowledge and reflection has potentially positive possibilities; sometimes referred to as "reflexive monitoring" (Giddens 1984: 5). Yet, Giddens recognizes the constraints of social structure and sees structure and agency as connected, interdependent and interrelated, in what he terms the "duality of structure". However as Lamsal (2012: 115) explains, agency is the fundamental element to create any sort of change, even with the constant interaction it has with power. Structures are reproduced by individuals repeating acts and are both the limits to and the outcomes of agency (Shevellar 2015: 459; O'Reilly 2012: 17). Agency has a vital part to play in changing the structure and the structure itself is a reflection of agency's power to influence their lived environment. Structure is then part and parcel of the agent and the agent is part and parcel of the structure (O'Reilly 2012: 17). In addition, the individual's capacity for action means they can overthrow dominant social structures (Block 2013: 133). In relation to aspirations, Hart (2012b: 34) would argue that individuals exert varying degrees of agency in both the determination and fulfilment of their aspirations as aspirations are subject to change.

Self-Determination Theory proposes that humans are naturally growth oriented and focuses on the social contexts that either support or undermine people's attempts to master and integrate their experience into a coherent sense of self (Ryan and Deci 2012: 27). Growth involves the ability to live an associated life and a need for others (Samuel 2015: 103). Children's development during adolescence is driven by basic 
psychological needs to achieve autonomy, competence and relatedness (Eccles 1999: 31; Church et al 2012: 2). Autonomy is defined as the need to have freely chosen behaviour, as opposed to imposed by external forces and is considered definitional to what constitutes agency (Miller and Das 2011: 46). Human agency refers to the sense of personal empowerment involving both knowing and having what it takes to achieve goals (Ginevra et al 2013: 1). Related to this is the concept of agency freedom; the freedom to achieve whatever the person decides he or she should achieve (Sen 1985: 203). Competency and relatedness are the needs to feel capable and connected, respectively. Competence occurs when one feels effective in one's behaviour (Domenech-Betoret and Gomez-Artiga 2014: 90). Parents who provide choices for their children whenever possible aid this promotion of 'volitional functioning' (Barni et al 2011: 109). These needs are hypothesized to be the basic features of basic human nature, for example, succeeding at something, experiencing a close relationship, belonging or becoming more self-regulating (Sheldon and Schuler 2011: 1107).

One must construct one's own identity (Bryant and Ellard 2015: 486). Being oneself is a requirement of contemporary social relationships of governance oriented around norms of individuality, choice, self-responsibility and self-reinvention (Allen and Mendick 2013: 460). The philosopher John Locke's view of personal identity was motivated by a consideration of what it is to be a person; a thinking being that has reason and reflection, and being that same thinking thing in different time and places (Merricks 1999: 984). If one starts with the here and now, then it can be broadened to include memories of the past and one's imaginations, wishes and fears about oneself in the future (Kashima et al 2011: 14). A major task of adolescence and emerging adulthood is to forge an identity that consolidates one's beliefs, values, and goals into a coherent story that can be used as a basis for making life decisions and the transition to adulthood (Yeager and Bundick 2009: 424; Malanchuk et al 2010: 97). Adulthood is characterised by specific markers such as leaving the parental home, completing school, getting a job, getting married or partnered and having children (Settersen Jr. and Ray 2010: 20; Mary 2013: 1; Speder and Murinko 2013: 874).

International migration has led to micro transnational networks and relationships' shaping cultures (O'Reilly 2012: 6). The relationship between global mobility and 
identity is also important here as it could involve a loss of attachment, isolation, anger, and acceptance issues (Grimshaw and Sears 2008: 259). It has been argued in the past that many students who have attended international schools experience a confused sense of identity due to the fragmented nature of their personal histories, so much so some feel they never fit in anywhere. They may view their lives as a sort of displacement, being jetsetters and globetrotters who are everybody but nobody (Caputo 2013: 72). For instance, going abroad for the first time can be a stressful experience (Sigalas 2010: 1347). Globally mobile individuals constitute their view of themselves in response to their changing circumstances (Sears 2012: 119).

\section{$\underline{2.3 \text { International Capital and International Schooling }}$}

\section{The Importance of Relationships Formed in International Schools}

Human social connection is important at many levels (Grace et al 2011: 15). It is a fact of our human condition that our daily life is spent in the presence of others and our doings are socially situated (Goffman 1983: 2). In our daily life, we have multiple encounters with individuals which can be positive, negative, or conflicting in emotion (Lagattuta 2014: 92). In schools, there is a vast array of social relationships and interactions that occur in the normal school day (Burridge 2014: 572). Democratic education takes place between teachers and students and it is the teacher who makes this possible (Bradshaw 2014: 1-3). Personal relations between teachers and students are emotionally loaded. Adaptive and positive development occurs in and with the support of significant relationships (Noam et al 2014: 99). Human beings are naturally relational and learning to relate is part of the process of a young person becoming mature. Education can be thought of as a period of transformation of the person which can contribute to deep changes in him or her (Morgan 2015: 292).

Feeling valued by people who are important to us may be our most central human need. Worrying about other people and their opinions of us is a tangled, fraught, exhausting affair, especially for teenagers (Bainbridge 2009: 216). Children's development between the ages of 11-14 is a sensitive social period, driven by the basic psychological needs to achieve competence, autonomy and relatedness to their peers (Blakemore and Mills 2014: 9.4; Eccles 1999: 31; Coffey 2013: 262). Every adult can 
play a significant role in aiding and guiding in that development. Part of that evolution involves relationships, as relating to one another provides what MacMurray (2012: 670) would describe as the basic structure within which all human experience and activity falls. If then by education we mean learning to be human, it is also learning to relate to other people.

Our allegiances to particular people and communities are what forge our identities (Keller 2013: 12). Many young people today want someone to believe that they are worthy to have the freedom to aspire and that they are worthy of the support of significant others (Hart 2012a: 3). The relationships young people cultivate will affect the kinds of relationships they are able to form in adult-hood (Griffiths 2014: 343). A lack of connection to a caring adult at school is cited as a major variable of student alienation, failure and disaffection from school (Bernstein-Yamashiro and Noam 2013: 17).

Education is a profession which embodies the values of dignity, respect, well-being, care and trust (Jensen and Kjeldsen 2014: 29). Education is fundamentally an interaction between human beings (Biesta 2014: 21). Classroom teaching is relational work; involving concerted action by the teacher and the student (Lampert 2010: 22). Human beings are dependent on the care of others. Personal relationships, from acquaintances to the closest intimates, have been singled out in classical social theory as fundamental to a secure sense of an agentic self, of a place in the social world, and of basic trust in others (Jamieson and Milne 2012: 266). A group within which there is extensive trustworthiness and extensive trust is able to accomplish much more than a comparable group without that trustworthiness and trust (Coleman 1988: 101). Better student-teacher relationships will occasion better student behaviour in the classroom (Nash and Schlosser 2015: 144). Marsh (2012: 161) explored how and why studentteacher relationships affected student engagement. Through questionnaires and pupil interviews, Marsh drew out key characteristics which students identified as helping to create positive relationships with teachers. These included the teachers exhibiting enthusiasm, being happy and noticing talent in the student. Busher (2012: 114) investigated students' perspectives on education and a component of that study was students' views on teacher-student relationships. Students cited qualities in their 
relationships with teachers which helped them learn such as respect, trust, care and concern. Vieluf et al (2015: 3) surveyed 271,760 students in 40 countries worldwide and found that students with higher socio-economic backgrounds had better studentteacher relations than their schoolmates.

Education is a way of producing a happier, more democratic and more just future (Griffiths 2014: 343). Education must raise the quality of a person's life and essential to this are the basic moral feelings of love, trust and thankfulness (Wilkinson and Wilkinson 2013: 108). Young people's friendships and relationships with others are very important and classroom relationships with both peers and teachers are a part of what creates an atmosphere of trust in international schools.

A critical component of developing relationships is knowing and understanding the learner (Beaty-O'Ferrall et al 2010: 5). Positive teacher-student relationships aid in social integration and experiences in school (Van Maele and Van Houtte 2011: 85-86). The notion of a classroom as a community refers to the student's feeling that they are a member of a positive learning community (Furlong et al 2003: 105). Positive, nurturing relationships facilitate children's development of empathy (Senland 2015: 117). Every teacher needs to forge positive relationships with students as teaching is one of the foremost of personal relations (Marsh 2012:161; Busher 2012: 114; Noddings 2012: 771).

Students appreciate teachers who show through their behaviour what kind of person they are and who dare to show their personality and identity as a human being (Sanderse 2013: 33). Qualities such as care, trust, support, respect, fairness, forgiveness and concern for young people are seen by students as key to helping them learn, take risks, engage and persevere (Busher 2012: 114; Aldridge and Ala'I 2013: 49; Lampert 2012: 364; Poore 2005: 359; Wentzel 2012: 19; McLaughlin and Gray 2015: 4). Caring and supportive relationships are the cornerstone of a good moral education (Senland 2015: 117). Caring is manifested in actions which promote the well-being of others and is a constitutive building block of one's identity (Nilsson et al 2015: 51; Apple 2013: 20). Trust is vital because no child can learn anything of real importance without the internal 'yes' to what is being offered. No child will say 'yes' to that of 
which they are frightened. Through interaction with teachers, children can learn important life lessons about empathy, respect for others and peaceful conflict resolution (Lucas-Molina et al 2015: 300).

Educational philosophers have long known that engaging students in ways of knowing is an ethical act and the inquiry of care pushes that ethical act to the fore (Nelson 2013: 363). In education the meaning of respect is the awareness that each person has his or her own aspirations, viewpoint and takes pride in his or her achievements (Peters 1966: 59). Young adolescents should be regarded as individuals with their own goals and expectations (Pendergast and Main 2013: 26).

In facilitating these relationships and positive interactions, schools have an opportunity to create what Cook-Sather (2009: 180) calls a "listening culture"; listening and responding to students in an atmosphere of mutual trust, open-mindedness, equality and modesty (Murris 2013: 258; Murris 2015: 331). Listening to students' views allows them to have some empowerment in their learning and schooling and supportive relationships are a critical factor in keeping them motivated. Listening philosophically makes it possible to listen to students' imaginative explorations and narratives and to allow them to formulate thoughts and ideas (Murris 2015: 333). Both child and teacher could miss out if this listening does not occur (Murris 2015: 334).

Teaching practice has shifted to become more student-centred and the empathetic teacher, one who shows special concern for another's welfare, is a key component to student well-being (Keller 2013: 104; Corcoran 2014: 1). The human experience must be described as an interaction of interactions (Ibanez 2014: 14). As learning is partly what Illeris (1999: 3) would call the interaction processes between the individual, the material, and the social environment, the teacher has a responsibility to nurture personal connections with students to encourage that learning to take place. A school's ability to create a positive learning environment may also influence educational outcomes (Gemici et al 2013: 15).

Mentoring roles are socially constructed by individuals and are maintained through interpersonal interaction and individual perception (Lucas 2001: 23). Emotional attachment to significant others is a key component of identity development and 
mentors have the potential to expand the opportunities of individuals, whilst at the same time encouraging them to keep searching and desiring (McDonald et al 2009: 4; Pearce 2011: 154; Grinberg 2013: 214).

Teachers fall into a category which McDonald et al (2009: 5) describe as informal mentors. Mentorship is an intensely complex and multifaceted interpersonal relationship where advising, supporting, caring, guiding and advocating for others takes place (Sloane-Seale 2012: 1; Xu and Payne 2013: 4). Advice can be given on a wide range of topics; from homework, relationships to university choice and careers. Academic choices which students in the middle years of schooling make have a strong bearing on educational and career development (Carney et al 2005: 136). In adolescent vocational development, the four 'adapt-abilities' which they employ in the process of early career construction are: concern, curiosity, confidence and control, which all have a positive impact on their career planning (Negru-Subtirica et al 2015: 132). Careers guidance has been described as activities which support individuals to learn about education and employment in order to plan for their future lives and help operationalise their aspirations (Hooley et al 2014: 4). Guidance is explained by Borgen and Hiebert (2006) as practitioners of guidance gaining knowledge of their 'client' and then conveying useful information to them based on the understanding of that client (Borgen and Hiebert 2006: 391). Successful mentoring has been defined as two or more individuals willingly forming a respectful and trusting relationship focussed on the goals that meet the needs of the mentee (Kochan 2002: 284).

We flourish best with a variety of mentors but the most powerful mentors are those with whom we are directly in touch (Ayalon 2011: xii). Mentors can provide guidance, support, and role modelling and also require patience in dealing with young people who experience what Ezra (2003: 131) calls the pressures and anxieties which can come from attending an unfamiliar school. Erickson et al (2009: 344) concluded that young people with many resources are more likely than others to have mentors. This implies that the privileged either have or have access to more mentors than the underprivileged. In its online polling of 2,161 young people aged 16-25 in the United Kingdom in 2013, The Prince's Trust found that 30\% of young people with 'no role model' reported feeling 'worthless' (The Prince's Trust 2014: 21). One can only aspire 
to be referred to as someone's mentor years later, when they are probably not there to hear it (Lucas 2001: 46).

However, not all relationships developed in international schools settings are between students and teachers. As previous research suggests, during early adolescence, young people exhibit increased psychological investment in peer groups as those relationships take on new qualities of reciprocity and intimacy (Wentzel et al 2004: 196; Noam et al 2014: 99). People with many friends are far more likely to be happy than those with a few (Shin 2015: 19) and people in high quality friendships are better adjusted (Hiatt et al 2015: 154). Adolescent friendships could be viewed as a way to practise social skills in a relatively risk-free environment and quality friendships are strongly linked to happiness and mental health (Bainbridge 2009: 224).

The nature of personal relationships is dependent on the social and economic contexts in which they occur (Allan 2008: 2). All teenagers worry, and the thing that worries them most is their relationship with other people (Bainbridge 2009: 216). In schools one learns how to manage being with others who are both the same and different (Apple 2013: 20). Friendship is among the best and most desirable of human relationships and the duties of a friendship make the relationship intrinsically valuable (Raz 1989: 20; Grayling 2013: 5). Different people provide the friendship we need at different times in our lives and the process of making new friends might be structured by the several social contexts an individual is embedded in during their lives (Grayling 2013: 2; Stauder 2014: 234). Individuals form relations more frequently with similar individuals because people with similar social positions have similar traits (Stauder 2014: 235). The unique situation of globally nomadic students means that they share a commonality with others of similar experience and as Pearce (2011:170) explains, develop skills in repeated loss and reconstruction of friendships. Some of these young people struggle with unresolved grief, feelings of isolation and rootlessness due to their transient lifestyles and have ambivalent feelings regarding home and roots (Bates 2013: 88; Fail et al 2004: 322). This potentially negative impact of mobility was explored by South and Haynie (2004: 316) who linked the character of friendship networks with highly-mobile students. Transient young people's sense of belonging is stronger to relationships than to a particular country (Fail et al 2004: 321). In addition, 
host country nationals may be experiencing only one transition by entering an international school, but that does not mean that the transition is either insignificant or easy for them (Bailey 2015a: 87).

Relationships based on values of mutual respect and trust should inform all aspects of education including curriculum, assessment and all school routines (Head 2014: 544). Education plays a critical role in wellbeing and much of an adolescent's social network is embedded in their school (Klimstra et al 2010: 158; Goldin et al 2014: 18). Positive emotional attachment to peers and teachers promotes not only healthy social, emotional and intellectual functioning but also positive feelings of self-worth and selfesteem; ultimately contributing to a sense of community (Martin and Dowson 2009: 330; Coffey 2013: 263). All human beings learn to make a habitat when they are socialised into members of a group (Van Den Bouwhuijsen 1995: 108). Feeling related to a group which shows affective concern and stability is a fundamental component of motivation and essential for well-being and the need to belong (Martin and Dowson 2009: 335; Church et al 2012: 2; Baumeister and Leary 1995: 500). Dorling (2011: 271) adds that being deprived of feeling connected to others has the potential to make us mentally ill. Young people's mental and physical health are intertwined, and are vital to their healthy relationships with others (N.H.S. England 2015: 21).

Also, educators should find ways to infuse agency, as Howard et al (2009: 106) recommend, so that young people can strengthen their self-efficacy, internal motivation and future goal setting in the context of what Fielding (2012: 679) describes as an inclusive and caring community. Everyday places that are invested with care reflect a sense of pride, commitment and worth not only about the environment but also its inhabitants (Prince 2013: 3). Higher levels of support to students within a positive and personalised school culture can result in fewer students 'getting lost' (McClure et al 2010: 3). In the context of international schooling, there is a need for teachers to know their pupils as individuals, improve their relationships with them, and to create opportunities for interchange between and among their culturally and linguistically diverse students (Langford 2013: 105). Additionally, relationships which are warm, supportive, understanding and accepting create positive school cultures (Carr 2014: 76). Trusting relationships among teachers, students and parents and 
shared norms regarding good habits of schooling can enhance school based social capital (Belfi et al 2015: 42). The aforementioned authors itemised characteristics of school based social capital which included teachers' frequent contact with parents, trusting relationships between teachers and students and a caring environment (Belfi et al 2015: 43). After all, a school is the people who occupy the buildings, with their aspirations, joys, sorrows, experiences, perceptions and beliefs (Hill 2014: 187). The very fabric of society is stronger when social cohesion and trust replace distinction and difference (Dorling 2011: xvii). Young people who have good relationships with adults and peers build a sound developmental base for their future well-being (McLaughlin and Gray 2015: 3).

\section{International Schooling and International Capital}

A knowledge of another culture should sharpen the ability to scrutinise our own (Mead 1973: 1). The intention of international education is to help the next generation better understand and cooperate with their fellow human beings across frontiers (Peterson 1987: 195). The origins of international education can be traced back to the seventeenth century and Comenius' proposal whereby scholars and students from different nations would come together to study (Hill 2007: 251). In an article written by Charles Dickens in the nineteenth century, it was proposed that students spend a year or two rotating amongst a network of 'international schools', learning other languages and experiencing other cultures. In 1865 an International Education Society was founded in London but it was not until after the First World War that international schools were created to respond to the demands of an increasingly mobile population and from the 1920s these types of schools began to grow (Hill 2007: 252). The International School of Geneva, known as the world's oldest private international school, opened in 1924 with nine students and under the name 'International School' (Dugonjic 2014: 138). Originally, that school sought to serve the children of foreigners working for international organisations and residing in Geneva, geared for students in the 'elite' (Dugonjic 2014: 145). The curriculum was designed to enable a mobile lifestyle for transnationals without detriment to their children's education and to nurture the global citizen (Doherty et al 2012: 316). 
Bunnell (2006: 156) uses the term "internationally minded schools", which cater to what Grimshaw and Sears (2008: 261) call 'global nomads', or those who spend a significant part of their developmental years on one or more countries outside their passport country. Fail et al (2004: 320) take the term 'third culture kids' from Pollock and Van Reken who describe such young people as those who have spent a significant part of their lives in a culture other than that of their parents, and while developing a sense of relationship to many cultures, do not possess ownership of any one culture (Pollock and Van Reken 1999: xi). They instead feel they belong to a culture shared by the globally mobile (Jabal 2013: 5). Linked to this relationship is the idea of children being comfortable around others whose mobile way of life is similar to their own, as Sears (2011: 84) found that children find comfort and confidence where this sort of nomadic life is considered normal. Young people in this environment are open to new friends and more inclusive of others. International schools also serve local students, or what Deveney (2005: 161) would describe as 'fourth culture kids'. These students find themselves in a school system which is not their home system, not a foreign system in a foreign country and not in an international school outside of their home country, but in an international school within their own country which does not necessarily represent their culture (Deveney 2005: 161). Although international schools were originally developed as a way for expatriate workers to educate their children whilst living abroad, today a majority of the students attending international schools are locally born (Bailey 2015a: 85). This involvement of nationals as well as expatriates in such schools may intensify the issues facing the process of cultural formation in international schools (Bates 2011: 7).

Hayden and Thompson (2013: 5) have classified international schools into three main subgroups. 'Type A' international schools were established to cater for globally mobile expatriates. The usual medium of teaching is English and sometimes they offer an international programme such as the International Baccalaureate (Hayden and Thompson 2013: 6). Until the relatively late twentieth century this type of school accounted for the vast majority of international schools in existence (Hayden and Thompson 2013: 5). They may also accept local students but their principal intention is to support the expatriate community of the city or region (Hayden and Thompson 
2013: 6). 'Type B' international schools were established on an ideological basis, bringing young people together from different parts of the world to be educated together with a view to promoting global peace and understanding (Hayden and Thompson 2013: 5). Groupings in Type B schools include the United World Colleges and, in a broad definition of 'international', the European Schools created in 1953 for children of employees of the European Union (Hayden and Thompson 2013: 8). The third type is 'Type C' or 'non-traditional' international schools. These schools were established to cater for host country nationals who are the elite of the host country. These families seek a form of education different from the national education system (Hayden and Thompson 2013: 5). Groupings in Type C schools include Cognita, Nord Anglia and the Dubai based Global Education Management Systems (GEMS) Education Ltd. (Hayden and Thompson 2013: 8; Bunnell et al 2016: 7). These new forms often operate on a for-profit basis and are for the wealthy local population (Bunnell et al 2016: 1). They have been defined as international because they are located in nonEnglish speaking countries and English is the school's medium of communication (Bunnell et al 2016: 1). These Type C schools also offer internationally recognised programmes and can be seen as a springboard to university entrance in the United States or the United Kingdom (Hayden and Thompson 2013: 7). This change in the international schooling landscape has been seen as significant and substantive (Bunnell 2016: 9). It has been predicted that the growth in Type C schools will overtake the growth in Type A schools (Hayden and Thompson 2013: 16).

The barriers of distance can readily be transcended with money (Kenway and Fahey 2015: 95). Young people today must manage a wide range of choices in relation to their futures and have far greater opportunities to continue their education, pursue careers and travel to numerous countries (Bryant and Ellard 2015: 485; Weston and Qu 2013: 2). Few would dispute that our world is characterised by unprecedented levels of mobility (Skrbis et al 2013: 1). Migration is thus no longer simply the permanent movement from one country to another: it can mean travelling through a sequence of countries (Faas et al 2014: 301). It is estimated that up to 214 million people are living, working or attending school outside of their home country (Bates 2013: 86). This denotes a dramatic jump of more than $40 \%$ from 150 million in 2000 
(Kuo 2014: 16). In 2000, there were 2,584 international schools worldwide teaching 988,600 students and employing 90,000 full-time teaching staff (Brummitt and Keeling 2013: 27). The countries dominating the market at that time were Spain, the United Arab Emirates, Hong Kong and Thailand (Brummitt and Keeling 2013: 27). Today, international schools play host to 3.4 million students and the market is worth some 30 billion USD (Machin 2014: 2). Even during the global recession of 2008, international schools still achieved a 6\% annual growth (Brummitt and Keeling 2013: 31). There has been an explosion in the number of international schools in developing countries in the past two decades, partly due to the thirst for positional advantage in the home country (Bates 2012: 263). International Schools Consultancy Research predicts that by 2022 the number of international schools will expand to 11,331 and the number of students attending them to 6.2 million (Brummitt and Keeling 2013: 34). The internationally experienced, top-quality teachers and leaders are in extremely high demand to work in these schools (Brummitt and Keeling 2013: 33). Whilst international schools may have large numbers of host country nationals on their teaching staff, it may well remain the case that overseas hire expatriates have an advantage over them (Hayden and Thompson 2013: 12). That being said, with increasing numbers of host country national teachers recruited to teach international programmes, hiring expatriate teachers may not be as essential as it was once believed to be (Hayden and Thompson 2013: 11).

International schools are inaccessible to the majority of the population (Hayden and Thompson 2013: 8). A good choice of school will reap personal dividends unavailable to the less fortunate (Passy 2013: 1062). Children from advantaged backgrounds are more likely to attend independent schools (de Vries and Rentfrow 2016: 1). Critics of privatised and elite schooling highlight its effects upon social inequalities. International schools are seen as elite-class reproducing institutions which also bolster pre-existing relations of social privilege and status upon a minority, thereby perpetuating economic and social advantage (Bunnell 2010b: 352; Dorling 2011: 35; Waters and Brooks 2011: 158; Boyask 2013: 11; Song 2013: 136). Parents impact the future of their children by acting alongside the school, as co-educators (Ule et al 2015: 329). Adolescents in families that possess the cultural resources shared by the dominant social class who 
are also enrolled in schools that sanction these cultural traits may obtain a double advantage, as the parents are better able to invest in the development and accumulation of their children's human, social and cultural capital (Swartz et al 2011: 417; Friedman 2012: 469; Marteleto and Andrade 2013: 2).

We are living in a time when the logic of capital subsumes every aspect of our lives and today's parents pour capital into their children (Senior 2014: 10; Skeggs 2014: 1). Social capital is the totality of resources and relations which procures a competitive advantage and a power over the 'field' (Bourdieu 2005: 194). Social capital is a set of connections and relations with acquaintances, family members, and friends which people can access for support in order to increase one's capacity to achieve one's goals (Coleman 1988: 100; Richter and Nolllert 2014: 461; Field 2005: 6). Social capital is a resource that is connected with group membership and social networks and the volume of social capital depends on the size of the network of connections that can be effectively mobilised (Bourdieu 1986: 249). Cognitive social capital, or feelings of trust in those around you, has been found to be linked to happiness (Han 2015: 251). Social capital is productive, making possible the achievement of certain ends that in its absence would not be possible (Coleman 1988: S98). Social agents are located in a hierarchical distribution of forms of capital rooted in or derived from the economic structure (Wacquant 2014: 120). Sadly, it is clear that those who need access to the cultural and social capital necessary for success in today's global economy - the poor do not have such access and therefore suffer from a 'lack of capital' (Dolby 2012: 372; Bryant and Ellard 2015: 485).

Social capital cannot be understood in isolation from other forms of capital (Sheng 2014: 562). A significant number of the middle and upper classes are investing more and more in internationalised resources, considered today to be an essential feature in their children's schooling for professional success, giving them competencies and dispositions that will allow effortless circulation amongst the international community (Aguiar and Noguiera 2012: 353-354). East Asian transnational families relocate overseas either to improve their well-being or to enhance their status through their children's international education (Igarashi 2015: 99). With respect to the school sector, research has shown that private schools show a more communal orientation 
than state schools, resulting in higher levels of social capital (Van Maele and Van Haute 2011: 88). International schools might be seen as the alchemist producing transnational capitals for their students who may potentially become global professionals on global labour markets, with a cosmopolitan habitus (Forbes and Lingard 2015: 118). Habitus is seen as a system of transposable dispositions or a way of thinking, acting and moving in and through a social environment (Bourdieu 1977: 72; Sweetman 2003: 532).

People with high levels of network capital experience high levels of geographical mobility and are at home in many diverse settings (Elliott and Urry 2010: 11). Cultural capital is inherited at an early age within privileged families (Kisida et al 2014: 281). Institutionalized cultural capital includes formal education (Erel 2010: 643). Young people in international schools gain access to various networks due to their transient and global lifestyles. Local students also gain access to various new networks as they come into contact with the so-called 'third culture kids' in international schools (Bailey 2015a: 87). Due to their privilege, all of these young people have more educational opportunities and aspirations for schooling, greater access to financial resources, role models, occupational knowledge and informal networks (Hauser and Anderson 1991: 246; Schoon and Polek 2011: 211; MacMillan et al 2013: 3). The accumulation of 'international capital' for the elites carries with it an investment logic, offering educational products oriented to the families' demands (Aguiar and Noguiera 2012: 367). All of this capital helps these young people navigate through life and contributes significantly to their experiences and life opportunities (DiAngelo and Sensoy 2014: 2; France and Haddon 2014: 308). Capitals therefore act to guide to the 'field of possibles' and elite schools are legendary for producing national leaders, politicians and high status professionals (Koh and Kenway 2012: 334; France and Haddon 2014: 319). Education is a process of human capital formation rendering education responsible for forming skills and attitudes (Bessant and Watts 2014: 127). According to human capital theory, individuals will embark upon a course of personal development and an investment in education increases the labour power of the individual (Bowles and Gintis 1975: 77-79). This multiple capitals frame in international schools reproduces power, advantage and privilege naturally and unaffectedly, 
underpinned by economic surety at both familial and school levels (Forbes and Lingard 2015: 120, 135).

Cultural and social capital are important concepts which help us to understand how people have different resources to enable them to make the choices they do (Thornton et al 2014: 12). Children's attitudes to schooling and education vary by the socioeconomic status of their parents (Rampino and Taylor 2012: 3). Students with less academic success or parental support, perhaps due to less cultural capital, are expected to have modest aspirations and more emotional problems (Sikora and Biddle 2015: 2; Moulton et al 2015: 925). Families of higher socioeconomic status have more resources to enable their children to pursue higher education and these educated parents function as role models for their children (Vuolo et al 2013: 147). The children of educated parents in professional occupations often take it for granted that they will follow their parents' footsteps along similar paths (Sikora and Biddle 2015: 2).

Class position can play a significant role in the way young people conceive higher education and in their understanding of the importance of making the right choices (Donnelly 2014: 57-58). Research has shown that children with professional parents in the U.S., U.K. and Australia are three times more likely to enter a high status university than those with working class parents and that a ten percent increase in family income is associated with a 1.4 percent increase in the probability of attending a four year college (Acemoglu and Pischke 2001: 890; O'Leary 2013: 3). Other U.K. based research states that pupils from affluent areas are five to six times more likely to enter university than $20 \%$ of those young people from deprived areas (Moogan 2011: 1).

Children of richer parents may have characteristics which make it easier to acquire the education which will often secure higher earnings in a more prestigious profession (Blanden and MacMillan 2014: 7; Macmillan and Vignoles 2013: 7). In the U.K., young people from disadvantaged backgrounds remain significantly underrepresented in the undergraduate population (Jerrim 2013: 1). In addressing this issue, the U.K. Government is investing large sums of money in widening participation in higher education courses, especially those from lower social classes (Moogan 2011: 1). One such venture is 'The Brilliant Club', a non-profit organisation that exists to widen 
access to top universities for outstanding pupils from low-participation backgrounds (Jerrim 2013: 16). The European Union's 'Youth Strategy' of 2009 also aimed to increase educational participation rates with the goal of creating better opportunities for young people (Bessant and Watts 2014: 125).

The participants in this study attend a financially selective, independent school. Research from Australia tells us that attending a Catholic or independent school impacts on one's probability of going to university (Gemici et al 2013: 36). Of the 650 members of the British Parliament in 2014, 33\% attended independent schools and 2\% attended international schools (Commission on Social Mobility and Child Poverty Commission 2014: 20). Of that current intake, $35 \%$ of British MPs were privately educated (Jones 2014: 68). All this amounts to what could be described as an educational frequent flyer program for the wealthy. In essence, the family culture and school culture work in harmony to make the idea of failure to reach university unthinkable (Smyth and Wrigley 2013: 126). The participants in this study appear to be schooled in the belief that 'learning equals earning' and the opinion that hard work in school entitles one to a good job as a way to maintain their 'positional advantage' relative to others (Brown et al 2010: 5; Settersen Jr. and Ray 2010: 26; Hall and Appleyard 2011: 248; Krahn and Galambos 2014: 93).

There is a high emphasis on the acquisition of education as capital (Basit 2014: 1). Academic degrees are an obvious form of educational capital and possessing a highly coveted degree will then augment one's economic capital (Rey 2004: 332-333). Research shows that between the ages of 26-42 an independently educated person is a third more likely to enter into a high status occupation and will earn on average $£ 193,700$ more than someone who was state educated (MacMillan et al 2013: 3; The Sutton Trust 2014: 11). Other research based in the United Kingdom shows that elite law and accountancy firms are dominated by people from more privileged socioeconomic backgrounds and who have attended fee-paying schools (Ashley et al 2015: 6).

Adolescent years are critical for exploring academic and career related interests (Shoffner et al 2015: 102). Careers are becoming more international and the skills 
needed to navigate the world of work have never been so challenging (Hooley et al 2015: 1). Worldwide, employers acknowledge the importance of intercultural skills in their employees, which include being open to new ideas and ways of thinking and having respect for others, in order to work successfully in a global setting (Messelink 2015: 67). These soft skills are certainly developed through international mobility.

To acquire a professional position requires extended periods of elite schooling (Hansen 2014: 460). Children from more advantaged backgrounds are more likely to develop personality characteristics and aspirations which will benefit them in the labour market (de Vries and Rentfrow 2016: 3). Being educated in an independent school increases the likelihood of earning a higher salary or achieving a senior position within the political, judicial and cultural sectors (Maxwell and Aggleton 2013: 4). More socioeconomically advantaged students in the U.K. will acquire more human capital and this in turn will enable them to access top jobs to a greater extent than students from more disadvantaged backgrounds (MacMillan et al 2013: 13). Other U.K. based research found that pupils attending selective state schools were more than 40 percent more likely to go to university than pupils attending non-selective state schools (Crawford 2014: 9). Research from Singapore reveals that many in the 'state nobility' attended overseas elite universities (Kenway and Koh 2013: 275). In France, the 'grandes ecoles' or elite schools have been the training ground for students who become state nobility (Kenway and Koh 2015: 5). Elite education could be said to be contributing to the division of society and conferring high status upon a minority (Dorling 2011: 35). It could be argued then that international schools contribute to the formation of a global ruling class since they can link internationally educated graduates with transnational corporations and senior level jobs (Resnik 2012: 300; Hansen 2014: 460).

The youth of today are facing unprecedented challenges and a 'turbulent career landscape' (Garcia et al 2015: 10). All around them the effects of such things as unemployment, growing economic inequalities, racism and violence are becoming ever more visible (Apple 2013: 1). Many more young people, from more diverse backgrounds and perspectives, are now exposed to precarious social and economic circumstances (Williamson 2014: 5; Carmo et al 2014: 337). There is a modern global 
situation where competition is increased, housing costs are high, employment is unstable and labour markets are increasingly precarious and insecure, giving young people unprecedented and widespread uncertainties about their futures and making it increasingly difficult to define their horizons (Brown et al 2010: 5; Hall and Appleyard 2011: 248; Swartz et al 2011: 414; Cebulla and Tomaszewski 2013: 141; Heggli et al 2013: 916; Carmo et al 2014: 354). Families across the income spectrum experienced feelings of worry, distress and uncertainty about the future during the 'Great Recession' (of 2008) which can affect levels of social capital (Leininger and Kalil 2014: 998; Iglic 2014: 7). Individuals and families are faced with lower incomes, limited access to public services and rising unemployment (Iglic 2014: 8). The unemployment rate of young people in the Eurozone in February 2014 was 22.9\%; ranging from 56\% in Greece, 49\% in Croatia, to 7.8\% in Germany (European Youth Press 2014: 11). Youth (aged 15-24) unemployment data from 2013 showed Spain at 56\%, Italy at 40\%, Portugal at 38\%, Belgium at $24 \%$ and the United Kingdom at 20\% (U.K.C.E.S. 2014: 7). In the U.K., $40 \%$ of young people have experienced mental health problems as a result of being out of work (The Prince's Trust 2014: 14). Youth unemployment follows a similar pattern in most European countries, tending to be double the adults' rate (Serracant 2015: 43). Proportions of young people not in employment, education or training ranged from $29 \%$ in Turkey, $20 \%$ in Brazil, $13 \%$ in Canada, 12\% in Australia and 7\% in The Netherlands in 2012 (Hutchinson and Kettlewell 2015: 114).

In May 2013 there were 19.3 million unemployed people in the euro area, the highest since 1995 (Bessant and Watts 2014: 125). Many young people presently in their twenties in the United States are also returning home after graduating college, the so -called 'boomerang kids' (Flaherty 2012: 237). In the United States, these boomerang kids are looked down upon by society as a whole as they are seen as stunted or a drain on their parents (Sandberg-Thoma et al 2015: 807). This phenomenon is also occurring in Germany, where those young people who return to the parental home are portrayed by the media as parasites (Berngruber 2015: 1274).

Most countries have seen a continued trend of social inequality, which points out that the economic crisis has not been shared equally by all social classes (Iglic 2014: 8). The U.K. is one of the most economically unequal of the rich countries (de Vries and 
Rentfrow 2016: 3). In 2010 in the city of London the best-off tenth of citizens had recourse to 273 times more wealth each than did the worst off tenth (Dorling 2010: 19). Wealth refers to things people own at a certain point in time (Keister 2014: 349). In Britain, the Gini coefficient, a measure of income inequality, worsened from 29 to 39 in the period between 1979 and 2013 (Smyth and Wrigley 2013: 48). Income is defined in this context as a flow of funds into the household over time in the form of wages, salaries or from other sources (Keister 2014: 349). At the start of 2014, Oxfam calculated that the richest 85 people on the planet owned as much as the poorest half of humanity (Oxfam 2014: 8). These developments are deeply troublesome. Over the past decade economic rewards have become increasingly concentrated in a few hands, with small fractions of the population possessing massive wealth whilst large groups of people have nothing (Khan 2012: 361; Hansen 2014: 457). Of course, there will always be people who are greedy and do not think it important to share and distribute wealth. Wealth can be passed on to other generations, thereby extending its benefits indefinitely (Keister 2014: 349). Self-made wealth has become more common, and will rise in Europe in the future (Hansen 2014: 459). Today, elite power is on the rise and requires a deeper understanding as wealth inequalities can be 'socially corrosive' (Khan 2012: 363-373; Wilkinson and Pickett 2010: x). In their research of 33 countries, Elgar and Aitken (2010) found that income inequality relates to homicide and unequal distributions of wealth identify the most dangerous places to live (Elgar and Aitken 2010: 244).

There is a belief that dropping out of high school leads to economic hardship (Campbell 2015: 108). The recent economic crisis has even reduced the protective effect of education as human capital, with the rewards of a costly degree being even less (European Commission 2014: 22; Mendick et al 2015: 4). Evidence from the U.K. suggests that young people have been finding it increasingly difficult to turn their aspirations into a lived reality (Cebulla and Tomaszewski 2013: 143). Such a situation can lead to delays in starting independent lives and starting a family (European Commission 2014: 22).

In the face of growing uncertainty, today's young people must exhibit a 'planful competence' (Skrbis et al 2011: 68). Young people construct their futures after 
considerations of the costs and benefits resulting from their choices (Carmo et al 2014: 339) and the idea that more education increases individual welfare is connected to a long standing idea about progress traceable back to Europe's Age of Reason (Bessant and Watts 2014: 135). After World War Two, industrial democracies began to invest heavily in their higher education infrastructure and as a result, university enrolment increased (Dodson 2015: 17).

Young people place a very high value on academic success and conceive higher education as a desirable good, a doxic aspiration (IPSOS MORI 2014: 12; Gale and Parker 2015: 87). Today's young people need to stay in school, graduate with academic skills and go on to further education (Orthner et al 2009: 250). Most youth today attempt to obtain as much schooling as they can to obtain a 'marginal advantage' (Ball 2013: 16; Vuolo et al 2013: 146) and over 40 per cent of school leavers in the United Kingdom go on to higher education today, which is a common trend across most developed countries, as well as emerging markets such as China and Korea (Clifton et al 2014: 3). China has approximately 20 million students in higher education, more than the United States (Ashton et al 2010: 842). In addition, dramatic gender shifts in recent decades have led to a situation where women are graduating from college at higher rates than men in the United States (Malin et al 2015: 34). There exists a school of thought which argues that some young people end up pursuing higher education options because they have no other attractive viable opportunities available (Hart 2012a: 172). Not to mention that not everyone who applies to university is ensured a place.

As the rich become more educated, this could have potentially important implications for social mobility. If individuals from wealthy backgrounds acquire more education and obtain a wage pay off for this education, already existing inequalities are transmitted more strongly and social mobility falls (Lindley and Machin 2012: 266). Those young people who even have an access to knowledge or understanding of higher education might be likely to have an advantage over others without such insights (Hart 2012a: 58). 
Human capital theory suggests that investments in people create economic benefits for society (Sweetland 1996: 341). Human capital theory develops a model which predicts a direct effect of parental income on children's outcomes (Anders 2012: 188). In human capital theory, individuals are willing to forego current earnings whilst they accumulate capital through education to boost future productivity and income (Davies et al 2014: 807). Higher education has been seen as the best way to ensure people have opportunities to access professional jobs, thereby generating a wage pay-off and increasing levels of 'human capital' (Lindley and Machin 2012: 266; Clifton et al 2014: 3). Investment in human capital is one of the most important channels to achieve the goal of an individual's capacity to succeed in the labour market (Castex and KoghanDechter 2014: 685). This is perhaps why there has been a doubling of the number of higher education students around the world (Ashton et al 2010: 842).

Global free-market capitalism has dominated the world since 1980 (Hall et al 2013: 3). In the new capitalism, Gee (2000: 122) would argue that wealth and power tend to stem from whether or not one has access to specific networks of people, information, and to specific experiences connected to these networks. Gee uses the term "affinity groups" to describe how companies tend to create atmospheres of affinity with their employees or customers, ensuring they gain certain experiences. Gee also argues that well off elites create affinity groups as well, sharing experiences with other privileged people across the world; transcending local and state borders (Gee 2000: 107). This description fits well with the young people who attend international schools. Their familial circumstances, mobility, exposure to different cultures and socio-economic background allow them to enter what Bates (2012:263) would call a 'first world citizenship'. This citizenship gives these young people a unique set of competencies, skills and capitals, termed international capital. This international capital puts these young people in a minority of their peers and allows them to thrive in a global environment (Yemini 2012: 162; Bates 2012: 263). This globalizing of the mind is a result of a social process and an everyday experience of cosmopolitan interdependence (Weenink 2008: 1091). Being cosmopolitan relates to being outward looking and interested in learning from people of different cultures and countries. Having started out in ancient Greece, being 'cosmopolitan' means having a sense of 
political non-affiliation - declaring oneself to be a 'citizen of the world' rather than of any particular polity (Inglis 2014: 99). This concept of being an 'international citizen' is one that describes an increasing number of people worldwide (Velliaris and Willis 2014: 235).

This modern day 'cosmopolitan capital' is accumulated while living abroad, visiting and hosting friends of different nationalities, maintaining a globally dispersed circle of friends and relatives and possessing mastery of at least one other language (Weenink 2008: 1092). Experiences of mobility can shape one's cosmopolitan openness or 'intercultural competence' - the ability to embrace, interact and deal with different people and cultures and develop attitudes against global injustices which can enable children to thrive in a globalised world (Skrbis et al 2013: 2; Deardorff 2011: 66; Merry and de Ruyter 2011: 2). People need to know about their own country's history but they also need a vision for a shared society, a disposition of openness towards others and to be equipped for a more globalised world in order to have a more 'cosmopolitan' identity (Perry 2013: 221; Skrbis and Woodward 2007: 730). The ability to understand other worldviews, perspectives and histories becomes another important consideration for thinking inter-culturally (Deardorff 2011: 68). A school which is 'internationally minded' attempts to instil an attitude of mind into its students which values empathy and respect for all human kind (Hill 2014: 177).

Given the mobility of capital, the transnational integration of national economies and the global fragmentation and decentralization of accumulation circuits, a new global ruling class has emerged (Robinson and Harris 2000: 12). However, growing up rich can distort children's relationship with the world and their sense of what is good enough (Pittman 1985: 461). Adolescents who are spoilt are at risk of suffering from being repeatedly told how gifted they are and believing it, which in turn could have affective consequences (Dorling 2011: 71; Rutherford 2015: 70). As a result society can end up with a 'privileged but pressured' youth, pressured by parents, peers, schools and themselves and more distressed than other youth, experiencing high rates of depression, substance abuse and anxiety (Luthar et al 2013: 1530; Luthar 2013: 1; Lyman and Luthar 2014: 927). The various factors associated with privilege - in particular, materialism and the pressure to achieve - combine to create a crisis for 
affluent adolescents (Howard et al 2014: 10-11). Young people of this 'transnational capitalist class' (Sklair 2001: 1) can experience a pressure in their education to contribute to the continuation of this social status, which, in turn, has the potential to transform their aspirations if there is a discrepancy between their expected and hoped-for future selves (Davidson 2008: 2829; Weenink 2007: 492; Rutherford 2015: 70).

Having an ethnically diverse network is associated with more access to social capital (van Tubergen and Volker 2014: 1). Some of these young people are attending international schools due to their parents' globally mobile lifestyles and experience what Pearce (2011: 160) would describe as life-trajectories which take them through a sequence of locations and cultural situations. These children have been uprooted from their familiar environments and have limited opportunity to choose the type of education they can pursue or the form or location in which it takes place. Young people of transient families settle in sometimes very unfamiliar territory. They have no choice where they live and the effects can be unintended, unforeseen and inescapable (Weenink 2008: 1091). Whilst relative affluence gives opportunities for travel, firsthand experience of new locations and people, and relationships with people from a range of different cultural backgrounds, the longer term impact can be more profound on some of these young people (Nette and Hayden 2007: 435; Grimshaw and Sears 2008: 259). Many students who have followed international schooling experience a fluid yet confused sense of identity due to the fragmented nature of their personal histories, so much so some feel they never fit in anywhere and hence view themselves in response to their changing circumstances (Grimshaw and Sears 2008: 259; Sears 2012: 119; Gee 2000: 121). That being said, these young people tend to feel a sense of belonging in this international school community, as it forms a protective net around them and increases their social capital (Grace et al 2011: 15).

Recognising that identity and its importance cannot be ignored, Tate (2012: 210) emphasises that helping young people to develop their own multiple identities is one of the biggest challenges facing not just international education but any kind of education in the contemporary world. This concept of personal identity should be a topic of interest to educators working in such diverse settings and as Apple (2011: 223) 
argues, teachers need to know much more about the multiple cultural traditions from which these populations come. Furthermore, where international displacements put young people in social environments for which their upbringing did not prepare them, or where they feel a unique pressure to fit in, those who work closely with them can help those young people adjust and cope (Lee and Kramer 2013: 19). After all, educational settings can have a degree of effect on children's aspirations (PimlottWilson 2011: 118).

\subsection{Summary}

The main research question for this study was How do a globalised lifestyle, international capital and an international schooling experience influence the identities and aspirations of young people?.

The focus of this chapter was on the key literature relevant to this study. I offered a focus on adolescents and how they are experiencing a period in their lives when they are discovering both who they are presently, whilst contemplating who they may become in the future. Just as they are experiencing many psychological and physical changes, there are many influences which may affect their present and future choices and identities. Aspirations and choices are strategic and rational and made within certain contexts and parameters. Aspirations are defined by the resources available to a young person. The literature strongly suggests that young people's aspirations are informed by the social and class contexts in which they are situated. This chapter offered a discussion of the literature surrounding identity formation and how identities can be fluid, changing, complex and multifaceted. I brought into focus the issues of home and homelands. I discussed the adolescent period of life, during which a salient period of self-identity is taking place. I linked agency and self-determination theory into the discussion of the development of personal identity. All of these issues are interwoven into the globally mobile adolescent, who is forming their own identity under changing geographical locations.

I discussed the opportunities and capitals available to young people within a particular class location. In terms of social capital, it is evident in the literature that young people benefit from developing strong relationships with their teachers and mentors. Young 
people who are experiencing the identity issues regarding adolescence and transience due to their privilege need and seek out strong relationships with their family and peers. I explored both of these points. I also put forward that all adults can also play a significant role in aiding and guiding young people, and for those students who find themselves in an unfamiliar country or school, this becomes even more important. From this standpoint, it is necessary to consider the way international schools meet the needs of their communities. I also discussed the global economic situation which this generation of young people face. I highlighted the common trend world wide of young people opting for the route of higher education as part of a 'planful competence' to increase their chances of success in life.

In the next chapter I discuss the methodology for both the pilot study and the main study. I introduce the participants of both studies and share their short biographies. I then explain how the data were collected and analysed and reflect on some ethical considerations when undertaking qualitative research with young people in a setting familiar to the researcher. I also recognise some limitations of the study. 


\section{Chapter Three}

\section{Methodology}

\subsection{Introduction}

The aim of the study was to gain rich insights into young people's perceptions of the factors that influence their current and evolving aspirations and how they envisage their future selves. It was guided by this main research question:

How do a globalised lifestyle, international capital and an international schooling experience influence the identities and aspirations of young people?

The subsidiary research questions for the study were:

1. Is there evidence of a link between these students' first world citizenship privilege and the nature of their aspirations?

2. To what extent do parents influence aspirations?

3. To what extent do:

i. Globally nomadic experiences and

ii. International Schooling

influence the identity and aspirations of young people?

4. How do young people of this transnational class:

i. Define success and

ii. View their future selves?

The purpose of this chapter is to provide an account of the research process with the aim of making transparent the rationale behind my choice of the use of semistructured and photo-elicitation interviews as the principal means of data collection. In this chapter I explain my methodological approach to undertaking this study and how it sits within the interpretivist paradigm. I also explain the construction of both the pilot and the main studies, which were conducted at the same school. I discuss how the participants were chosen, offer accounts of the participants involved, how the 
studies were conducted, how the data were gathered, organised and analysed. I briefly discuss some limitations of the pilot study.

All of the twenty participants in the main study attended both of their interviews, provided answers to every question posed to them and completely fulfilled their agreement to take part in the study.

I discuss constant comparative method as the approach to data analysis and the trustworthiness of the research of the main study. Tables revealing the details of the participants in the main study are shown, with pseudonyms for all the participants. I also discuss the ethical considerations implicit in the main study and the ways I addressed them. These ethical considerations include working with a vulnerable group, being an insider researcher, confidentiality and validity. Finally, I reflect on the limitations of the main study. The study is small scale and modest in its intentions, though its implications may be potentially wide-reaching to other international school contexts. The young people involved were not intended to represent all young people in international schools, but that is not to say that the findings cannot inform our understandings of young people in similar situations in other schools.

\subsection{Interpretivism and Qualitative Educational Research}

This study was guided by the question 'How do a globalised lifestyle, international capital and an international schooling experience influence the identities and aspirations of young people?'. An appropriate research design and method is needed to explore young people's thoughts, interpretations and perceptions of their present and future selves. This study is located within an interpretivist paradigm, employing qualitative research methods which seek to subjectively interpret a phenomenon (Kort and Gharbi 2011: 1). Interpretation is a key element of qualitative research (Symon and Cassell 2012: 205). Interpretivists believe there is no objective truth and that all human life is experienced and constructed from a subjective point of view, from which meanings are sought by the social researcher (Johnson 1994: 7). Qualitative research is concerned with understanding individual experiences and feelings about their condition and meanings people give to their lives. As Blaxter et al (2010:61) suggest, the social sciences are concerned with understanding and interpreting the social 
world. Interpretivists believe qualitative research may give more telling results and I was concerned with exploring young people's perspectives, views, interpretations, feelings, life histories and everyday behaviour, favouring a qualitative method of investigation (Silverman 2004: 25). Through this understanding, I wished to build a theory, in keeping with qualitative methods.

Qualitative approaches to research allow the researcher considerable flexibility and freedom and exemplify a common belief that they can provide a deep understanding of social phenomena (Newby 2010: 115; Silverman 2004: 32). Qualitative approaches are concerned with how and why things happen as they do and are "held to stem from a humanistic tradition", drawing on insight, description, meaning and interpretation. This type of research is characterised by the researcher's objective to explore and to comprehend in-depth the subjects' perceptions, to achieve deeper knowledge (Sarantakos 1998: 254). Interpretivists seek an in-depth understanding of a context, or lived experience by collecting data about participants' experiences, views, feelings or perceptions. The researcher is the 'focal point of interest' (Duberley et al 2012: 21) and my challenge was to make sense of the sense the participants made out of their experiences.

For interpretivists, it is essential to see humans as actors in the social world rather than re-acting like objects in the natural world (O'Reilly 2012: 15). The goal is not 'truth', but rather to try to understand a phenomenon and to reach the lived experience of participants without disturbing their setting. Taysum (2011: 1) writes of four core beliefs in the search for truth. The first is to be critical to the self, the second to be respectful of others, the third to be tolerant of those opposing your view and the fourth being a commitment to generating new knowledge. Linked to this is how to know what truth is and the issue that individuals' meanings of truth vary as every person's understanding of the truth is different. For the interpretivist, the expected product is no longer truth but an acceptable rendering of what had been produced in the moments of the inquiry ( $O^{\prime}$ Connor et al 2008: 31$)$.

Another aim of interpretivism is to make sense of, or to interpret, phenomena with respect to the meanings people bring to the research, including the researcher 
(Onwuengbuzie and Leech 2007: 240; Thomas 2013: 235). In contrast, positivists profess that the scientific method provides for the acquisition of new knowledge. Positivist research is designed with causal relationships, patterns, questions, operational definitions, generalizable assumptions and hypotheses in mind. Positivists assume that an objective physical and social world exists independent from humans (Kort and Gharbi 2011: 1). Positivists aim to be as objective as possible, seeing the researcher as independent of the study. I saw myself as very much a part of the research process and not at all independent from the study.

This study is located within an interpretivist paradigm. As I wished to gain an insight into perspectives of young people regarding their identities and aspirations, my readings focussed on qualitative methodologies. The use of qualitative methods allows young people to conceptualise their identities in their own words (Faas 2009: 303). Qualitative research is not concerned with one reality as there is not, in the view of qualitative researchers, one truth (Newby 2010: 117). Truths are always partial and knowledge always situated, produced in particular circumstances at particular times (MacLure 2013: 167). Qualitative research feels more authentic (Hollenbeck 2015: 150), as qualitative researchers collect stories by listening to research participants and seeing their situations in order to, as Onwuengbuzie and Leech (2007: 238) explain, adequately capture lived experiences from a natural setting. This approach also deals with building up relationships to obtain information from the participants. In wishing to find out how the students involved in the study perceive and view their own environments and lives, I decided this project would adopt a qualitative approach, in line with Pring (2000: 248), who notes that each situation is unique and each transaction is constituted by the perceptions and interpretations of the participants. This resonates with Van Oord and Corn (2013: 10) who see the value of sharing life stories and appreciate how a 'many cultured experience' shapes a sense of self.

Qualitative paradigms are concerned with understanding behaviour from the actors' own frames of reference and see the researcher as 'close to the data' (Blaxter et al 2010: 66). As the primary instrument of data gathering, collection and analysis, I was 
the key to unlocking the sense the participants made out of their realities. I analysed the participants' perspectives and the meanings they made out of their lives.

Studying people is problematic as they do strange, unpredictable things; acting irrationally while they learn and change (Thomas 2013: 119). Knowledge and how it is formulated is an important part of educational research. Burgess et al (2006: 54) define the term ontology as the study of being and reality and epistemology as the theory of knowledge; how knowledge is obtained and what makes it knowledge. Ontology is about what you are looking at-the kinds of events that exist in the world (Thomas 2013: 120). The social world is not at all clear in revealing to us what we should be studying (Thomas 2013: 119). I will now explain the pilot and the main studies.

\subsection{The Pilot Study}

A pilot study was undertaken in an international school in Belgium, where I was employed at the time. The pilot study included four participants aged 13: two boys and two girls. They were interviewed on their own on two occasions, the interviews being conducted three weeks apart. The participants were all $8^{\text {th }}$ grade students whom I taught. This is an example of what Blaxter et al (2010: 170) define as 'convenience sampling', as participants are taken from the researcher's place of work, for convenience of access. Ethical approval was granted by the University of Leicester in December of 2012 and written consent was gained from the participants' parents in December 2012, one month before the pilot began in January 2013. Permission from the international school was also granted in the autumn of 2012.

A meeting was held with all four participants present in late December 2012 during which I explained the focus and purpose of the research project and the participants' roles in it. It was explained that they were taking part in a research project which would help explain what factors young people who attend international schools perceive influence their identities and aspirations. I explained in the initial meeting that the participants were under no obligation to participate in the project, the study had no relation to their grades in school, and that they could choose to opt out of the study at any time if they so wished. All participants acknowledged understanding of 
this message and agreed to participate. Permission was then sought from and granted by the parents in writing so that the pilot project could begin.

The first individual interviews took place during the first week of January 2013. Each participant was interviewed, allowing for 30 minutes during the students' lunch hour, and the interviews were recorded using the program Audacity which was already installed on my computer. The participants answered a series of eleven questions. These questions centred around people that influence them, being happy in school, experiences where they felt inspired, expectations of what an international education could give them, role models, their definitions of success and their future plans after secondary school. At the end of the interview the participants were then asked to return for a second interview in three weeks, again during mutually convenient lunch hours.

At the follow-up interview, the participants brought photos with them. I told them to bring up to ten photos to give them some kind of benchmark number. These images were to be of something or someone who the students felt had an influence on their aspirations or future identities. The images were used as a discussion starter so that I could construct a narrative of the participants' viewpoints and experiences. This method of investigation was influenced by the work of Croghan et al (2008) and Smith et al (2012), who used this approach in their respective studies. Again these interviews were recorded using the same software as used in the first round of interviews. Pseudonyms were given to each participant to protect their identities and all information was kept safely and securely in my possession for the duration of the pilot study.

The participants in the pilot included one American girl and one Brazilian girl, along with one Italian boy and one Australian boy. Nationality for the purposes of the pilot was determined by what nationality appeared on their passport. The participants are identified as Jill and Manuela for the American girl and Brazilian girl, respectively. For the boys, pseudonyms of Ozzie (Australia) and Vinny (Italy) were used. For two of the participants, English was not their mother tongue. However, they had been mainstreamed into a full English environment in their middle schooling and were 
deemed by me beforehand to be able to understand the interview questions sufficiently well enough to give responses.

Jill had lived all over the world and attended international schools all of her life. She would be what Ezra (2003: 126) describes as the 'internationally mobile child', having moved frequently due to her parents' employment. For Manuela, this was her first year in her first international schooling environment, coming directly from her home country, Brazil. Ozzie had attended his present school all of his life and was born in Belgium to parents of Greek and Australian descent, and Vinny was born in the country of the school he currently attended and had attended two international schools in Belgium in his lifetime. I did not know these details before the participants were chosen for the pilot study. Four of the 50 school nationalities were represented in the pilot study and the participants came from the continents of North America, South America, Europe and Australasia.

Another meeting was held with the four participants in early February 2013, during which I thanked the participants for their taking part in the study. The participants expressed that they had a positive experience in the pilot study and also communicated the value in reflecting and talking about their lives. One participant even commented on how much she enjoyed the opportunity to be able to discuss her life and how all students should do so.

In the data analysis of the pilot study, a system of open coding was used for the interview and visual data. Each interview question was examined in the interview transcriptions. This involved highlighting characteristics and single pieces of information as suggested by the data where each label is meant to capture a meaning of the phenomenon observed. The aim was to break the data down to uncover as many categories and sub-categories as possible by linking concepts together. The coding structure for this pilot project was not completely predetermined as some of it emerged from the data itself whilst other parts emerged from the literature reviewed. There are downsides of coding, in that there appear to be no limits as to when to stop, it takes considerable time and it runs the risk of creating less than thorough work, especially for the first time researcher (Newby 2010: 465). Aware of these noted risks, 
I used the coding system for the interview data. I gathered, transcribed, and analysed all of the data alone, with hope to increase my engagement with and ownership of the data.

The object of analysing qualitative data is to determine the categories, relationships and assumptions that inform the respondents' views of the world and of the topic (Basit 2003: 143). The same author writes that category names can come from a pool of concepts which the researcher already possess or are words and phrases used by the informants themselves. Information was gathered from the data itself, otherwise known as 'inductive coding' and themes were generated from the words and phrases offered by the participants through their interview data.

Using the transcriptions, I printed them out and highlighted key issues as they emerged in the text. These issues were identified as being common in all the interviews and came directly from the language used by the participants. All of the interviews classified 23 separate issues. Five issues were only mentioned on one occasion; making an impact on the world, pets, pressure to know what to do in life, presenting yourself in school and homelessness. These singular issues were not included in the themes as they only came up once during the interviews and were mentioned only briefly.

The pilot study found that family had a significant impact on the participants' lives and aspirations.

Jill: my parents...are the ones that mean the most to me and because no matter what happens they will always be there for me...

Manuela: Yeah I think my parents because they actually like teach me and tell me what is right and what is wrong in life...

Ozzie: I would have to say probably parents cos, it's also just my family basically, it's all about family for me with me...

Vinny: My parents are the biggest influence as they grew me up...taught my manners, my family in general really... 
Also, the participants saw the value of education as a means to a better life and a central part of their lives. All of the students in the pilot study expressed positive hopes and desires for their futures. All wanted to be happy, have a home, a good job, and to be educated. All saw education as the main key to unlocking those gifts to them in their lives. This resonates with the work of Hart (2012a) and her claim that aspirations are sequential; one being fulfilled before another is possible.

Jill: after High School I have plans to go to college you know... and I think you know I think college is the route to you know the route to life

Manuela: I think I'm gonna be like in college...science things and like already looking for a job...

Ozzie: this school can set me up for the future and everything.

Vinny: I like high standards and this school expects that. It opens you to many universities.

The evidence suggests that the young people in this study, whose lives are characterised by transience, value emotional attachments and develop particular relational skills via their experiences of frequently changing and evolving friendships. The participants mentioned the value of friendships, however long or short, as important to their lives.

Jill: ... it's hard because I do make a lot of friends but because of the fact I have to move everywhere I have to say goodbye to so many friends.

Ozzie: this is an international school so everyone is gonna leave at some point.

A summary of issues and themes from the pilot study can be found in Table One. 
Table One: Issues and Themes from the Pilot Study

\begin{tabular}{|l|l|}
\hline Issues & Theme \\
\hline $\begin{array}{l}\text { Teachers, school atmosphere, school } \\
\text { presenters, appreciation of differences }\end{array}$ & $\begin{array}{l}\text { Schooling (Discussed in depth by all } \\
\text { participants) }\end{array}$ \\
\hline $\begin{array}{l}\text { Sports, media, home country, moving, } \\
\text { identity }\end{array}$ & $\begin{array}{l}\text { Identity (Discussed in depth by two of } \\
\text { four) }\end{array}$ \\
\hline Education and College, success, careers & The Future (Discussed in depth by all) \\
\hline Parents, family, adults & Family (Discussed in depth by all) \\
\hline $\begin{array}{l}\text { Friends, losing friends, making new } \\
\text { friends }\end{array}$ & $\begin{array}{l}\text { Friends (Discussed in depth by three of } \\
\text { four) }\end{array}$ \\
\hline
\end{tabular}

\subsection{Limitations of the Pilot Study and Modifications for the Main Study}

One noticeable limitation of the pilot study was the sample of nationalities and numbers of participants used. Although an attempt was made to have participants who came from all over the world, regions such as Africa and East Asia were not represented in the pilot study. It would be interesting to see if participants from these parts of the world have similar views of their future selves. In fact, as the two boys interviewed in the pilot were both born in Belgium, it could be argued that they were local students. Given that argument, two local students were used in the pilot study and two expatriates. Participants from more regions of the world were represented in the main study.

The sample size was very small and certainly did not represent the views of all of the many diverse students in the school. The main study sample size was larger, 20, but still not an extremely large group, due to the semi-structured and elicitation interview approach to the study and the volume of data generated from the participants' narratives. In addition, the semi-structured interview questions in the pilot study tended to be slightly repetitive. To address this issue, there were fewer and more concise questions in the main study. In the main study I also switched the order of the interviews. The photo-elicitation interviews were conducted first in the main study. 
This was done to encourage participant interest in the study in the hope that they would continue their participation and attend the second semi-structured interview.

In the pilot study, I wanted to explore the issue of gendered aspirations to see if there was a noticeable difference in the aspirations of the female and male participants. As both the girls and boys expressed similar aspirations in the pilot study, I dropped the research question regarding gendered aspirations in the main study. What follows is the story of the main study.

\subsection{The Main Study}

You have to be sure you are finding out what you set out to find out and look for logical consistency and comprehensiveness in the construction and content of your project (Thomas 2013: 134; Burgess et al 2006: 62). This project set out to find out what influences the identities and aspirations of young people who attend international schools. It is worth recognising that the study is, in some ways, ethnographic. Ethnography literally means 'a written account of a people' (Yanow et al 2012: 331). The research strategy in ethnography can involve talking to people, commonly called 'interviews', in order to obtain their perceptions and views (Yanow et al 2012: 331; Cohen et al 2011: 128). I see this project as 'giving a sense of what life is like under the setting of the study' (Yanow et al 2012: 332). I was also in the setting myself and was familiar with it as a teacher. Ethnographers see themselves as coconstructors and co-interpreters of the meanings of events along with the situational members (Yanow et al 2012: 332-333). Beneito-Montagut (2011: 719) writes that the objective of any ethnography is to describe the lives and experiences of people and, in doing so, the ethnographic researcher is required to be accurate, sensitive and reflexive towards his/her subject/object of analysis and the context in which it is acting and performing. This is in keeping with Blaxter et al (2010) who claim that research should be thought of in terms of rigour, reliability and professionalism (Blaxter et al 2010: 14).

The past and the future are constructed in the present (Carmo et al 2014: 339). Guided by the research questions and given the ontological perspectives outlined above, semistructured interviews appeared to be a valuable tool for exploring the meanings and 
interpretations that young people attach to their worlds. The word 'interview' means 'an interchange of views between people', although, more often than not, it is the interviewer who is extracting data and knowledge from the interviewee and not the other way around (Cohen et al 2011: 205, 409). The semi-structured approach to interviews provides richness of data regarding the individual and allows for flexibility to explore topics of interest to the participants (Wiles 2008: 121). Less structured interviews are consistent with the commitment to hearing what students have to say and are explained by Burgess et al (2006: 75) as being about feelings, attitudes and individual life experiences. Open-ended questions are respondent-driven and respondent focussed and they can take greater account of children with limited linguistic abilities (Cohen et al 2011: 433). These kinds of questions enabled me to ask participants to reflect on prior experiences which afforded me insights into their social realities which could not have been gleaned from, for example, questionnaire tick-box data alone (Smith 2014: 6). Qualitative research is, by definition, stronger on long descriptive narratives than on statistical tables (Silverman 2004: 33).

Families are a collection of stories which are both passed down and created. People everywhere always tell stories about themselves and others and the interview is a primary way and central technique of getting to know people (Brubaker and Cooper 2000: 12; Alvesson and Ashcraft 2012: 239). As qualitative researchers, we must take these personal stories seriously in their own terms (Goodson et al 2010: 127). Adolescence is a phase in life in which the ability to construct a story about an individual's personal development takes place, allowing adolescents to recognise the influence of their own familial, sociocultural and historical contexts (Habermas and Hatiboglu 2014: 38). The past is like a vast ocean that we swim across, often unaware of how its movement can buoy us up. Narratives are a meaning-making system that makes sense out of the chaotic mass of perceptions and experiences of a life (Josselson and Lieblich 1995: 32). Narratives also provide people with a vehicle to achieve a sense of self and to understand what they do with their lives (Sihvonen 2015: 177). In effect, learning can take place for the participants through expressing the narrative and use the term 'narrative capital' which can assist people in navigating change and transition in their lives (Goodson et al 2010: 128). Interviewees will tell 
stories even when not encouraged to and narrative learning can be a promising gateway to self-development (Chase 1995: 2). The experience of being listened to with the aim of understanding is at the core of participants' benefits of being interviewed (Wolgemuth et al 2015: 361).

No one knows in advance what will come out of a conversation (Gadamer 2013: 385). However, these interviews were not conversations in that I was aiming to be neutral and objective whilst encouraging the participants to share their thoughts and talk as much as possible. Interviews do share with conversations an involvement in moral realities as they both offer a rich source of data which provide access to how people account for their troubles and good fortunes (Silverman 2004: 114). The interview has also been described as a two person conversation initiated by the interviewer (Cohen et al 2011: 411). In contrast to a conversation, interviews have a specific purpose. Interviews encourage explicit responses on the part of the interviewee and are usually specifically planned events rather than a naturally occurring situation (Cohen et al 2011: 409). The interview has also been described as an authentic dialogue that can draw out knowledge through attempting a relationship (Alvesson and Ashcraft 2012: 242).

Although I had a list of set questions for all participants to answer to structure the open-ended interview, I was free to change the wording of the questions if necessary whilst at the same time ensuring the key issues I wanted to explore were addressed (Cohen et al 2011: 411), thereby making the interviews less formal in nature.

At the heart of a philosopher's approach lies the activity of asking questions (Timmermans 2010: 3). Interviewing has become the predominant method of data collection in qualitative research, where the authentic voices of the participants are revered by researchers (St. Pierre and Jackson 2014: 715). The interview is a modified oral survey instrument through which 'softer' forms of objective knowledge can be discovered (Alvesson and Ashcraft 2012: 241). The use of interviews relies on language as the privileged medium for the creation and communication of knowledge and language can complicate the interview situation (Bagnoli 2009: 547; Alvesson and Ashcraft 2012: 245). For this study, participants were chosen for whom English is a first 
or second language. While this excluded some students from being participants in the study, adequate communication in English was important to the data collection method of using interviews and the need for clear and coherent language communication.

Elicitation interviews that discuss still images in particular have emerged as a valued approach in research with youth and operate independently or side by side with narratives to claim their legitimacy (Liebenberg et al 2013: 3; Subedi 2013: 279). The focus of interviews that review photos is how these images are given meaning by participants (Liebenberg et al 2013: 4). Photo elicitation is based on the simple idea of inserting a photograph into a research interview to unlock the subjectivity of those who see the image differently from the researcher (Harper 2002: 13; Harper 2003: 195). The use of photographs, as Newby (2010: 352) explains, is that they provide a conversation stimulus for each participant, a stimulated narrative. Photographs can be used as discussion starters, to stimulate recall and commentary on contexts and experiences and amplify voice through improved articulation of these experiences and perspectives (Liebenberg et al 2013: 2). Photos assess the importance that people ascribe to objects and can be regarded as texts which can be read (Ali 2012: 284). After all photographs 'haunt us' and show their significance by being chosen by the people who have produced them (Mitchell 2011: 199). Also, allowing the participants to select photos puts greater control of the interview into their hands.

The photo may produce a 'rupture' in our habitual modes of thinking (Coats 2015: 1). Photo-elicitation allows for some students to communicate their thoughts in the different manner, offer different information, and for the researcher to gain further insight and a broader understanding of their perceptions and thoughts. Photo elicitation can help participants overcome the fatigue and repetition of conventional interviews and release emotional statements about the informant's life (Harper 2002: 14). It also allows for the participants to show rather than tell certain aspects of their identity which may otherwise have remained hidden and stimulate conversation (Croghan et al 2008: 345; Smith et al 2012: 368; Leonard and McKnight 2015: 639). Self-representational methods such as photographs can aid the researcher in better understanding the ways in which young people construct their identities (Eglinton 
2013: 253). Using both the semi-structured and photo-elicitation interviews adds to the credibility of the study and the extent to which the findings can be believed (Howell 2013: 190).

Where power imbalances are at play, the use of photographs also can stimulate storytelling by the participant to the researcher and ultimately empower the participant (Allen 2012: 443; Newby 2010: 352; Liebenberg et al 2013: 4). Newby does however cite some disadvantages to this approach, such as the stability of interpretation and that images may tell the researcher more about popular culture than personality. A picture has also been said to offer only a narrow account of the reality of a young person's life (Pyyry 2015: 150). This challenge can be overcome with careful questioning and a realisation that visual perception is only one of the ways in which we sense with the world (Pyyry 2015: 150).

I wanted to see the ways in which the participants behaved when they shared their photographs. Photo-elicitation can have an emotional impact on participants as the encounter with the images themselves may prove disturbing or upsetting (University of Leicester 2012a: 73). Although no participant outwardly revealed any feelings of distress to me during the interviews, I was well aware that this could have been the case and the possibility of terminating the interview could exist.

Photography is an elemental part of many young people's lives today (Pyyry 2015: 149). By incorporating the use of visual sources as a discussion starter, the participants have an active voice in the study and take a "vested interest in the study" by being both the creator of the visual images as well as analysing those images (Davidson et al 2009: 11). This method offers young people a chance to reflect on their lives and identities, and provide a source of data which might be used to construct an understanding of youth experiences from the point of view of youth themselves (Eglinton 2013: 255). It also gives the participants the latitude to talk about themselves more freely about issues that connect with their own individual and unique experiences.

The photograph tumbles one instantly into memory where imagination intersects with reality (Crow 2013: 689). Some of the participants had difficulty finding the words to 
adequately express how they felt in a typical interview setting. In a study conducted on pupil voice with 11-16 year old students, Cremin et al (2011) used photographs as a visual prompt to help students articulate their thoughts.

All research could be visual to some extent because researchers are always engaged in conjuring up an image of what they study in the 'mind's eye' of the reader of the research (University of Leicester 2012a: 65). The first round of interviews involved the students using images to explain what impacts their identities and aspirations. It appeared during the interviews that these images inspired thinking and brought back memories to the participants (Pyyry 2015: 160).

\section{The Participants}

The comments of the participants were a product of how they perceived the world and how I interpreted their perceptions. The aim was to reveal aspects of complex issues in their life histories using semi-structured and photo-elicitation interviews. Rather than conduct one long and perhaps potentially tedious and tiring interview for the participants, the study involved interviewing 20 eighth grade boys (10) and girls (10), individually, on two occasions. Qualitative researchers generally study many fewer people, but delve deeply into those individuals' settings, subcultures and scenes (Adler and Adler 2012: 8). Bryman (2012: 425) suggests the minimum number of interviews needs to be between twenty and thirty for an interview-based qualitative study to be published. A strategy for maintaining reflexivity includes repeated interviews (Berger 2015: 222). Also, mixed qualitative methods, such as used for this study, can strengthen a study with a relatively small number of interviews (Charmaz 2012: 22). Having time in between interviews also allowed the participants to reflect on the first interview and potentially formulate information they may want to share in the second interview.

What follows are twenty short biographies about the twenty participants in the main study. All names are pseudonyms to protect their identities. Nationalities of the participants are according to which country appeared on their passports. Some participants also held more than one passport at the time of the study. 
Juan

Juan is a Spanish national born to two Spanish parents. A triplet, Juan feels his identity is deeply rooted in this unusual familial situation. He has lived in Belgium for two years, at his present school for the same period. His first language is Spanish.

Allie

Allie was born in Belgium to South African and Lebanese parents and holds a Belgian and a South African passport. She has been at her present school for two years and values her familial and peer relationships. Her first language is French.

Melanie

Melanie is a U.K. national born to an Irish mum and an English dad. She has been in Belgium and attending her present school for eleven years. Born in Wales, she travels extensively; Germany, Spain, Switzerland, Ireland, Wales and France. Her extended family are very important to her. Her first language is English.

Minty

Minty is a Swiss national born to Swiss and Iranian parents. She has travelled extensively and has lived in America and Africa. She would be what Ezra (2003: 126) describes as the 'internationally mobile child', having moved frequently due to her parents' employment. She is very active and has been at her present school for five years. Her first language is French.

Mel

Mel is a Chinese born boy, holding a French passport and adopted by French and German parents. He has been at his present school for eight years and spends a lot of time in Corsica. His first language is French.

Doreen

Doreen is a Norwegian girl born to Norwegian parents. She holds a significant bond to her home country and mentions the Oslo massacre as something important to her. She has been at her present school for three years. She acknowledges Harry Potter as giving her "morals". Her first language is Norwegian. 
Bobbi

Bobbi was born in Belgium and holds a U.K. passport. Her mother is Irish and her father is English/Swedish. She has been at her present school for three years and possesses a good knowledge of her family history. Her global citizenship saw her travel to China when she was 12 to help a local school. She has lived in Belgium all of her life and travels widely (Mallorca, Sweden). Her first language is English.

Sandra

Sandra is a German national whose parents are both German. At her present school for three years, this is her first time living outside Germany. She speaks at significant length about her family. Her first language is German.

Mary

Mary was born in the U.K. but holds four passports; French, Canadian, Belgian and German. Her parents are Canadian and French and horse-riding is her passion. She is new to the school and her first language is French.

Gabby

Gabby is an American who moved directly from the U.S.A. to Belgium and her present school three years ago. Placing much emphasis on her family, home country and her religion, both of her parents are American. She expresses her appreciation of the opportunities for travel that living overseas affords her. Her first language is English.

Anya

Anya is a Polish national born to Polish parents. She has been at her present school for two years and mentions her extensive travel all over Europe, mostly by car. She has lived in America and is aspiring to be a vet. Her first language is Polish.

Johan

Johan is a Swedish national born to Swedish parents. He has been at his present school for four years and thinks highly of his family and background, as evident in his photoelicitation interview. His first language is Swedish. 
Louis

Louis is a Belgian born to two Belgian parents. He has been at his present school for eleven years and is very sporty. His first language is French.

Karl

Karl is a Danish boy born to Danish parents. He has been in his present school for three years and his first language is Danish.

Osawa

Osawa is a Japanese passport holder but was born in the U.K. to two Japanese parents. He has been at his present school for eight years and his first language is Japanese.

Valerie

Valerie is a Belgian girl born to two Belgian parents. She travels extensively and shared more than 50 photos in the photo-elicitation interview. Her global citizenship has seen her help poor children in Africa. She has been at her present school for eight years and her first language is French.

Hector

Hector is a passport holder of Tanzania, but was born in Uganda to two Tanzanian parents. He cites the music of Eminem as a main influence on his life and has been at his present school for three years. His first language is English.

Jaap

Jaap is a Dutch born boy to two Dutch parents. He holds a Dutch passport and has lived in five countries in his lifetime. He has been at his present school for three years and his first language is Dutch.

Micky

Micky was born in Belgium but holds a French passport. His parents are Italian and French and he has been at his present school for four years. His first language is French. 
Felipe

Felipe is an Argentinian born to two Argentinian parents. He has been at his present school for two years and holds his native culture close to his heart. His first language is Spanish.

The average number of years this group had attended this international school was 4.45 and their patterns of movement vary. At the time of the study, Louis and Melanie had both attended the school for eleven years. This study involved two local students, Louis and Valerie, who fit this description and are what could be called the 'local aspiring elite' (Waters and Brooks 2011: 157). This is an interesting pair, who have not been globally mobile in their schooling experiences, but who attend a locally based international school, moving in and out of their home cultural context and the school's more international context (Hayden 2011: 220). Whilst they may travel with their families, they have not lived outside of Belgium, their birth and passport country. Also they have attended their present international school for significant periods of time; Valerie for eight years and Louis for eleven years, not having ever spent more than a year in the national school system of their own country, Belgium.

A meeting was held with the twenty participants after they were chosen for the study. This was conducted in my classroom very briefly in early September 2013 during a student lunch break. During this group meeting I explained to the participants that I was conducting a research study and I was asking for their help in the form of being interviewed about their lives. I assured all of them at that meeting that anything they told me would be kept confidential and I defined what that term meant for them. I told the participants that I would be also approaching each one of them individually to talk about this study in more depth and to give them more details and instructions as to what exactly their role in the study would entail. I told them that if they then all agreed to participate then I would proceed with the study. The students were instructed not to share with other students that they were participating in the study but I have no way of knowing if that confidentiality was kept or not.

Before the interviews were conducted, I instructed the participants individually to choose images of people, places or situations which they felt affected their identity. 
The aim was to reveal aspects of the life histories of the participants using photoelicitation. The participants were encouraged to describe the images in their own words, to identify the image and to express the meaning of the image for them (University of Leicester 2012a: 68). I used one question to begin the interview: "Tell me about these photos and why you chose them?". During the second round of interviews, a mix of individualised questions to each participant and a set of semistructured questions for all of the participants were posed. At the end of the second interview the participants were all asked if they had anything else they wished to share or add to their testimonies. This was done in order to supplement earlier responses or introduce something else they felt was relevant which was not directly asked of them in the previous interview questions (Alvesson and Ashcraft 2012: 250). The following are the questions common to all of the participants in the second interview:

1. Tell me about the people in your life who influence you?

2. What do you think an international school gives you?

3. What do you hope to do after you have left school?

4. Tell me a bit about your life outside school?

5. What does it mean to be successful to you?

6. Is there anywhere you feel you belong?

7. Do you have anything else you want to share or to add?

Young people make important decisions about their futures at ages 14, 16 and 18 (Mann et al 2013: 3). The design of the study came from many months of discussion with my supervisors at The University of Leicester. It also adds new knowledge the work of Smyth (2012), Gale and Parker (2015), Ferrante (2009), McLachlan (2007), McDevitt et al (2013), Hadjar and Aeschlimann (2015), St. Clair et al (2013), Kintrea et al (2015), Shoffner et al (2015) and Jantzer et al (2009). These authors recognised that 13-15 year olds ( $8^{\text {th }}$ grade students in the context of my study) represent a unique population as they transition from late childhood into early adolescence and are contemplating their educational and vocational futures as they begin to develop their identities (Jantzer et al 2009: 117). Interviewing young people on two occasions, Kintrea et al (2015) aimed to gather data regarding changing aspirations between the 
ages of 13 and 15 (Kintrea et al 2015: 671). Factors included in decisions about the future for the participants in McDevitt et al's (2013) study included parents, second language proficiency, travel and experiences with other cultures (McDevitt et al 2013: 531). This project also relates to the work of Waytz et al (2015), who in one of their studies, induced adults to write about past and future events and found that this induction increases self-reported meaning in life (Waytz et al 2015: 339).

The participants in this study enjoyed high levels of capital and privilege due to their parents' occupations and wealth. Participants for this study came from the students whom I taught during that academic year of 2013-2014 and were from 17 countries, representing each of the following areas of the world: North America, South America, East Asia, Western Europe, Eastern Europe, Northern Europe, Africa and two students from Belgium in order to obtain a more globally representative view of the student body of the school and include local students attending an international school. I selected all of the participants myself as I was initiating the research. Taking participants from your own student body is an example of what Blaxter et al (2010: 170) define as 'convenience sampling', as participants are taken from the researcher's place of work, whom the researcher is confident will take part and to which access is most convenient. The choice of the participants was appropriate for the research aim of gaining insights into what privileged young people consider to be the influences on their identities and aspirations. Seeking out the viewpoint of the local students is in keeping with Kanan and Baker's (2006) study where the researchers sought out the perspectives of the local students attending an international school in Qatar.

Written consent was given by the school to conduct the main study. Written consent was also granted by the parents of the participants to allow their children to participate in the study. See appendices for the parental consent form. Table Two below shows the participants' details. 
Table Two - The Participants of the Main Study (M-Male/F-Female)

\begin{tabular}{|c|c|c|c|c|c|c|}
\hline Name & $\begin{array}{l}\text { Sex } \\
M / F\end{array}$ & $\begin{array}{l}\text { Country of } \\
\text { Birth* }\end{array}$ & $\begin{array}{l}\text { Country on } \\
\text { Passport* }\end{array}$ & $\begin{array}{l}\text { Years } \\
\text { in } \\
\text { Present } \\
\text { School* }\end{array}$ & $\begin{array}{l}\text { First } \\
\text { Language* }\end{array}$ & $\begin{array}{l}\text { Parents' } \\
\text { Home } \\
\text { Countries* }\end{array}$ \\
\hline Anya & $\mathrm{F}$ & Poland & Poland & 2 & Polish & Poland (2) \\
\hline Allie & $\mathrm{F}$ & Belgium & $\begin{array}{l}\text { Belgium/South } \\
\text { Africa }\end{array}$ & 2 & French & $\begin{array}{l}\text { South Africa } \\
\text { and } \\
\text { Lebanon }\end{array}$ \\
\hline Melanie & $\mathrm{F}$ & UK & UK & 11 & English & $\begin{array}{l}\text { Ireland and } \\
\text { UK }\end{array}$ \\
\hline Minty & $\mathrm{F}$ & Switzerland & Switzerland & 5 & French & $\begin{array}{l}\text { Switzerland } \\
\text { and Iran }\end{array}$ \\
\hline Bobbi & $\mathrm{F}$ & Belgium & UK & 3 & English & $\begin{array}{l}\text { Ireland and } \\
\text { UK }\end{array}$ \\
\hline Mary & $\mathrm{F}$ & UK & $\begin{array}{l}\text { Canada/France/ } \\
\text { Germany } \\
\text { Belgium }\end{array}$ & 1 & French & $\begin{array}{l}\text { Canada and } \\
\text { France }\end{array}$ \\
\hline Gabby & $F$ & USA & Ireland/USA & 3 & English & USA (2) \\
\hline Valerie & $F$ & Belgium & Belgium & 8 & French & Belgium (2) \\
\hline Doreen & $\mathrm{F}$ & Norway & Norway & 3 & Norwegian & Norway (2) \\
\hline Sandra & $F$ & Germany & Germany & 3 & German & $\begin{array}{l}\text { Germany } \\
(2)\end{array}$ \\
\hline Juan & $M$ & Spain & Spain & 2 & Spanish & Spain (2) \\
\hline Jaap & $M$ & $\begin{array}{l}\text { The } \\
\text { Netherlands }\end{array}$ & $\begin{array}{l}\text { The } \\
\text { Netherlands }\end{array}$ & 3 & Dutch & $\begin{array}{l}\text { The } \\
\text { Netherlands } \\
\text { (2) }\end{array}$ \\
\hline Karl & $M$ & Denmark & Denmark & 3 & Danish & $\begin{array}{l}\text { Denmark } \\
(2)\end{array}$ \\
\hline Felipe & $M$ & Argentina & Argentina & 2 & Spanish & $\begin{array}{l}\text { Argentina } \\
(2)\end{array}$ \\
\hline
\end{tabular}




\begin{tabular}{|l|l|l|l|l|l|l|}
\hline Mel & M & China & France & 8 & French & $\begin{array}{l}\text { France and } \\
\text { Germany }\end{array}$ \\
\hline Micky & $\mathrm{M}$ & Belgium & France & 4 & French & $\begin{array}{l}\text { Italy and } \\
\text { France }\end{array}$ \\
\hline Hector & $\mathrm{M}$ & Uganda & Tanzania & 3 & English & Tanzania (2) \\
\hline Osawa & $\mathrm{M}$ & UK & Japan & 8 & Japanese & Japan (2) \\
\hline Johan & $\mathrm{M}$ & Sweden & Sweden & 4 & Swedish & Sweden (2) \\
\hline Louis & $\mathrm{M}$ & Belgium & Belgium & 11 & French & Belgium (2) \\
\hline
\end{tabular}

*I asked the participants to give me the above information at the beginning of their first interview.

\subsection{Gathering and Organising the Data}

I will now offer full details of how I gathered and organised the interview data of the main study. By doing so, I aim to 'evoke an acceptance of the trustworthiness' of the research (Polkinghorne 1988: 177). Upon reflection of the experience of the pilot, adjustments were made to conduct the main research study using twenty participants. I interviewed twenty eighth grade boys (10) and girls (10), individually in two waves, on two occasions, in the autumn of 2013. All of the participants were between the ages of 12 and 14. The two interviews for each participant were conducted between six and eight weeks apart, depending on the availability of both the participant and myself. All participants took part in two interviews and not one was pressed into participating in any way (Molloy 2015: 469).

Data generation in narrative studies is affected by context and sequence of the interviews (Polkinghorne 1988: 177). All of the interviews were conducted in my classroom, during the students' designated lunch hour so as not to interrupt or interfere with any of their classes or daily routine, and were recorded using the recording software Audacity, which was already installed on my computer. The recording device, as a data gathering tool in qualitative research, captures the realities and meanings outside of the researcher, which are linked to the participants' lived 
experiences (Nordstrom 2015: 389). During each individual interview the participant and I sat at a table across from one another, with the computer being slightly left of centre of both of us. The participants were asked to speak into the microphone of the computer so as to ensure all of their words could be accurately recorded. Although there was a time limit involved of $\mathbf{4 5}$ minutes, none of the interviews had to be suspended due to lack of time. Girls tended to speak more than boys overall so their interviews lasted longer. However, no interview went over the amount of time we had nor had to be cut short. All of the interviews were uninterrupted and conducted in the quiet setting of my classroom whilst the other students were either in the cafeteria or outside of the school building during their daily lunch break.

Before the first interview, the participants were instructed privately by me on an individual basis to choose images of people, places or situations which they felt affected their identities. The aim in that interview was to reveal aspects of the life histories of the participants using photo-elicitation. During the interview, the participants were encouraged to describe the images in their own words, to identify the image and to express the emotional meaning of the image for them (University of Leicester 2012a: 68). I used just one question to begin the interview: "Tell me about these photos and why you chose them?". In these interviews, the participants focussed on the photographs and spoke freely rather than having to make continuous eye contact with me (Pyyry 2015: 157). I asked the participants' permission to keep the photographs shared during the interviews. All of the participants agreed to my request.

During the second round of interviews, a mix of individualised questions to each participant and a set of semi-structured questions for all of the participants were posed. These questions were more geared towards having the students reveal what they felt about their present and future lives.

Each participant was permitted to read their transcripts after their individual interviews. Every participant read their complete interview transcripts. This was done on an informal basis when I could see them during break times and lunch periods. This helped to ensure validity and helped to build theory as well as ensuring the 
importance of the issues raised in the interviews. All participants agreed to what they had said in their interviews, made no amendments to the transcripts and gave their verbal consent that I could use this data to report the findings of the project.

\subsection{Data Analysis}

The integrity of qualitative data depends on the competence of the data collection instruments-human beings (Kuh and Andreas 1991: 402). Good qualitative research must be transparent and coherent, as well as showing in-depth engagement with the topic (Yardley 2000: 219). This requires reflection and ongoing interpretation (Howell 2013: 189). Below is a step by step reflection as to how I organised and analysed the data using the constant comparison method as my guide. Constant comparison is an analytic process where all units of data are compared to all other units to discover properties and dimensions in the data and establish underlying uniformity in order to generate theory which is integrated, consistent, plausible and close to the data (Glaser 1965: 437; Glaser and Holton 2007: 60; O'Connor et al 2008: 31). The constant comparative method involves going through your data again and again, comparing each element-phrase, sentence or paragraph-with all the other elements and continually categorising data and concepts (Thomas 2013: 235; Howell 2013: 137). Coding and analysis are done at the same time (Kolb 2012: 83). Constant comparison assures that all data are systematically compared to all other data in the data set to ensure all data produced will be analysed rather than potentially disregarded (O'Connor et al 2008: 41). This helps to ensure that the findings are reliable and not based on researcher bias or expectations. Incidents or data are compared to other incidents or data, line by line, incident by incident or word by word, during the process of coding (Floersch et al 2010: 409; Fram 2013: 3). This method allows for the formation of categories, establishing the boundaries of those categories, assigning the segments to categories and to summarize their content (Tesch 1990: 96).

1. I recorded and listened to the interviews then manually transcribed the data, word for word in English. I noted pauses and the use of ' $\mathrm{hmm}$ ' and other soft utterances. Listening to and typing the transcripts proved a slow process, sometimes taking up to two hours at a time to complete a transcript of an 
interview. Electronic and printed copies of all the data were generated and stored in both electronic and printed forms. Participants were then permitted to read the transcribed interviews before any marks were put on the printed transcripts. Taking one's findings back to those subjects being studied for verification is known as 'respondent validation' (Silverman 2004: 233).

2. The transcriptions were read by me a number of times and key words and phrases highlighted for coding. This process of collecting, and analysing and repeating the process is the format of the constant comparative method (Williams 2007: 69).

3. Themes were drawn from the interview data based on frequency of occurrence of the coded issues.

4. Theory was generated from what was grounded in the data.

Our individuality is that of events (Deleuze 1995: 141). Identities are constituted through narratives and formed in particular relational settings (Brubaker and Cooper 2000: 12). Even though life narratives are to some degree post hoc fabrications, they still influence people's behaviour, relationships and mental health (Haidt 2012: 328). All data contain a story, a narrative and narratives can tell us something about ourselves, sometimes things we do not want to hear (Caputo 2013: 59). I aimed to report the authentic voices of the participants and was aware of the potential for misinterpretation of the responses. Therefore, a direct transcription of the speech and language of the participants was made. Discourse transcription has been defined as the process of creating a representation in writing of a speech event so as to make it accessible to discourse research (du Bois 1991: 72). I made this decision to directly transcribe the interviews myself in an attempt to ensure the voice of the participants was recorded as accurately as possible, keeping the aim of the project in mind. There is no single "correct" transcription and decisions must be made with regards to transcription (Newby 2010: 461). The construction or analysis of the interview material occurs both during the interview as well as after the event (Cronin 2014: 73). Images were kept by me and stored over time, allowing me to 'revisit' data collected earlier (University of Leicester 2012a: 66). Recording the interviews, transcribing them and having the participants read and agree to them validated the interviews. 
The qualitative researcher analyses the interviews by coding text (Burgess et al 2006: 66). Data analysis can be the most fun but challenging and time-consuming part of qualitative research; a painstaking process when dealing with the volume of interview data (University of Leicester 2012a: 79). I completed the first round of interviews before attempting any analysis. I then completed a second round of analysis after the second round of interviews were conducted. In line with many qualitative interview based analyses, the data were created rather than captured (Cronin 2014: 73). In the data analysis, a system of open coding was used for the interview and visual data. Coding is always subject to change, open-ended and ongoing in the process of making sense of the data (MacLure 2013: 181). Coding demands immersion in and entanglement with the minutiae of the data to find out what it is fundamentally about (MacLure 2013: 174; University of Leicester 2012a: 83). The process of coding searches for patterns and order in a body of data and identifies recurring themes, categories or concepts (MacLure 2013: 164).

The transcripts of the interviews were laid out on the floor of my dining room to ensure a more personal touch to the analysis was gained. Each interview question was examined in the interview transcriptions. This involved highlighting characteristics and single pieces of information as suggested by the data where each label is meant to capture a meaning of the phenomenon observed. The aim was to break the data down to uncover as many categories and sub-categories as possible by linking concepts together. The coding structure for this project was not completely predetermined as some of it emerged from the data itself whilst other parts emerged from the literature reviewed. Words can be both data waiting to be interpreted and meaningful (St. Pierre and Jackson 2014: 716). The data need to be analysed in such a way where sense can be made of the issues within the words (University of Leicester 2012a: 80). I highlighted what I thought to be important issues in the transcripts then gave these issues theme or category names. See Table Three below.

Interpretation and coding can be carried out to infinity and everything interpreted is already an interpretation itself (Deleuze and Guattari 1987: 133). There are downsides of coding, in that there appear to be no limits as to when to stop, it takes considerable time and it runs the risk of creating less than thorough work, especially for the first 
time researcher (Newby 2010: 465). Aware of these noted risks, I used the coding system for the interview data. I gathered, transcribed, and analysed all of the data alone, with hope to increase engagement with and ownership of the data. I coded until saturation; until nothing new emerged from the data. Below is a table which highlights issues and themes arising from the data of the main study.

Table Three: Issues and Themes from the Main Study

Themes within this table were mentioned by all of the participants in the Main Study.

\begin{tabular}{|l|l|}
\hline Issues & Themes \\
\hline Being happy with what you do, & Success \\
\hline $\begin{array}{l}\text { Parents, sisters, brothers, grandparents, } \\
\text { uncles, cousins }\end{array}$ & Family \\
\hline Friends & Friends \\
\hline $\begin{array}{l}\text { Media } \\
\text { Horseback riding, swimming, harp, } \\
\text { tennis, judo, acrobatics, piano, volleyball, } \\
\text { gymnastics, skiing, ballet, golf, } \\
\text { skateboarding, acting, track and field, } \\
\text { choir, soccer, cross country, motorsports, } \\
\text { wakeboarding, sailing, basketball, } \\
\text { hockey, karate }\end{array}$ & Activity \\
\hline \begin{tabular}{l} 
Education, Perspectives \\
\hline \begin{tabular}{l} 
Moving, travel \\
\hline
\end{tabular}
\end{tabular} & International Schooling Experiences \\
\hline
\end{tabular}

Coded Extracts from the interviews. Underlined texts show where issues and themes emerged.

Melanie: it...(international schooling) gives you a perspective on different cultures, like I have friends that go to the European School and they say that they don't get to learn that much on different cultures and religions and stuff... Theme: International

\section{Schooling Experiences}


Minty: yeah well my family really likes to see the world and stuff, when I say my family I mean my mum and my dad because they are the ones who choose to go to other countries and I really like travelling now, it has gotten into me or maybe it has been there since the beginning so I really like it and that's why I talk a lot about travel...

\section{Theme: Transience}

Juan:... because I am with them (family) every day of life and they give me everything I have and that's most important ... Theme: Family

Jaap: ...traditions are mostly what keeps us "Dutch" I would say like Sinterklaas which is typical Dutch and Dutch people and maybe some in Belgium celebrate it and for us it's really special because we don't really do Xmas with presents so we have Sinterklaas who gives us presents... Theme: Cultural Traditions (not mentioned by all participants)

Anya: Well, in this season I was doing volleyball, but it just ended and we did it twice a week, and all year round I do piano, on Friday, I have been doing it, this is my 4th year and I really enjoy it, it's my dad's piano and I started playing it and I do gymnastics/acrobatics on Tuesdays, all year round also but this is with my commune, which is all in French, so it also helps me learn French, it is kinda like an extra French class I guess, yeah and I started swimming but I think I might quit this year because I have so much like homework... Theme: Activity

Hector: people in my life who influence me, I want to talk about my favourite sport soccer, one of my favourite players, is Christiano Ronaldo, he's an inspiration, he grew up like I grew up, playing soccer on the streets, I also did play soccer on the streets back in Tanzania so I can kinda relate to him and he had a poor family so he had to improve every day, just like me, I, when I got here I wasn't so good at soccer so I had to improve to be able to make the team two years in a row, so I think he influences me...

\section{Theme: Identity}

Below is a table which explains the type of aspirations which were revealed by the participants, examples of such aspirations, as well as the number of participants who mentioned them in their interviews. For this table, participants did not fit into more than one category. 
Table Four-Categories of Aspirations

\begin{tabular}{|l|l|l|}
\hline Type of Aspiration & Example & $\begin{array}{l}\text { Number of participants } \\
\text { expressing such an } \\
\text { aspiration }\end{array}$ \\
\hline Traditional and Long Term & $\begin{array}{l}\text { Educational and } \\
\text { Occupational }\end{array}$ & 16 \\
\hline $\begin{array}{l}\text { Socially Responsible and } \\
\text { Long Term }\end{array}$ & $\begin{array}{l}\text { Wanting to improve global } \\
\text { warming and global } \\
\text { politics }\end{array}$ & 2 \\
\hline $\begin{array}{l}\text { Personal and Medium } \\
\text { Term }\end{array}$ & $\begin{array}{l}\text { Expressing a hope to travel } \\
\text { and be near friends upon } \\
\text { finishing secondary school }\end{array}$ & 2 \\
\hline
\end{tabular}

\subsection{Ethical Considerations}

Ethics is that branch of philosophy in which we address the question of how we ought to live (Taylor 2012: 39). In keeping with good practice, research must be legal, consensual, confidential and respectful (Horton 2008: 367). The research process is systematic in that defining the objective, managing the data, and communicating the findings occur within established frameworks and in accordance with guidelines (Williams 2007: 65). The purpose of such guidelines is to foster, promote, direct and support good practice in everyday practices and interactions which constitute research with human beings (Horton 2008: 367). Educational research should be conducted within an ethic of respect for the person, quality of the research and academic freedom (British Educational Research Association 2001: 4).

Researchers must at all times, attempt to place humanity and the welfare of others at the centre of their considerations when conducting educational research (Stutchbury and Fox 2009: 502). The principle of consent protects the individual's right not to be harmed. Burgess et al (2006: 33) argue that the researcher has a 'moral duty to respect the privacy and dignity' of those whom they research as we enter into their 'private worlds' (Cohen et al 2011: 204). Researchers must be 'sensitive to the context' of their research setting (Yardley 2000: 219) and have a duty of care to ensure they do 
not deliberately mislead participants as to the nature of the research or cause any physical or psychological harm to the participant (Briggs and Coleman 2007: 112). After all the interviewee is the searchlight held up by the interviewer (Cohen et al 2011: 204). I made every attempt to strongly adhere to these important guidelines and no pressure was placed on the participants to either take part in the study or continue against their will. I was conscious of my position of power as the participants' teacher who could impose sanctions on them (Cohen et al 2011: 204).

Permission was sought by the school, the participants and their parents for participation in the study. I was upfront from the beginning of my research about my intentions. The participants were informed about the entire research project: why I was conducting such a study, why the topic was chosen, why they were chosen as participants, what roles and responsibilities were expected of them, how the data would be collected and how it would be shared (Mazzoni and Harcourt 2014: 260). Burgess et al (2006: 37) recommend a kind of contract between the researcher and the informants, a series of implicit and/or explicit agreements by which the researcher and the informants are bound. This contract deals with the concept of research relationships, with Burgess et al (2006: 36) recommending that the researcher needs to remember that they are using the informant as a source and the importance of representing the participants' lives to others (Berbary 2013: 10). So, a letter was drawn up and shared with the parents to sign their consent for their child to participate in the study. The letter explained that the interviews were to be transcribed and hard copies kept safely at my home, that the participants could withdraw at any time, and that all participants would be anonymised in the dissemination of the findings (Smith 2014: 5). This consent form can be found in the appendices. Not one participant withdrew from the study.

The challenges of qualitative data amplify ethical issues of confidentiality and privacy generated through long term relationships (Henderson et al 2012: 17). Keeping identities and information confidential required greater attention in order to respect the personal relationships formed during the period of study and beyond. The participants were fully informed of their role in the project as well as their freedom to opt out of the study at any time of their choosing. Anonymity was promised in that 
what they said will not be used in a way in which they would be identified.

Pseudonyms were given to all participants. The group were told that they would need to keep a confidence within the group of their participation in the study. However, I had no way of knowing if they kept this confidence.

As a teacher in the school, gaining access to participants for the study was not an issue for me. Insider researchers are 'within the system' and possess intimate knowledge of the community so are never neutral (Biddle 2010: 21). The juggling of the role of an employee and a researcher role required a degree of emotional and intellectual flexibility in terms of handling researcher engagement with the research scene (Tietze 2012: 60). I needed to recognise my 'emotional involvement' in the research, being both a teacher and a researcher in the school where the study took place (Hadfield-Hill and Horton 2014: 136). I am confident that I made every effort to step back from the setting of the school and my role as a teacher and conduct the role of researcher as independently and objectively as I was able, given the situation.

The quality of the rapport between the researcher and the researched is crucial to the quality of the relationship established to meet the research objectives (Ochieng 2010: 1729). Interviews are interpersonal and social experiences, a human to human encounter (Cohen et al 2011: 204). Degree of disclosure can create changes in relationships between the researcher and those who provide the data. However, an insider has greater access to students and more often than not a greater rapport with them (Burgess et al 2006: 36). As I was known to all the participants by virtue of my role in the school, 'rapport' did not need to be established. I felt I had positive relationships with the students in the school and the participants felt comfortable in my presence. During the interviews, I maintained an 'empathetic distance' as a vehicle to establish a good rapport between interviewer and interviewee.

The effects that characteristics of interviewers have on the answers respondents give are important when it comes to the sensitive topics of ethnicity and ethnic identification (van Bochove et al 2015: 652-653). In order to understand the role of the self in the creation of knowledge, I needed to carefully monitor the impact of my biases, race, gender, ethnic background and personal experiences on this research 
(Berger 2015: 220). I had to turn the lens back on myself and take responsibility for my situatedness in the research (Berger 2015: 220). I had no experience of having a 'racial position' in such a study (Mazzei 2013: 96), meaning I could not relate to the participants' various racial and class identities. It has been recommended that interviewer and respondents be matched on the basis of their ethnic background (van Bochove et al 2015: 663). In this respect it could be argued that class matching is desirable between interviewer and participant as it engenders empathy on the part of the interviewer which allows for openness on the part of the participant (Mellor et al 2014: 135). However, class matching critics argue that class matching makes assumptions that the researchers and the researched know each other's lives, thereby presenting a challenge in separating the professional self and personal life experiences (Ochieng 2010: 1725; Mellor et al 2014: 138). Researchers should not only research those with whom they share social categories, characteristics, positionalities or experiences as differences may actually allow the researcher to have a unique perspective (Berbary 2013: 6).

Additionally, as a male adult who works with young people, I am constantly aware of my gender (Horton 2008: 364). Therefore, I find making sense of my positionality matters in and for my research practice. Research does not take place within a vacuum, but is ethically implicated in all manner of relations and situations and reflecting on one's positionality constructs more ethical research (Horton 2008: 377; Berbary 2013: 11). Researchers are both inside and outside the phenomena under investigation (McNess et al 2015: 311). The participants treated me as someone with insider knowledge of the school although it was apparent they did not consider me to be 'one of them' in every respect (Ochieng 2010: 1730). Although we all lived in Belgium, were part of the same school and shared some similar experiences of living in different countries, I certainly did not have the international capital which the participants possessed, placing me very much outside the participants' worlds. I was an insider, whilst feeling like an outsider (McNess et al 2015: 301). Therefore, in this regard, I was both present with and separate from those under study (Hollenbeck 2015: 149) but not insensitive to the participants' circumstances and various cultural backgrounds (Cohen et al 2011: 194). 
Ethics is an approach to conducting research. A conscious effort was made to minimise input during the interviews and 'take proactive steps to encourage children to express their views' (Lundy 2007: 934) by encouraging body language and eye contact. I attempted to keep the interviews as fluid and flexible as possible, allowing the participants to share their perspectives and stories. Great care was taken not to prime the participants or direct them in any way (Murdock et al 2014: 122). I was also aware of the need to progress through the research questions while at the same time trying to conduct a relaxed dialogue with the participants. I was also systematic in organising the data, transcribing every spoken word, so as not to stifle the voices of the participants in any way so as to allow themes and new insights to emerge.

The researcher can influence the research process from start to finish; unwittingly demanding certain responses, for example (Gorard 2013: 165). Research is a social activity that can be powerfully affected by the researcher's own motivations and values (Blaxter et al 2010: 14). Sub-contracting parts of the research to an outsider can help protect against what Gorard (2013: 165) calls the 'researcher effect'. Perhaps the most practical way of achieving greater validity is to minimise bias (Cohen et al 2011: 204). These biases include the characteristics of the interviewer, the participant and the content of the questions (Cohen et al 2011: 204). In qualitative data the subjectivity of the respondents, their opinions, attitudes and perspectives together contribute to some degree of bias (Cohen et al 2011: 179). Reducing bias includes careful formulation of questions so that meanings are clear (Cohen et al 2011: 205). It also involves honest reporting on the part of the researcher about the self-reporting of the researched, what Cohen et al (2011: 181) call 'interpretive validity'. All of the interview questions did not lead the participants in any way and were carefully created to ensure no particular kind of response was encouraged. There were two rounds of interviews with each participant. This allowed me to check for congruence and consistency in the participants' responses and strengthens the validity of the study.

Validity relates to the accuracy of the researcher's claim to truth, which aims to be well-grounded and supportable by the data (Polkinghorne 1988: 175). In the context of this qualitative study which investigates meanings and interpretations of individuals' 
narratives, truth is taken to mean 'results that have the appearance of truth or reality' (Polkinghorne 1988: 176). Validity also deals with methods and how they relate to issues which have been explored (Blaxter et al 2010: 245), in other words, the relationship between the measuring instrument and the concept it is attempting to measure (Polkinghorne 1988: 175). Validity is also used to judge whether the research accurately describes the phenomenon which it is intended to describe and actually reflects what the researcher has done; discussing honesty, depth, richness and scope in qualitative data (Busher and Watling 2003: 3; Burgess et al 2006: 62). It is important that qualitative research provide a clear and detailed description so that others can decide the extent to which findings from one piece of research are generalizable to another situation; otherwise known as external validity (Cohen et al 2011: 186).

Reliability is concerned with the extent that an experiment can be repeated and lends itself more to positivist than interpretivist research, but is important in both quantitative and qualitative research (Howell 2013: 183). Reliability is essentially a synonym for dependability, consistency, trustworthiness, applicability and replicability over time (Cohen et al 2011: 199). This is a study which involves my interpretation of the sense the individual participants make out of their circumstances and this underpins the entire research process. While I challenged the notion of the 'neutral' interviewer in my approach as an 'insider', that is not to say that I did not aim for neutrality in the interviews. I collected, organised, transcribed and analysed all of the data alone and I needed to be aware of the impact this had on the entire research process. I was an active player in the research process and was interpreting the evidence I was given by the participants in their interviews (Staller 2015: 147).

Reflection on subjectivity in the qualitative research process is fundamental to the methodology (Hollenbeck 2015: 149). As all our speech and actions arise from a particular social context, completely separating oneself from the research process is neither necessary nor possible (Yardley 2000: 223; Harper and Kuh 2007: 6-7). Accounts can only be representations of reality rather than reproductions of it (Cohen et al 2011: 181). 
Researchers are 'situated' and bring a particular socio-political, historical, gendered, generational, ethnic and racial background to their research, making it a conflictridden personal experience (Tietze 2012: 54). I was privy to much information and possessed substantial understanding about the schools programs, staff and curriculum; being aware of the routines, processes and practices of the organisation (Tietze 2012: 56). I had a sound knowledge of the educational context in which the participants found themselves. I also had access to files of students, some of which contained confidential information. I did not consult the participants' files before or after the interviews took place. In my position, being 'objective' was not entirely possible and I needed to be aware of my convictions, prior or 'local' knowledge, power and principles. As an insider researcher, personal and social interactions with students needed sensitive handling. Being an insider can have its advantages and disadvantages. Being an insider can make one feel comfortable and that they belong (McNess et al 2015: 301). Ease of access and rapport with participants, setting up the research time and cost are advantages whilst being too familiar with the setting can be a disadvantage as developing an objective viewpoint can prove challenging (Burgess et al 2006: 36) because the 'self' is brought to the research situation (Howell 2013: 186). For the sake of convenience, the interviews were conducted in my own classroom, not exactly a neutral space and an issue which has been seen as a possible source of bias in qualitative research (Plummer 1983: 103). This lack of objectivity, lack of a vantage point and being too close to the work could have influenced the participants' responses and their narratives. I attempted to address this issue by communicating to the participants during all of the interviews the reasons for the research and that the approach that both I and they should take to the experience was to be one of gathering information. They were reminded that they were participants being interviewed as part of a study, not students being interviewed as part of their 'schooling' experience.

What people show to the other is more disguise than disclosure, even if we'd prefer it to be otherwise (Cohen 2013: 29). The interviewee always has the power to hold back certain aspects of and information about their lives (Cohen et al 2011: 410). The interviewer must consider the extent to which a question might influence a participant 
to show themselves in a good light (Cohen et al 2011: 207). For example, when I posed the question 'What do you want to do after you have left school?', all of the participants who responded with an occupation mentioned highly professional positions such as doctor, lawyer and politician. I kept this in mind when interviewing the participants. There is a chance that they only revealed to me the positive aspects of their lives, the fact that pride and bravado played a part in their responses and also the factor that perhaps they told me what they thought I wanted to hear. I addressed these issues by establishing good rapport with the participants, asking appropriate and acceptable questions and by having willing and cooperative participants.

The researcher should be honest as possible to the self-reporting of the researched (Cohen et al 2011: 181). I made all efforts to focus on the words the participants actually said, not overly leading them to speak, and therefore not leading the findings. I maximised the space for the participants to tell their stories (Berger 2015: 225). This ensured that the voices of the participants were well represented and not obscured by my own biases or interventions during interviews. I even noted pauses in the transcripts, an apparently trivial but crucial component of the interview (Silverman 2004: 33). This constant reflection and ongoing interpretation ensured the validity of the findings.

It is important to understand the world of children through their own eyes rather than the lens of an adult (Cohen et al 2011: 433). One must be cautious and reflect upon what one seeks to gain by knowing how children feel and the impact that process may have on them (Kraftl 2013: 21). Children must be allowed time to think about questions posed to them and combining methods and activities in the interview, as this study did, can aid in that understanding of abstract questions (Cohen et al 2011: 433). A key concept here is possessing empathy for those under investigation (Howell 2013: 190); the capacity to recognise and share thoughts or feelings that are being experienced by others (McNess et al 2015: 311). Empathy shapes the research moment and affects understanding of that moment (Jones and Ficklin 2012: 103).

This project dealt with adolescent children, considered to be what is called a "vulnerable group" of people. My many years of experience with this age group 
brought with it an understanding of their vulnerability. There is a principle of care adopted when it comes to researching young people in order to ensure their protection (Farrell 2005: 3). Establishing trust, maintaining a degree of informality, choice of vocabulary, keeping to the point and pitching the questions at the right level are all considerations when interviewing young people (Cohen et al 2011: 207). This project required an appreciation of childhood; its innocence and naivety which was fully considered and respected throughout the entire interview process. Throughout this study, there was a conscious effort on my part to have relationships based on trust, mutual respect, empathy and understanding with the participants in order to conduct ethical research. Each stage of the interview was clearly explained to each participant, as I told them why I wanted to ask them every question posed to them.

I explained the research project clearly enough to the young participants so that they could make an informed decision about their contribution and their option to continue their participation. Also, the young participants' responses, views and feelings were indeed varied and open to my interpretation. I had to realise and work with the fact that what is important to the child may be unimportant or overlooked by the interviewer and vice versa, leading to the possible distortion of the data (Morrison 2013: 322). I aimed to keep the interviews non-threatening, enjoyable, relaxed, respectful, good-natured, positive, and clear in order to help the participants feel confident so that they could comfortably speak freely and be 'heard' (Morrison 2013: 334; Tietze 2012: 62).

The University of Leicester (2012b: 1) provides guidelines regarding research with children. These include the level of decision making capacity children possess, given they have sufficient maturity. Other issues raised include ensuring parental consent is obtained, taking care to ensure children are given opportunities to opt out of the research, and the appropriate use of images; ensuring no negative impact is made on the participants. I did use a parental consent form but I did not have the participants formally sign a consent form themselves. I did this because I did not feel it necessary to over-formalise the process and wanted to keep the relationships of mutual trust and respect with the participants in tact during the study. In keeping with this 
objective I did not use the vast majority of the photos in this thesis as using them would have revealed the identities of the participants and their families.

\subsection{Limitations of the Study}

Unfortunately this study was not longitudinal. This study did not examine how the hopes and dreams of young people evolve as they progress through education and into employment and adulthood. This was due to time constraints on my part. It would be interesting to conduct a longitudinal study of international students to follow them into their future employment, to see if their aspirations changed over time and if both occupational and other aspirations were affected by their international schooling experiences.

Like any other non-academically selective school, there is clear diversity in the performance of children in international schools. There is evidence to suggest that young people who do well in school have high occupational aspirations (Schoon and Polek: 2011: 211). This study did not take into account the academic level of the participating students. It would have been extremely useful to include information on teachers' evaluations of the participants' academic abilities in this study. Although it was concluded that all of the participants held high aspirations, the study did not relate these aspirations to their academic performance in school. There is a possibility that these high career aspirations they hold are unrealistic, causing them to pursue educational journeys which may ultimately lead them to struggle to find relevant, appropriate or even satisfying work (Mann et al 2013: 9).

Participant selection can seriously affect research findings. Given the research design of only interviewing students, there is no way to determine whether the aspirations young people openly express are their own, those of their parents or at least partially influenced by their parents. Therefore, another possible investigation would be to interview parents of students who are involved in international schooling. Comparing points of view of both parties could provide interesting and useful information and further Hart's (2012a) findings on young people's aspirations reflecting those of their parents. Also, Rutherford (2013: 1) found that middle school children who have expectations that do not meet their parents' aspirations for them have lower well- 
being. Given this, not one participant in the study either mentioned or compared their aspirations to that of what their parents desired for them. Therefore it cannot be confidently concluded that these young people's aspirations are actually their own authentic hopes for their futures. I acknowledge the small sample size used on the study and recognise that it cannot be representative of all students who attend international schools.

John Rachjman has written, 'language becomes the limits of our being' (1985: 24). Language is central to shaping meanings (Charmaz 2014: 1078). Language is a dimension which complicated this study. Only four of the twenty participants said that English was their mother tongue language. In the Middle School where the study was conducted only $34 \%$ of the students reported that English was their mother tongue language. Although the other 16 participants' English proficiency was deemed a sufficiently good standard to participate in the interviews, it would be useful to see their responses if the interviews were conducted in their respective mother-tongue languages. For the participants whose second (or even third) language was English, they would sometimes pause to search for words, inwardly translate, to explain their thoughts and responses to the interview questions.

In my transcriptions of the interviews, although I noted pauses which noted silence in participants' responses, I did not take down notes of facial expressions or changes in body language of the participants as they reacted to my questions. The face is what fuels interpretation (Deleuze and Guattari 1987: 134) and I did not take note of changes in facial expression, shrugs, snorts or laughter during the interviews and I recognise that as a limitation of the project.

\subsection{Summary}

The main research question for this study was How do a globalised lifestyle, international capital and an international schooling experience influence the identities and aspirations of young people?.

The aim of the study was to gain rich insights into young people's perceptions of the factors that influence their current and evolving aspirations and how they envisage their future selves. This chapter focussed on the research methodology, which 
included using semi-structured and photo-elicitation interviews. The purpose of the study was to gain insights into students' perspectives of the factors influencing their identities and aspirations. The sample was collected 'conveniently' as the participants were also my students in the school where I was teaching. I explained the process of access and permission granted to undertake the study.

In this chapter, I explained how the study was appropriately situated in the interpretivist paradigm. I interpreted the participants' perceptions of their lives, making sense of the sense they made of themselves and their experiences. I also explained how I conducted both the pilot study and the main study. The design of the main study was based on the experiences of the pilot study. I discussed the strengths of both semi-structured and photo-elicitation methods to obtain information from participants. The interview questions related to the literature discussed on aspirations, identity and international schooling and to the main research questions. What emerged were honest, deep and rich narrative data. This study focussed on a relatively small sample but aimed to capture in-depth views of the participants and delve into their unique experiences through semi-structured interviews and stimulated narratives. By using two methods of data collection; the semi-structured and the photo-elicitation interview, the study gains credibility.

The two rounds of interviews in the main study were conducted smoothly, with all participants attending both their interviews, which communicated to me their enthusiasm and interest in being part of the study. I had to ensure that my own personal and professional biases did not influence the interviews in any way and I was systematic in organising the data so I did not stifle the participants' voices. However, I was not completely detached from the data as I did have trusting relationships and good rapport with the participants as they were also my students.

The story that emerged was a subjective account and interpretation of events on the part of the participants, their definition of their situations (Cohen et al 2011: 205). The participants in this study related personal stories and reflected on their lives due to their life experiences and way of looking at the world (Goodson et al 2010: 127; Cohen et al 2011: 205). 
Ethical considerations were kept at the forefront during the study and I reflected upon them in this chapter. I explained my position as an insider researcher and the issues that involved. I reflected on how my own personal history, biography, gender and class position both shaped and brought their own potential biases to the study. I discussed the issues of self-awareness and the ability to acknowledge and manage my impact on the research process as both a teacher in the research setting and a researcher. Steps were taken to ensure validity and credibility, including open-ended questions, the use of two methods of data collection and the comparison with existing theory and research. This ensures that the study has replicability, in that it could be repeated by another researcher in a different context. I reflected on the limitations of the study, which included sample size, language proficiency, the participants' academic profiles and the issues surrounding parental effect on aspirations.

In the next chapter I discuss the findings of the main study. I will explain the themes and sub-themes generated and extracted from the interview data and offer a link back to how the findings offer answers to each of the research questions. 


\section{Chapter Four}

\section{Findings and Analysis}

\subsection{Introduction}

The main research question for this study was How do a globalised lifestyle, international capital and an international schooling experience influence the identities and aspirations of young people?

This is a qualitative study which investigated the influences of a globalised lifestyle, international capital and international schooling on the identities and aspirations of a cohort of privileged young people. Two rounds of interviews were conducted with twenty participants who were my students over a period of approximately four months in the autumn of 2013. Each participant attended both of their interviews which were conducted in my classroom during lunch breaks. Parental and school permission were sought and obtained for the participants' participation in the study. I conducted, recorded, transcribed, analysed and coded all of the interviews. A wealth of data came out of the participants' narratives. As the active player in this research process, I extracted and identified the themes from the interview data.

To highlight the fact that not all of the participants have exactly the same life experience, I categorised them. I created four categories: local students, locally bornforeign students, ex-patriate veterans and first time ex-patriates. I mention these categories as I highlight the participants' narratives in this chapter. A complete explanation is shown in Table Five of the appendices.

In this chapter, I present two main themes which I extracted from the interview data: Relationships and International Privilege. Each of these themes is then divided into three sub-themes: Home, Family and Friends under 'Relationships' and Travel, International Schooling and The Future under 'International Privilege'. Each of these sub-themes has a participant's story added to it, to provide supporting data and further highlight those participants' narratives as they relate to the sub-theme. These themes were selected on the basis of the frequency of the responses in the interviews 
and their relevance to the research aims and questions. I also merge and discuss the themes, findings and data as they relate to the research questions. The research questions are not presented in any particular order. Rather, I insert the research questions where the data and sub-theme address and relate to them. The sub-theme of 'Home' addresses the research question To What Extent Does a Globally Nomadic Experience Influence the Identities of Young People?. The sub-theme of 'Family' addresses the research question To What Extent do Parents Influence Aspirations?. The sub-theme of 'International Schooling' addresses the research question To what extent does an international schooling experience influence aspirations of young people?. The sub-theme of 'The Future' addresses the research question How do young people of this transnational class view their future selves?. The other research questions are presented with interview data which address and support them. Issues and themes from the main study were shown in Table Three in the previous chapter. $A$ summary of other themes mentioned by some but not all of the participants in the main study can be found in Table Six in the appendices.

For the participants in this study, identities are grounded in strong familial ties and for some, a powerfully emotional tie to their 'homelands'. As evident in some participants' photo-elicitation interviews, homelands not only represent where they once lived in the past, but play an important part in the present. Additionally, these privileged young people enjoy an elite schooling experience and see much of the world first hand due to extensive travelling with their families. Possessing this international capital also allows some of the participants to see the injustices and inequalities in the world for themselves and they shows signs of affect from these experiences. Finally, the participants in this study possess high educational and occupational aspirations for their futures and are optimistic that these aspirations can be realised. 


\subsection{Theme One}

\section{$\underline{\text { Relationships }}$}

The participants in this study appear to keep their identities unhindered and solid despite their transient lifestyles. This is due to their perceived strong and solid familial relationships and friendships, which they highly value and communicated strongly in their interviews. These close bonds add to their concepts and feelings of security, place, belonging, a sense of 'home', allegiances and identity. The sub-themes for this main theme of Relationships are Home, Family and Friends. I insert the research questions where they are addressed by the sub-themes and interview data.

Research Question: To What Extent Does a Globally Nomadic Experience Influence the Identities of Young People?

\section{Sub-Theme which addresses the question: Home}

Some of these 'global nomads' have spent time in a variety of locations, changing home and friendships, sometimes regularly and having little geographical notion of 'home' (Hayden 2011: 220). Anya illustrated this point perfectly when she commented that 'the whole world is my home'. Mary shared that she holds passports from Belgium, Germany, Canada and France but 'feels closest' to her Canadian passport, even though she did not live there at the time of the study. Both of these girls would be what I would term as 'ex-patriate veterans'; having lived in many countries.

These young people never leave their original home behind or totally arrive at a new one and the achievements of exile are coupled with the loss of something left behind forever (Liu 2014: 19; Said 2001: 137). Despite having to leave friends and family behind, the participants of this study view their nomadic but privileged circumstances with optimism: they see the opportunities this global lifestyle affords them and are content with their 'trajectories' (Friedman 2013: 1). Allie reflects below and her story supports these points made above.

Allie: I like more cultures around the world than just Belgian and I am more interested in Lebanon and South Africa because it is where my family was born, kind of, and even though I was not born there, most of my family is in Lebanon, so I do feel Belgian 
because I have been here most of my life and I do everything here but I still feel a lot South African because I have a passport and I go there a lot and I like the culture and the people are nice and polite and my mum raised me like South African people would be raised...

People have strong attachments to places which become part of who they are, and where they feel comfortable and relaxed, and able to be themselves (Foresight 2013: 37). Therefore, home is both a place or physical location and a set of feelings which include allegiances to friends (Blunt and Dowling 2006: 254; Maalouf 2000: 10). The participants shared their feelings of pride, emotional attachment and identification with their birth countries and the traditions each respective country enjoys as well as a feeling of belonging to the world. Jaap shared photos of his family and how they celebrate and keep their Dutch heritage and traditions alive whilst living in Belgium.

Jaap: ... this is a tradition we have, we do our birthdays in bed (new photo), and we get presents in bed and unwrap them in bed and after we go downstairs to have breakfast and-the next picture is when we had breakfast (new) after we unwrapped the presents and in this picture my grandparents are there... and this is my house in Holland ... we lived close to the sea and we were doing another one of our walks and at Easter (new), we were searching eggs at a friend's house and we do it because it is a tradition we have and this is my house now (new) and this is a picture of my grandma reading a story to us (new) because we have to keep up our Dutch language so she is reading a book in Dutch...

The extract above is in keeping with Smith (1991) who speaks of national symbols such as flags, anthems, parades and ceremonies being shared by 'members of a community of historical culture' (Smith 1991: 77) which in turn serve as 'identity markers' (Wiltgren 2013: 1). These objects or images make us look, feel and talk in a specific way (Wiltgren 2013: 3). The role of place - experienced, remembered and imagined has an important role to play in youth identity formation (Prince 2013: 2).

To illustrate this sub-theme more clearly, Doreen's story fits well. Doreen is a Norwegian girl born to Norwegian parents. She is what I termed a 'first time ex-pat', in that Belgium is the first country she has lived outside her country of birth and 
nationality, in her case Norway. She holds a significant bond to her home country and mentions the Oslo massacre as something important to her. "I was about ten minutes away from the bomb and I heard it and I felt the door to my house slammed open and I was scared for the hours after....the next two weeks everything was on TV and it was really scary'. Doreen did not express a specific career she wanted to pursue after leaving education but shared that she wanted to explore the world as she "had only been out of Europe once'. She accredits her mother with giving her the 'curiosity about the world'.

Doreen had been at her present school for three years at the time of the study. She acknowledges Harry Potter as giving her "morals". "I really like Harry Potter, which has given me many morals and I also like Doctor Who and Divergent'. Her first language is Norwegian and her English was of a very good spoken level during her two interviews. She shared 28 hard copied photographs in her interview, the majority of them being from her time and life in Norway. Her thoughts below sum up her feelings about her home country.

Doreen: I chose these photos because they mean a lot to me and they really make me smile...I really love Norway because so I chose some pictures from the national day, which is the 1st of May and we did that every year and have so many memories with our family and friends and yeah.... and also another thing about Norway is the opera, I like the opera because well ...I don't have a close memory with the opera I just like it...well I have a memory of when I was at a concert and I had a very nice time and also this photo (new) that's the city hall in Norway and I performed a dance in front of the King and Queen of Norway and I am really proud of that.... when I was 7 me and my friends always went to the beaches.... we did it like almost every day and we could talk a whole day of all the memories we had...

The participants spoke of their national identities when sharing photos of their birth countries and their contingent networks of family and friends which constitute their personal community; relationships which are linked through trust and security. They spoke of themselves on a 'supranational' level; identities which transcend boundaries on a global level, not in the homeland but also not in the host country (Biswas 2002: 
176; Noble 2013: 346). Home, for these participants, is therefore not a 'real' place but rather a 'shifting definition', which is arguably, real to them (Sichel 2004: 185).

The participants in this study are negotiating home, identity and belonging in a transnational social space (Liu 2014: 21). By being away from 'home' in some cases, they are developing new perspectives on 'home' (Wiles 2008: 116). Their attitudes and identities have been affected by their new environment, otherwise known as the theory of 'acculturation' (Rudnev 2014: 1627). In some cases these new experiences caused the emergence of an emotional attachment to either the school culture or the culture of the country for these participants. In their openness to familiarise themselves with cultures outside their national setting, these participants are exhibiting part of their cosmopolitanism (Skrbis and Woodward 2007: 732).

A migrant's sense of home closely relates to his/her emotional journey when travelling between places (Liu 2014: 24). Their lived experiences and spatial imaginaries revolve around relationships between home and homeland, the existence of multiple homes, and the intersections of home, memory, identity and belonging (Blunt and Dowling 2006: 199). Home itself is a multi-layered, ongoing process; home can be both a space and affective family and social relations (Wiles 2008: 116). Environments and experiences that shape their worlds are indeed 'home' (Veness 1993: 319). Hector describes his move from Africa to Belgium below.

Hector: Ever since I moved here I have gotten to adapt into the new western culture, back in Africa it was a lot different than here....how I dressed, how I thought, how I interacted with people... when I got here I changed completely, I discovered new media, starting listening to different types of music and started learning new things that I wouldn't have learned. My parents... helped me adapt into the new culture but they also help me stay connected with the old culture in Africa... we speak Swahili at home and they give me traditional African food at the same time letting me adapt to the new world.

For these participants, there exists an attachment and appreciation of their countries of birth and friends still living there, as exhibited in the photo-elicitation interviews. They hold nostalgic memories for their home countries, in which there exists another 
presence of their social networks (Koh 2015: 531). They exhibited feelings of pride, contentment, satisfaction and general concern with their countries of birth. The participants see their country of birth as something important to them and part of their identity but they do not view it as rooting or bounding them, rather seeing their identity as taking more mobile routes (Blunt and Dowling 2006: 199). This supports Ong's (1996) theory that cultural citizenship is a process of self-making and is made in relation to nation states and transnational processes (Ong 1996: 737).

\section{Research Question: To What Extent do Parents Influence Aspirations?}

\section{Sub-Theme which addresses the research question: Family}

The second sub-theme under Relationships is 'Family'. Every one of the participants in this study credited their families as being the major influence on their lives. They perceive that parents and family have a significant impact on them and provide a 'general framework' for their aspirations (Allen and Hollingworth 2013: 500). This supports the work of Kintrea et al (2011), Strand and Winston (2008), Garg et al (2002) and Cuiting and Kerpelman (2007).

There are both big and small things that parents can do that can have a huge impact on children and how they are able to live their lives (Hart 2012a: 4). Evidence from the transcripts supports this below.

Minty: ...my parents because they have always been there for me...

Allie: yeah family is like really important to me because I only have my dad and my mum in Belgium and my family is like all over the place...I don't see them every day and stuff like that.... the person who influences me most is my mum, because she is a single mum... we created a bond...go on trips and stuff like that...I can talk a lot with my mum, I tell her everything and really look up to her because she has this like great career and she really is a nice and caring person...

Anya: ... I have a really big bond with my parents cos I know that I can always trust them and tell them about like mostly everything ... this is kinda like the adults in my life and the adults that I kinda look up to as kind of my inspirations... 
Sandra:...I also think that my mother and my father they are really big role models to me... so my sister she always tells me because she has more experiences and stuff she tells me that I should not do stuff but even if I would do something like that my sister would help me how to deal with it...

Valerie:...it's my mum and dad cos they kind of educated me also and then my sisters because they sometimes put things in my head...

Felipe:...definitely my family, all four of them, my sister, my brother and both my parents...I take a lot of ideas from them.

Doreen: ...my mum is a very big influence on me, I feel like she like always like to be like her because she is smiling and she is positive all the time.

In this study, Micky stands out as the participant who best illustrates the importance of family. Micky was born in Belgium to Italian and French parents. He holds a French passport and French is his first language. In his present school for four years at the time of the study, he is what I would term an 'ex-pat veteran', having lived in many countries and attending so many international schools he feels that is where he belongs. He said, 'I feel like I belong in an international school'. He shared 15 photos in his interview and spoke of his educational aspiration of attending university. The family album expresses the essence of social memory (Bourdieu 1990b: 30) and Micky actually took the time to point out each and every family member in the photos he shared with me during his photo-elicitation interview. He also shared some of the destinations of his travels with his family (America, Greece and France). Micky also spoke about his active lifestyle of participating in judo, tennis and swimming.

Micky: I always go and visit my family that doesn't live with me in the summer so that we can see each other and it is a nice vacation time.... here is a photo of when we went to Wyoming, so there is my mother, my sister and me in front of a geyser.... here is my family (showing photo) in the last vacation and here is my family with my aunt, my mother, my mother's father, my mother's mother, my dad, my dad's family...my three cousins, my grandma on my dad's side... and here I have a photo of my grandpa and grandma from my mother's side with my sister... every year, well almost, we go sailing, 
and we always stay in nice harbours, and it is always us four.... we just cut ourselves off from the world...my parents always influenced me in my decisions and sort of like my daily life, they were the ones that chose to go to America and that was a big change in my life which really helped me and it will help me a lot later on and yeah I guess...

The richest inheritance any child can have is a stable, loving and disciplined family life (Patterson 2015: 3). There is a process of family culture and school culture working in harmony for more advantaged young people (Smyth and Wrigley 2013: 119). The participants appear to be confident, optimistic and positive as they express a significant gratitude to their families for affording them the international capital they possess. It must be recognised that it has been put forth in previous research that children are often reluctant to admit to possible negative aspects of their relationships (Bowker 2004: 103). These participants all describe happy family backgrounds where they are valued and supported economically, educationally and emotionally (Hoskins and Barker 2014: 94).

The participants in this study expressed their sense of union with their parents and shared their close feelings to their parents and family members but did not share whether or not they wanted to necessarily 'copy' their parents' lives or that their aspirations were directed by their parents' wishes for them. However, every participant's account was permeated by an awareness and appreciation that family, past and present, are significant to their lives and an important influence on them (Hoskins and Barker 2014: 120). The participants hold strong feelings of trust in their families, adding to the cognitive dimension of their social capital (Han 2015: 242). This is consistent with the work of Hoskins and Barker (2014) finding that young people's identities and aspirations drew from their varied sources of capital. It also adds to the work done by McDevitt et al (2013) who found parents do shape the career aspirations of their children. This would also resonate with Leighton (2013) who puts forth that children of judges and politicians might be doing more than following a family tradition, just as miners followed miners and farmers followed farmers through generations (Leighton 2013: 426). 


\section{Friends}

The third sub-theme under Relationships is 'Friends'. In the context of this study involving young people in an international schooling environment, it was apparent that relational values underpinned feelings of belonging and happiness in schools and lives in general. Relationships with friends, both past and present were important to the lives of the participants in this study. Felipe shared photos of his friends from Brazil who recently visited him in Belgium, exhibiting feelings of pride and happiness as he told the story, and commented that 'it was great... we don't get a lot of visits from there'. This supports Cronin's (2014) work on emotions, context and friendship and Minoura's (1992: 305) argument that the sensitive period for interpersonal relationships occurs between the ages of 9 and 15. Emotions are created and made in relationships and friendships between people (Cronin 2014: 71). These close relationships formed between members of the international school student community are in fact what is known as 'bonding social capital', that is, social capital networks that reinforce links between members of the same community, in this context the international school community (Huschke 2014: 2020). Below are both Bobbi's and Osawa's comments on photos of their friends.

Bobbi... I also wanted to put a picture of my friendships (new photo) because I think friendships are a really good part of you know, our lives... I think my friends are a really big part of this because they are the ones who are there for you, they are the ones you can talk to about, not with your family sometimes but with your friends, and you can laugh about different stuff and they are the ones who you can maybe be with the rest of your life...

Osawa: ... there was only like mainly English kids in that school and me and my sister were the only Japanese kids there so when I first went there I was very nervous, there wasn't anybody who was from the same country as me... so um I wasn't able to find any picture of my friends in that time in the school but I was able to make many more friends than I expected so my class was about ten people, four girls and 6 boys, and I was able to become friends with all of them and I had three major best friends, I forgot their names but we always played together outside we always worked together then in 
2005 we moved to Belgium and it was very sad because I had to separate with my best friends and since then I haven't had any contact with them...

Allie's interviews clearly showed how much she valued her friends. She communicated a real sense of how much her friends in her previous school meant to her. She will not let herself forget them or let go of them. Allie was born in Belgium to South African and Lebanese parents (divorced) and holds a Belgian and a South African passport. I would classify her a 'locally born foreigner'. She has been at her present school for two years and values her familial and peer relationships. Her first language is French. She shared 16 photos in her first interview. She too spoke of her 'belonging' in international schools. 'I feel like I belong here....I was in Belgian school and now that I am in an international school I see how many people live'. Her educational aspiration is to attend university and her occupational aspiration is to become a lawyer. Below is an extract from her photo-elicitation interview.

Allie: ok so um this picture, this is most of my friends so those three like all them all them (points to three children), so most of them I had them in my class for nine years, in the same class and so they were my friends in my old school and so they mean a lot to me because we shared a lot of things together and I mean nine years is really long, like we kinda grew up together and so when I came to (this school), it was really hard to separate myself from them ...my best friend Rosalie.... know her for about ten and a half years now and she means like everything to me cos I tell her all my secrets and when I feel bad I go to her and we talk about everything together, I see her nearly every weekend and I used to see her every day at school but not anymore but so she is like a sister to me...

Although the participants shared that they experience frequent loss of close friends, these young people look forward to meeting new friends and develop strong skills of adaptability and acceptance and as a result, are comfortable in many situations.

The participants' personal networks change as a result of their mobility but the use of electronic technologies allows for relational maintenance (Allan 2008: 5-6). The participants also develop meta-cultural skills of acceptance in their mobile upbringing (Pearce 2013b: 75). This resonates with the work of MacMurray (2012), Sanchez-Marti 
and Ramirez-Iniguez (2012) and Pearce (2011) and their work on human relationships and friendships. Student relationships can be developed in many different ways in inclusive multicultural environments (Sanchez-Marti and Ramirez-Iniguez 2012: 491). This recognition that trusting relationships in schools are beneficial means that a caring and supportive school atmosphere, with empathetic school personnel who encourage these cross-cultural friendships, can help students who experience these transient and unique life-styles.

\subsection{Theme Two}

\section{International Privilege}

The participants expressed genuine appreciation for their privileged positions and embrace the opportunities and possibilities afforded them; either through travel, elite schooling or learning about different cultures. They hold high educational and occupational aspirations for their futures. The sub-themes for this second main theme of International Privilege are Travel, International Schooling and The Future. As with the first theme of Relationships, I insert the research questions where they are addressed by the sub-themes and interview data.

\section{Travel}

A family who travels will encounter many other ways of life and cultures and allows the children to open their minds and hearts to other people in the world. The participants in this study all travel, some extensively. Valerie commented, 'we really travel a lot, a lot of places with my family... a tradition in our family is that our grandpa arranges a boat trip each summer, like in Turkey'. This cosmopolitan capital is accumulated while living abroad, visiting and hosting friends of different nationalities, maintaining a globally dispersed circle of friends and relatives, having extensive and extended connections and possessing mastery of at least one other language (Weenink 2008: 1092; Kenway and Fahey 2015: 96).

Gabby: ...my favourite thing is probably the travel, I love to go like on our breaks and stuff, over the summer and Xmas, with my with one of my favourite travel memories was over my birthday last year, it was over the February break and it was my 13th, and we were in Italy skiing and on my birthday, I had my ski lesson and after we skied 
down to have lunch at the restaurant and my two best friends were skiing at another resort were there, my mum had coordinated that so that was great...so that was something that was really really amazing but we just love to travel, especially my parents, they are really like excited about that ...every summer since we've been here we always go back to the States...

Mel:...my mum is French, my dad is German, my sister are I are adopted from China and my big sister is married to an Englishman and this photo is in Corsica at her wedding...

Bobbi:... have been to China in 2012...to help a migrant school...this photo is Gothenburg...we went to see our relatives this summer and we visited this mansion which my great great grandfather owned...this photo is from Mallorca where we have all our friends and where we just sail for two weeks.

Melanie: ... this is us again when we were younger in Spain(new photo), this one is international day at school (new), this is me and my family (new), this is me and my mum in Switzerland (new), that is me in Germany (new), this was in Belgium (new), I think that was in Wales (new), that was in Spain (new)...

Micky: we like going on vacation as you can see here, this was in Greece... I go skiing about two weeks a year... every year, well almost, we go sailing, and we always stay in nice bays and it is always us four, and maybe I bring a friend like I did last year, so we just put our anchor in a bay, and just cut ourselves off from the world...

Figure One, entitled 'Holiday', is one of Micky's photos.

Anya spoke at length about her travels. Anya is a Polish national born to Polish parents and still practices Polish traditions whilst living in Belgium. She has been at her present school for two years and mentions her extensive travel all over Europe, mostly by car. She has lived in Belgium and America where she perfected her English and is aspiring to be a vet when she grows up. 'I like spending time with animals so that inspires me to be a vet'. Her first language is Polish and she is what is classified for this study as an 'ex-pat veteran'. 'I lived in Poland for two years, then Denmark for two or three years, then Czech Republic for two years, then America for five years and then here'. 
However, travel and transience does not sit totally comfortable with Anya. 'I am hoping to stay here for a while because I really don't like moving that much...the longer you stay in a place the more you get attached to it'. She shared 10 photos in her interview, showing her family and her holidays.

Anya: ...yeah this summer we went to Croatia, and to Italy and to three different places in Poland all by car and on the way we stopped in Austria, Czech Republic, and we went through like Germany... f feel like the whole world is my home .... my parents took us to so many different places and really to experience so many different things, it has always been a part of me to visit different places and drive to new towns, cities and countries and they took us to the beach and the mountains and we went hiking, just a lot of different fun experiences...the car symbolises how we move around a lot and we travel a lot and we travel to a bunch of different places... when I say we travel a lot I mean a lot...

Figure 1: 'Holiday'

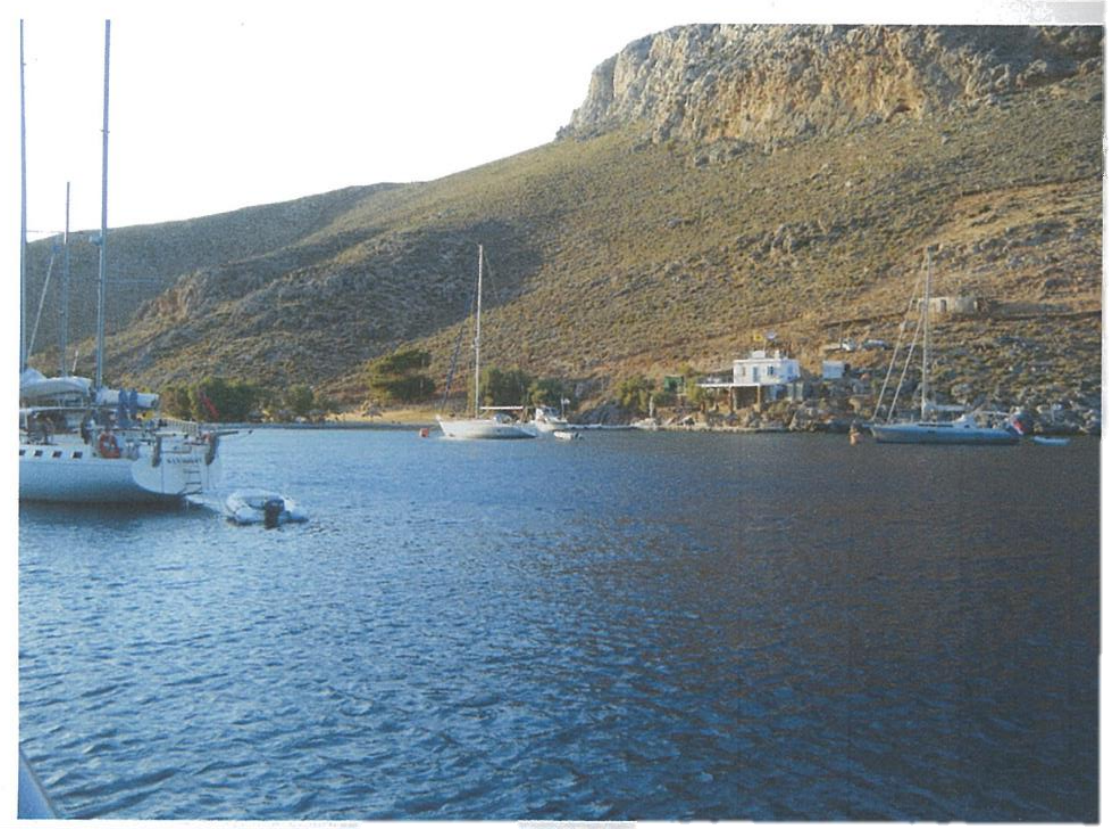


It is clear that the participants of this study appreciate the educational and exciting aspects of being afforded opportunities to see the world. Their parents appear to be making a concerted effort that their children get the most out of their special circumstances and see as much as they can in their free time and school holidays. Overall, what results is a positive experience for these young people, who are grateful to their families for affording them such experiences which shape who they are and who they will become.

Research Question: To what extent does an international schooling experience influence aspirations of young people?

\section{Sub-Theme which addresses the question: International Schooling}

The second sub-theme under the theme of International Privilege is 'International Schooling'. A particular type of parent may be attracted to a particular type of independent school, one which relates to their own values and attitudes (Leighton 2013: 426). As mentioned previously, the international school in this study advertises its values of companionship, respect and integrity but it is not clear from the study whether or not the school itself is the main influence of the participants' values. The socioeconomic status of parents makes a huge influence on an individual's values (Leonavicius and Ozolinciute 2015: 43) and socioeconomic status also has an effect on the resources that people have available to them when participating in volunteering (Scott and Serek 2015: 184).

Character is a skill, not a trait (Kautz et al 2014: 1). Some participants in this study were involved in charity work through their families and possessed a commitment to do things without waiting out of a duty of kindness, decency, civility and care (Sen 2008: 332; O'Donnell 2014: 266). Two of the participants have direct contact with individuals outside of their social class context whom they visit and help regularly. Valerie's parents run a charity in Belgium. She shared that her family gives a woman they know 'a lot of money for the school that she is doing and hospitals and stuff like that and my mum helps out a lot in different countries like Argentina and around the world.... that's what she does.... our family helps a lot of poor children around the world'. She saw first-hand her parents' charity work in 2012. 
Bobbi has travelled to China to assist in the creation of a school for the underprivileged. For these young people, there is an intergenerational transmission of volunteering and it is the normal thing to do for them (Scott and Serek 2015: 184). These two participants believed that it was their responsibility to find solutions for others less fortunate. They both expressed a desire for being with the people, talking to the underprivileged and getting to know them and their needs (GaztambideFernandez and Howard 2014: 3). They appeared to observe a connection between themselves and others and act as part of the duty of benevolence for those less fortunate and develop real-world services that benefit mankind and affect real social change (Jackson 2014: 13; Newman et al 2015: 49). International schools have an opportunity to teach the privileged young people of the world about the underprivileged.

Bobbi: I have been to China in 2012 because I went there with a group of people because we were going to help a migrant school, we helped them raise more money so they could have more bathrooms, nicer ones, and so we also painted their walls in their schools and we bought them ping pong tables and it was really cool because we got to see how their life was because they were only there for like 5 years and once they reached $5^{\text {th }}$ grade they could either just stop school or do it again, and again and again ..so many of them decided to you know, do it again but it is kind of sad to know that we have the choice to go up the grades and they just stop at $5^{\text {th }}$ grade....

Open-minded reflection about diverse perspectives and worldviews held by others plays a salient role in 'thinking well' (Soutter et al 2014: 508). Allie's view was 'in an international school they want you to be open-minded and see everything...think about different things and not just one thing...there are so many cultures'. Juan added that 'it is really cool because there are people from around the world and you respect more each other because everyone is different'. Anya reflects:

...an international school lets you meet people from a bunch of different places... Minty was clear about what she perceived to be the benefits of an international school experience. Minty is a Swiss national born to Swiss and Iranian parents. She has travelled extensively and has lived in America and Africa. She would be what Ezra 
(2003: 126) describes as the' internationally mobile child', and what I term an 'ex-pat veteran', having moved frequently due to her parents' employment. She is very active and has been at her present school for five years and has high career aspirations of becoming a scientist and 'to do global warming because it is a problem that is happening'. Her first language is French. She brought over 100 photos to her photo interview, some 30 of which she discussed and presented to me. Minty appreciates the cultural diversity, learning of languages and the confidence you feel from attending an international school. She is aware of her privilege and feels a sense of responsibility to help those in less fortunate circumstances. Stronger feelings of compassion and egalitarian values by the lower classes compared to their upper class counterparts is illustrated in the work of Piff et al (2010: 780). This has implications for promoting more prosocial behaviour based on social class in international schools.

Minty:... well first of all I get to meet lots of people from different cultures and I do after school activities so I get to talk to people... and that is another thing I like, speaking English, it is like the international language and so I am happy I speak English and French cos I can travel lots of places around the world and I am trying to learn Spanish and that is spoken in other parts of the world, mainly in South America and in an international school too.... like the system... here is more like expressing what you think and that is something I like a lot and my mum told me also that people who come to international schools have a tendency to talk easier in front of a crowd... and I like that. I have more opportunities than certain people that were born in dumps for example and I feel like I want to help them out but I don't know how yet....being an international person I feel like I need a home of the whole world and not have one country or support one football team, I just decided I am for everybody...

The two local students who were interviewed saw their international schooling experience as a way to augment their social, academic and human capital; seeing the International Baccalaureate and being exposed to different cultures as good investments in their futures. This 'Western' form of education is seen by the participants as giving them a competitive edge. 
Valerie:...you don't stay in the culture of Belgium....you...understand different things that maybe will help...to find a job...

Louis: (what is good)...is the IB, it helps you study the world.

Thoughts from other participants can be seen in the appendices.

There are participants in this study who shared that they aspire to attend university after their secondary education and are surrounded by like-minded peers. Aspiring to attend university is in keeping with the studies of Dupriez et al (2012) and Frost (2007).

How a person responds to the one who has nothing, reveals who one is and the wealthy are confronted with a particular set of moral, social and political questions, not least of which is the question of how to be a good human being (GaztambideFernandez and Howard 2014: 1; O'Donnell 2014: 265). Some in this cohort of young people may indeed be developing a greater sense of global responsibility and a stronger attitude toward civic participation than other young people due to their global awareness, travel, privilege and values.

In could be argued that the international school has an accidental impact on this particular cohort of students. In the space of international education, teachers and students experiment with how to belong with and to each other formed by global and personal circumstances (Tarc and Tarc 2015: 41). The participants did not mention teachers as having a direct impact on their aspirations but I did not directly ask them the question as to whether they perceived their teachers as influential.

Research Question: How do young people of this transnational class view their future selves?

\section{Sub-Theme which addresses the question: The Future}

The third sub-theme under the theme of International Privilege is 'The Future'. Gabby will be in the spotlight for this last sub-theme. Gabby is an American who moved directly from the U.S.A. to Belgium and her present school three years previous. This makes her a 'first time ex-pat'. She places much emphasis on her family, home country and her religion; 'Being Catholic is very important to $m e^{\prime}$. Both of her parents are 
American. She expressed her appreciation of the opportunities for travel that living overseas affords her.

Gabby aspires to a career in politics. She describes herself as 'Irish-American' and her first language is English. Students from advantaged backgrounds are more likely to be politically interested (Sohl and Arensmeier 2015: 134) as civic engagement is a construct deeply rooted in social relationships (Oosterhoff et al 2015: 386).

Gabby:... For me, I would like to go into politics, I think that would be really interesting, I am not sure what part of politics but I think global relations would be interesting and I think that's something that coming from an international school would help me with because I think when you are able to relate to people who are not the same as you, like whether ethnically, culturally.... that is a really good thing that can really help the world and I think my experiences here help me to make friends with people from like all over would help me in that area.... when you die you want to be happy with what you have done on earth...I think that would be 'successful'...to have good relationships with people...

Gabby's aspirations to go into politics arise out of a desire to help others and is in keeping with the work of Malin et al (2015) who, in their analysis of survey and interview data with 1578 high school seniors in the United States, found that girls' civic motivations were based on a desire to help (Malin et al 2015: 34).

Where you get to depends on where you are coming from (Putnam 1993: 179). Sets of agents who occupy similar positions and who are placed in similar conditions have every likelihood of adopting similar dispositions and producing similar practices (Bourdieu 1985: 725). Young people whose habitus is least likely to be challenged by the conditions they encounter are those whose cultural capital ensures a relatively smooth pathway through life (Farrugia 2013: 689). The participants in this study are the children of the resourceful and well-resourced, born with the odds stacked in their favour and can be bought positional advantages (Ball 2013: 112; Blum 2013: 303; Jones 2014: 3). Furthermore, the participants in this study shared their busy schedules of activities outside school, a concerted effort on the part of the parents to encourage academic and personal development and intensify parent-child interaction (Dufur et al 
2010: 8). Perhaps this is why the young people in these circumstances speak in an agentic way about their futures. They are not attempting to transform a social structure but rather maintain their exclusive networks which reinforce their position within the privileged structure they inhabit (Letki and Mierina 2015: 220). Allie stated that she wanted to 'keep the same kinda life'. The world is imagined as a stage upon which they can readily and freely act and on which they can effect change and achieve their desires (Kenway and Fahey 2014: 191). Expectations of success are steering these young people towards an already expected destiny. It could be argued that they appear to be closed to the possibility of failure, seeking success in their sphere at any cost (O’Donnell 2014: 263).

Optimism is defined as a general expectation of future good outcomes (Bayramoglu and Sahin 2015: 155). An optimistic attitude is largely inherited, affects actions, and it is part of a general disposition for well-being, which may also include a preference for seeing the bright side of everything (Kahneman 2011: 255; Smyth and Wrigley 2013: 120). Optimistic people expect good things to happen to them and are inclined to expect the best possible outcomes (Tenney et al 2015: 377). These same authors, in their study with North Americans on optimism, caution against misattributing success to optimism or attributing more of the variance in success to optimism than it deserves (Tenney et al 2015: 394).

The participants in this study appeared confident that they possessed the skills to 'preserve or enhance their initial reserves of received capital' but at the same time express a view that experiences come to constitute a greater part of the self than do material possessions (Bourdieu 1984: 110; Carter and Gilovich 2012: 1304). Materialism is the importance attributed to the accumulation and acquisition of material goods to accomplish life goals (Sidhu and Foo 2015: 78). The participants did not mention aspiring to amass material possessions nor express a devotion to material desires and needs but they did express a desire to live securely and be happy (Ergen et al 2015: 512; Bryant and Ellard 2015: 485). This supports and adds to the recent body of work which argues that materialism is negatively associated with personal wellbeing and does not result in high levels of happiness (Dittmar et al 2014: 879; Sidhu and Foo 2015: 88). 
For the elite, desire tends to inform possibility: what is imagined is simply made possible (Sellar and Gale 2011: 129). The participants in this study possess knowledge of the game' and how to play it. Children from wealthy and highly educated backgrounds have instilled within them a sense of expectation and entitlement to progress to the more elite (Donnelly 2014: 58). There is an air of assurance and optimism that the door of opportunity stands open, with a pool of opportunities behind it, and all they need to do is want something hard enough (Batchelor 2006: 229; Caletrio 2012: 146; Cross 2013: 89).

Research Question: Is there evidence of a link between these students' first world citizenship privilege and the nature of their aspirations?

These participants have what Bates (2012: 263) would call 'multiple citizenships', which are the result of their parents' high level qualifications, giving them access to a privileged 'first world citizenship'. They do not automatically align themselves with only one particular national group, although some hold special feelings for their home countries, and they are not seeking the approval to do so. This is especially true for the participants whose parents were not of the same nationality.

When asked about what they wanted to do when they left school, the participants tended to respond concretely, focussing on tangible outcomes like university or a career (Shoffner et al 2015: 110). In their discussions about their futures, these participants shared the following:

Allie: ...I would like to be a lawyer, and go to Harvard and I hope I will be successful and have a good career...

Anya:... like maybe a lawyer or something I guess...

Melanie: ... I want to something which has to do with art...

The participants in this study hold high educational and occupational aspirations. Jaap: ... hope to go to university...

Karl: I would like to be a pilot

Hector: I want to be an architect... 
Sandra: First I want to practice medicine and then while I am doing that I want to do the army study... and then I hope if everything works out I want to become an army doctor...

Whilst education is seen by these participants as not only accessible to them, it is also seen as affording them options, hence their 'readiness' for school (lannelli 2013: 908). It goes without saying that a decent standard of living and a good job today requires a college education, if not a professional degree (Settersen Jr. and Ray 2010: 22). However, it appears that, in the views of these participants, this educational achievement and qualification alone will not make them successful and happy in life. This resonates with the work of Rose and Baird (2013) and their survey findings of young people's hopes and goals.

The participants in this study spoke both of their imagined communities and personal communities; their perceived future selves and their present selves (Alexander et al 2007: 788). The belief that one can accomplish a goal or achieve an outcome is an important determinant of action (Rutherford 2015: 70). These educational aspirations expressed by the participants are in keeping with previous research which found that over two-thirds of young people aged 14 reported it 'very' or 'fairly' likely that they will apply to university (Anders and Micklewright 2013: 25). However, as previous research suggests, educational aspirations are on average higher when students attend a school where the average sociocultural intake is also higher as informal contact with privileged students has a positive impact on the way students view schooling (Dupriez et al 2012: 506). Also, the level of education that a parent has obtained seems to have a dramatic effect on the educational aspirations of their children (Kirk et al 2011: 90). As 'engaged' young people, they are more likely to aspire to continue with their education in the long term and have positive attitudes toward school (Ross 2009: 15).

The participants in this study possess an assumed sense of personal advancement. They also have a feeling of social responsibility due to their privileged positions and interactions with people of other cultures and classes. They hold high occupational and educational aspirations, planning to further their education after graduating High 
School and aspiring to professions requiring post-secondary education. This connects with prior evidence that sociocultural background is related to educational aspirations (Dupriez et al 2012: 515).

\section{Research Question: How do young people of this transnational class define success?}

Success is impacted by, among other things, mind-set, personality, motivation and the support obtained by one's family (Guy and Beaman 2003: 1007). People's behaviour is connected to their goal perspectives, which relate to how people define success (Peiro-Velert et al 2014: 187). The participants in this study defined success in some very interesting ways, showing that their aspirations are, overall, characterised by intrinsic rather than extrinsic forms of motivation.

The participants in this study certainly possess both the ability to read a map of their journey into the future as well as having the confidence to explore unmapped possibilities (Appadurai 2004: 76; Bok 2010: 164). Their future self-perception is one of expected fulfilment of their goals, 'elite aspirations', success and to lead a 'happy adult life' (Brown 2011: 8; Kenway and Fahey 2014: 183). They are confident in their abilities to succeed and this shapes their behaviour. They certainly appear to be motivated and persistent, two of the personality traits which matter for success in life (Heckman et al 2006: 412).

Allie: ...being successful is wanting to do it so pushing yourself to work, study to have good grades and after to have a good career so being successful is when you push yourself and you do the best you can, not compared to other people, but to yourself. Jaap:....to have accomplished something meaningful and important, which might not be important for other people but is for you...

Anya: ...success for me, the first thing that pops in my mind is happy...because in order to be successful you have to be happy about what you are doing so let's say I become like a great philosopher but I am not really happy about it, I am not really happy about the job I do, that wouldn't really be success... 
Bobbi: I think successful is knowing what you want to be when you are older, to be driven, to have a talent or just work hard and accomplishing things because I think that everyone wants to accomplish something in life...

Micky:... to be successful is to have achieved your goal in life and it doesn't necessarily mean that you have to be rich, but that's what people think it is, but I think that successful means that you have a good social level.

Success is so predictable, it is almost as if they can see the elite destinations awaiting them (Koh and Kenway 2012: 333). This has been termed as 'map knowledge', knowing the route to a particular destination and having their route all mapped out to get there (Gale and Parker 2015: 90). Profound happiness is contentment in becoming what one wills one's being to be (Gibbs 2015: 56). In the 'complex task' (Prince 2013: 16) of imagining the future, these young people want to better themselves, grow, help others and be happy. Louis defined success as 'doing what you like and not being forced to do what you don't like'. This resonates with Johan's view of success; 'doing what you want to do and living your dream'. Therein lies a sense of agency; in being able to have the choice to direct oneself into a pathway which one enjoys. Their ideal of working hard to achieve and enjoy success is in keeping with the work of Mendick et al (2015) and their group interviews with 14-17 year olds across six schools in England.

It is an aspiration to have a meaningful existence in the world (Malin et al 2013: 186) and these participants possess such an aspiration. Anya wants to be happy while Gabby explained that she wished "to have a more positive impact on the world... actually do actions that make a difference". Juan wants to "make a change, make something happen' while Hector wants to 'do something which has never been done before'. Finally, Felipe defines success as 'something that not only influences you but is an achievement for other people'. These young people are happy, positively driven and inspired to be highly educated, achieve meaningful goals and to continue to have strong personal relationships. All of these things will make them happy and feel successful. Moreover, they feel secure and confident that they have the support from 
family and social networks needed to pursue their dreams. They are also expecting to continue to lead the lifestyles they presently enjoy.

\subsection{Summary}

The main research question for this study was How do a globalised lifestyle, international capital and an international schooling experience influence the identities and aspirations of young people?.

In this findings and analysis chapter I presented the themes and sub-themes which I identified and extracted from the interview data of this study. I incorporated the research questions into the analysis as they related to the sub-themes. Other research questions which did not directly link with the themes were presented and discussed separately with supporting interview data. All of the research questions for this study were answered by the narratives of the forty interviews conducted.

The international experiences of the participants in this study enabled these individuals to acquire extensive linguistic and cultural knowledge (Messelink et al 2015: 64). The international schooling experience allows this cohort of young people to interact and befriend other young people of many different cultures. As a result, not only do they learn about other cultures, they develop values of tolerance and acceptance for all human beings. This special and privileged cohort of young people also enjoy opportunities of travel, where again, they experience first-hand other world cultures and some even bear witness to the vast inequalities and deprivation which exist in the world. For some, this is a call to act, help and change what they have seen to be the cruelty and injustices to which other young people their age are subject. These kinds of altruistic acts can have a 'civilising effect' on these privileged students' identities (Kenway and Fahey 2015: 98).

Due to its 'elite' nature, this kind of schooling also gives the young people perceived avenues to higher education which may not have been accessible had they followed another sort of education in their 'homelands'. Identities for these participants are strongly rooted in ties with family and friends, and although multifaceted and fluid, their sense of who they are is in no way fragmented or conflicted. 
Although there was little or no mention of achieving personal wealth or the desire for status, the participants' optimistic reflections and expectations provided examples of the transmission of international capital and evidence of expectant social reproduction of the 'comfortable conditions they know' (Hoskins and Barker 2014: 143). This would suggest they wish to continue to be a part of the transnational elite class of which they are presently a part (Findlay et al 2012: 129).

In this study, the notion of 'success' was equated with choice, empowerment, freedom to pursue goals, accomplishment and happiness. The qualitative data revealed that the most significant aspiration for these participants is happiness and helping others; achieved with the support of sound familial ties and strong international capital, which in turn gives them a confident sense of who they are as young people. Being happy in the future matters to them and this may indeed shape their adult lives (Finlay et al 2014: 1).

In the next and final chapter of the thesis I revisit the findings of the study. I discuss the originality of the research as well as its professional relevance. Finally I discuss the possible implications of this work and some areas and opportunities for further investigation. I close the concluding chapter with a personal reflection of the experience of undertaking doctoral research and how it has affected me both personally and professionally. 


\section{Chapter Five}

\section{Conclusions and Recommendations}

\subsection{Introduction}

The main research question for this study was How do a globalised lifestyle, international capital and an international schooling experience influence the identities and aspirations of young people?

This qualitative study has been an exploration into how privileged young people following international schooling perceive the effects of a globalised lifestyle, international capital and an international schooling experience on their identities and aspirations. This research is based on the analysis of spoken words gathered through interviews which capture some dimensions of young people's lives. Through two rounds of interviews with 20 of my own students in my former place of work, I aimed to offer insights into the lives of a special cohort of young people. The data gathered was both rich and detailed, enabling fresh insights to be gained into the factors influencing the identities and aspirations of this unique group of Generation Z.

In this thesis I have reported the findings of two rounds of interviews conducted with twenty young people who attended an international school in Belgium where I was employed. I set out to seek out young people's perceptions of factors which influence their identities and aspirations. I opened the thesis by discussing, in Chapter One, the rationale for and background of the study. In Chapter Two, I discussed the relevant literature around the study. In Chapter Three, I explained the process by which I obtained rich and detailed data through the use of semi-structured and photoelicitation interviews. I recognised the limitations of the project in Chapter Three, and if I were to begin again now, I would conduct a longitudinal study of this group of young people as they follow an international schooling experience and globalised lifestyle. Other recognised limitations of the study involved not interviewing parents, the issue of language proficiency and not taking into consideration the academic performance of the participants in the school. I offered the findings and analysis in Chapter Four, relating the themes and data to the original research questions. 
In this chapter I revisit and discuss the main findings of the study. I identify the originality of the work, the professional relevance of the study to international education, implications for practice and offer my recommendations for further research. I conclude the chapter and the thesis by offering a personal reflection on the experience of undertaking doctoral study.

\subsection{Discussion of the Findings of the Study}

The thesis was constructed around the themes which I drew from the narratives of the participants in the study. I identified two main themes: Relationships and International Privilege, each having their own sub-themes. A rich and broad range of testimony emerged from this study. As the testimonies have revealed, the participants' agency and identity were well in-tact due to their international capital and solid familial ties. The accounts in this study can be read in multiple ways and could be taken as a reflection of the naivety of youth, the value of a happy life or as evidence of individualism (Hoskins and Barker 2014: 97). The young people in this study brought with them the social and cultural capital that framed their self-perceptions and aspirations (Smith 2014: 3).

These narratives of meritocracy involved the participants' discussions of their own aspirations, success and imagined futures, infused with the language of hard work and individualism (Harvey et al 2015: 14; Xie 2015: 31). Young people in these circumstances are quite aware of the world around them, have a broad world view, possess a 'transnational competence' (Johnson et al 2011: 503) and see the benefits a global lifestyle can offer them. They are in a permanent state of transformation and adaptation which are a reflection of the society in which we live today (Grinberg 2013: 201). Their 'habitus' is functional in familial contexts yet cumulative and generative in new circumstances; both stable and conservative and yet profoundly dynamic (Noble 2013: 344). The participants' experience of living in a world of privilege does not limit their ability to see themselves as 'Other'. The participants are aware of their position in society and appreciate their unique circumstances. They do not appear to be materialistic in that they did not communicate that they place too high a value on money, possessions, appearances, or fame (James 2013: 12). 
At the heart of this study is that in adjusting to new cultures and surroundings, as well as experiencing adolescence, the young person in the international school is engaged in many facets of identity development. The participants' concepts of their identities are understood as a core aspect of their individual selfhoods and a product of multiple and competing discourses (Brubaker and Cooper 2000: 7-8). All of the participants move between national and transnational spaces and displayed 'emotional connections of being and belonging' (Nayak 2010: 2389). Their extensive travelling experiences also contribute to their cosmopolitan capital and a sense of who they are becoming. Central to this is the recognition that, whilst these young people are moving away from their homeland in some instances, this does not result in the divorce of these young people from their national territory and they have strong ideas of nationhood. This is of course aided by the technological advances of a globalised world and their families' financial abilities to allow their children frequent visits and access to these 'homelands'.

The participants' identities are comprised of many facets, which are not in absolute isolation from one another. The participants, whilst undergoing the cognitive and emotional changes of adolescence, are also balancing both a deeply personal and foundational identity with fluctuating, multiple and changing identities given their circumstances. Therefore they fit in because they are 'insider outsiders', who find place by grappling with the differences of difference (Noble 2013: 355).

Female and male participants were equally likely to stress personal happiness and contentment with intrinsically rewarding future careers. As both the boys and girls expressed similar aspirations in the interviews, there does not appear to be a gender difference in their visions of their future selves. However it must be recognised that the sample size was limited and that, in the case of these participants, it is class which has a greater influence on their aspirations than gender. This is in contrast to the conclusions of Barni et al (2011) who wrote that the socialisation of boys and girls differs. They put forth that girls give more value to the importance of relationships whilst boys give more importance to values related to agency and power (Barni et al 2011: 107). The participants are also not limited in their thinking as to what their 
future lives will be like. On the contrary, both boys and girls in this study offered clear, confident and concise life plans and ways forward.

I would like to briefly discuss how the findings align. Firstly, these families' privileged positions permit and provide for the elite schooling experiences of their children, as well as the vast travel experiences they are afforded. Secondly, as the interview data shows, friends from other cultures play a significant role in why the participants perceive the international schooling experience to be so rewarding. Thirdly, the fact that these young people travel causes both an appreciation of their own personal home culture and an opportunity to reflect on their own identity through the exposure to other cultures. Finally, these young people have instilled in them a strong belief that attending this type of elite school is a sound investment in their futures and truly appreciate being surrounded by other cultures and points of view.

\subsection{The Originality of the Study}

A key contribution of this study, much like that of the work of Rose and Baird (2013), is the use of a more open-ended approach to studying young people's aspirations, allowing the importance of life satisfaction and young people's definitions of success to factor in to their 'future selves' concept (Rose and Baird 2013: 169). The methodological stance, from the perspective of the young people themselves, reflects an under used approach to studying aspirations. The study makes an important sociological contribution to our understanding of agency in adolescence, highlighting how this particular cohort of young people imagine their futures within an intersection of multiple influences and a globalised lifestyle.

This project offers a novel approach to examining the identities of young people attending an international school by gathering their personal perspectives. It is also an original contribution to knowledge as it offers a new emphasis on both local and expatriate international school students' own perceptions of the influences on their aspirations, identities and future thinking. The study offers a new sample population, students in an international school context, whose view is often invisible and is in a new geographical location, Belgium. Klimstra et al (2012) suggested that a crosscultural comparison of personal identity formation, parenting and the linkages 
between personal identity formation and parenting may provide an important avenue for future research. This study goes some way in resolving the gap in that area of research by comparing identity formation across cultures in an international school.

\subsection{Professional Relevance to International Education and Implications of the Study}

Schools should be places of democracy, community, trust and solidarity. This study has the potential to have implications in the ways in which those in international schools relate to the students in their care and help them to recognise their own aspirations. Education is a paternalistic project that perpetuates authoritarian teacher/student relationships and challenging this can create democratic schooling environments (Keddie 2014b: 317). Providing learning environments that accord all a voice is a cornerstone of democratic schooling (Keddie 2014b: 314). Students may feel more closely connected to their school environment when teachers take the time to encourage their voices and listen to their points of view and perspectives. The participants expressed an appreciation about being given the opportunity to talk about their lives in this study. Children in international schools have not been given a voice in a project such as this, which looked for their feelings and insights into what factors they perceive influences their aspirations and identities. This project offers a deeper insight into the resources and strategies this cohort of young people draw upon for pursuing their future possibilities (Zipin et al 2013: 5).

International schools can help students to develop a moral judgement competence, seen as a core competence for democracy (Bienengraber 2014: 536). Other approaches that could be associated with democratic competencies are moral courage, character education, assertiveness and self-control (Bienengraber 2014: 538). International schools would do well to examine the inclusion of such topics into their curricula.

These findings point to the need to strengthen the skills and capacities of young people on the path to adulthood as well as to improve the effectiveness of the institutions through which they move (Settersen Jr. and Ray 2010: 20). Schools can also further foster that agentic aspiration in their students so that they perceive the affordances of their future lives. 
Young people with an expansive future self-concept are able to vision boldly and exhibit a sense of hopefulness about their futures (Prince 2013: 3). There exists an opportunity for international schools to modify their curricula in a way which can name and frame aspirations to help students' ways of being and seeing (Kenway and Hickey-Moody 2011: 162). Empowering young people will not only help these students reflect upon their current and future selves, but will also help those in international schools better understand and serve their students. Allowing students more opportunities to reflect upon their histories is also a starting point for new approaches to child-centred learning. There is a need for schools to pay greater attention to the relationships and social networks that young people have and perceive these young people as individuals with future possibilities (Arshad 2012: 206). I would position international school teachers in the 'middle of these interactions' (Tarc and Tarc 2015: 34).

Elite schools can develop students' understandings of themselves as significant players on regional, national or global stages (Kenway and Fahey 2014: 193). International schools can also clarify their mission as to what they are trying to achieve with their students. For instance, is there an express intention to develop a sense of global citizenship and social responsibility? This project can serve as a useful reflective tool for teachers to explicitly think about the very conceptions of what it means to be a justice oriented privileged person; one who understands injustice and feels a sense of empowered agency to make a change (Swalwell 2013: 9).

Testing and examinations have become a technology of classification, division and exclusion, which make the learner visible, calculable and manageable (Ball 2015: 299). Schools designed to control and standardise are unlikely to have thriving school communities (Thomas 2015: 46). In today's climate of high stakes educational testing, we must not forget the importance of global education, approaching globalisation pedagogically and the moral obligation we have to educate about issues which affect all of us, so that young people can function in our globalised, socially diverse and multicultural world (Johnson et al 2011: 515; Myers 2010: 154; James 2015: 102). 
Opportunities that prepare young people to educate others, advocate for and be a voice for those who are underrepresented or underprivileged are potentially powerful ways to help young people develop a sense of political leadership (Malin et al 2015: 48). Schools do little to educate students about inequality in the world (Flanagan 2014: 423) and doing so may go some way to reducing the social and class divisions which these schools are perceived to create. Inequality is more than the lack of income or capital, it is about how people suffer due to their lack of power and is ultimately about social injustice (Jones 2014: 731). A strong democratic civic education program rooted in social justice, social trust, tolerance and the common good is important work in an increasingly self-segregated society with a widening gap between the rich and the poor (Swalwell 2013: 10; Flanagan 2014: 424). Linked to this is the possibility for international schools to better educate students about both social class privilege and disadvantage. This carries on the argument made by White et al (2013) and Williams and Carter (2014) who suggest improved teacher training and professional development with regards to inequality and social class (White et al 2013: 385). It was remarked by one participant in this study that students in international schools are encouraged to think for themselves and possess the confidence to speak out. Perhaps global injustices and inequalities can be the issues for young people in international schools to highlight.

As students are both consumers of the service of education and the producers of the school's outcomes, their involvement is fundamental to all improvement. Ethical policy would support young people in developing critical awareness of the advantages and disadvantages of the different future pathways they consider (Hart 2012a: 183). Schools are about connecting young people to their futures and ensuring they are well-equipped to face them (Thomas 2015: 43). All parties involved in international schools should strive to serve their students to the best of their capabilities and empower them to achieve their imagined futures, which for this cohort of students involved in this study, included the importance of happiness. Part of this empowerment is careers guidance for students aged 13-14 and could be done through pastoral care programs which nurture students' existing aspirations in school and helps them work toward clear and achievable goals in life. Education and the 
development of career thinking are intertwined and young people value information on jobs and careers and through such experience can be better prepared to make the education and training decisions that shape their futures (Hooley et al 2015: 3; Heseltine 2012: 166). This information could include work-place visits, mentoring, mock interviews, competitions as well as careers advice (U.K.C.E.S. 2012: 4). Providing students with contact with professional people in a working environment and making referrals to other professionals who can help them further could prove very successful (Hooley et al 2015: 22).

Careers guidance can help privileged young people better see themselves in relation to the perceived opportunities they believe lie ahead of them. International schools should look at all options for their students, after secondary school completion, so as not to give the impression that university constitutes a higher aspiration than leaving school to do something else (Hart 2012a: 183). Hart (2012a: 183) points out the ethical questions raised about how schools guide individuals in terms of their identity construction and aspirational development. This relates back to the importance of teachers knowing students and developing strong, mentoring relationships with them.

It has been claimed that children and young people are expressing fear of failure at increasingly younger ages (P.S.H.E. Association 2015: 25). Guidance in how to deal with frustration, disappointment and rejection could also aid this cohort of young people in making career decisions which are the right fit for them (Law 1996: 95). After all, not every one of the participants will necessarily be working in the professions they mentioned in this study and they need to be resilient in the face of loss, setback or rejection. Young people could greatly benefit from information based on a wide range of career options and international schools are in a position to provide such valuable guidance.

As Apple (2001: 410) writes, education must begin in critical dialogue, open to rigorous questioning in order to create a truly democratic education. By listening to students' perspectives and taking their experiences more seriously, educators can re-assess the importance of student voice in their own learning environment and those in international schooling can improve their practice of serving these first world citizens. 
There exists an opportunity for those that work in international schools to review their practice in working with transient and affluent young people. Such professional responsibility can be reinforced by teacher professional development courses in child psychology and in-service training. Furthermore, where international displacements put young people in social environments for which their upbringing did not prepare them, or where they feel a unique pressure to fit in, those who work closely with them can help those young people adjust and cope (Lee and Kramer 2013: 19). These people who work closely with young people can include teachers, counsellors, special educators, librarians, nurses, secretaries and other educational support staff who may be directly or indirectly related to the educational content of the school (Frelin and Grannas 2015: 66).

An ideal school would foster the emotional and learning needs of newly relocated students through a nurturing atmosphere, with teaching staff who are reflexive about their own biases (Hacohen 2012: 123). The vast majority of international school teachers have domestic qualifications and upbringing and the total output of teachers undertaking specialist programs available in international education is limited (Pearce 2013b: 63). There is an opportunity for international schools to re-examine the qualifications they wish their teaching staff to possess before hiring them. I would propose four main recommendations for policy makers, leaders and governance of international schools.

1. Some teachers find it difficult to communicate with their students. International schools would do well to consider professional development for teachers and teacher leaders in empathy and relationship-building in both the work-place and in the classroom.

2. Have child psychology and behavioral psychology courses compulsory components of teacher professional development programs.

3. Offer students professional guidance in their choice of subjects and on career/university decisions in the early years of secondary school. Waiting until the end of high school can be too late (Orthner et al 2009: 267).

4. It would be unrealistic to expect that provision for vocational education in this regard could ever be very extensive within the current international school 
structures, but there is every possibility of exploring the possibility of vocational courses so they are fit for purpose in the modern age, and offering such subjects to students aged 14-19 who may have a more practical inclination for their occupational aspiration. This is possible without compromising the needs of high academic achievers heading for elite universities such as the U.S. Ivy League, Grandes Écoles and Oxbridge. The emphasis in this scenario would be on meeting individual preferences and needs and allowing wider choice across subject streams (Hayden and Thompson 2013: 20).

Schools in the $21^{\text {st }}$ century need to become more responsive to the broadening array of cultures, languages and experiences of their student populations (Tomlinson 2015: 1). Globalisation is seen to mean the school now has to understand itself as a strategic actor on a global as well as a national stage (Kenway and Fahey 2014: 190). The 'home country' privileged families are increasingly opting for international schools where students learn about multiculturalism and follow their studies in the English language. International schools have the opportunity to improve their practice of fostering internationally minded interpersonal qualities in both its staff and students (Van Oord 2008: 132). International schools can capitalise on diversity by becoming practice grounds for intergroup encounters, broadening youth perspectives about the interdependence of their fates with the fates of others (Van Oord 2008: 132; Flanagan 2014: 423). Skills such as openness, empathy, humility, tolerance of diverse opinions and the ability to engage productively in society are valued in the labour market, in school and in society at large (Kautz et al 2014: 2). Living in diverse communities such as the international schooling environment helps young people to open up and become more tolerant as well as learning from others. Schools can therefore look at how they develop strategies for the complex existence of intergroup difference. This intercultural model responds to every democratic society's ethical requirement of respect for the rights of every citizen and their representation in social and political life (Miravet and Garcia 2013: 1383).

International educators can aid in supporting young people's intercultural skills they acquire abroad and help young people become aware of what they are learning, to 
further increase their chances of employability (Messelink et al 2015: 70). The concept of 'interculturalism' focusses less on difference and more on integration and internationalism. Intercultural learning can also help one develop one's own identity. The participants in this study dispense with past language about difference and recognise that the world is made up of just 'one human race' (Cantle 2012: 41). They see the 'world as their home' and 'support everyone', endorsing a more intercultural view of the world, one that is more fair and reflective of an increasingly globalised world which emphasises what holds societies together rather than differences between communities (Cantle 2012: 41; Faas et al 2014: 301).

Today's international school students are the diplomats of tomorrow who will broker peace through their ability to empathise and interact with those of different cultural backgrounds (Hayden 2011: 221). This study allowed for young people to relate and share their stories and if more of that kind of practice was encouraged in international schools, a more accepting atmosphere and thereby a more peaceful world, could then be created. International schools have a social and educational responsibility to transform pedagogy and curriculum to promote values of social justice, equity and supporting students to become 'righteous and good' (Faas et al 2014: 306; Soutter 2014: 532). In addition, so much learning for these young people is done outside of the classroom, is not 'visible' to educators and is not currently recognised (MacDonald 2013: 52). If we take students' life experiences into account, and well as their global competencies and mass socialisation, we can then find new ways of measuring whether they are likely to be part of the solutions to the world's problems and be justice oriented citizens who question and challenge the status quo (Young 2014: 40; Griffiths and Arnove 2015: 91; Ghosh 2015: 25).

\subsection{Recommendations for Further Research}

This study has highlighted some issues that lend themselves to further investigation. Based upon reflection of the study, I would like to offer some recommendations for further research. Firstly, this study is based on only twenty participants. A large scale study within one or across international schools based on personal interviews and histories of the participants would prove useful and test the transferability of this one 
case study school. That sort of project would require sponsorship and funding beyond obvious sources. As Van Houtte and Stevens (2010) comment in their study of the aspirations of immigrant students in Belgian state schools, more research is needed into the factors that help shape students' aspirations in ethically heterogeneous schools (Van Houtte and Stevens 2010: 233). In addition there is scope to further explore gendered aspirations and how young females and males learn to talk about themselves and envisage their future lives.

It would also be useful for a future study to compare the aspirational dispositions of students attending international schools with local students attending local schools in their home country. Another such study could compare the aspirations of local students attending local schools with local students attending international schools within the same country. These kinds of studies could open up the discussion of aspirations beyond the mobile and transient young person and provide greater insight into the impacts of the international school on local young people of a certain socioeconomic background. Additionally, a study which compares the aspirations of the privileged to underprivileged young people both in Belgium and in other geographical contexts would be useful to conduct. There is a need for further research to examine the interplay between the individual and the school environment (Furlong et al 2003: 101). There is room for further research into these issues.

I would also echo Hansen (2014: 478) and her call for global studies into wealth mobility among the wealthiest people. Following some students as they return to their respective 'homelands' could also prove an interesting study as often people returning to their home country realise that their identity is changed and they are not the person they were before they left (Noble 2013: 350).

Further research into the concept of the 'world state' would prove useful (Biswas 2002: 196). World culture theorists take the stance that global social change is not driven by nation-states but rather from the wider world and that globalisation, with its shared values of progress and justice, is the next phase in educational models (Rappleye 2015: 59; Silova and Rappleye 2015: 1; Takayama 2015: 35). The idea of the nation state and its future in a globalised world is a salient topic to explore. I would 
echo Silova and Rappleye (2015) and their call for more robust and rich exchanges over globalisation and its effects on education (Silova and Rappleye 2015: 7).

The international school landscape is changing rapidly and substantively (Bunnell et al 2016: 26). The phenomenon of international schools is certain to increase (Hayden 2011: 221). Further research is urgently needed if the world is to understand the impact of international education as the twenty-first century progresses. For instance, the impact international schools may have on national education systems and the claim that international schools may indeed be contributors to a growing social inequality in societies (Hayden 2011: 221; Resnik 2008: 148). National forms of education are increasingly including international dimensions in recognition that the future for which school-age students are being prepared can no longer be assumed to be constrained by national boundaries (Hayden and Thompson 2013: 17). There is room for further research in this area. There is also room for exploration into why local parents in Belgium choose international schools over local schools. I would also echo the call for more research on the careers, professional development and professional identities of teachers in international schools (Bailey 2015b: 4).

One participant in the study compared the European School system to that of the International School system. There is room to explore how multicultural learning is taught in a comparative study of both systems in Belgium.

There are also opportunities for further research on the interplay between adolescence, belonging, privilege, social justice and transience in the international schooling context. Research in these areas can also provide an opportunity for current and future international school students to examine their own lives and aid educators in the development of more effective ways of understanding the lives of young people.

I anticipate that my findings will stimulate research which explores these and other issues dealing with international education. 


\subsection{Personal Reflection}

I have been teaching in international schools for 18 years. I set out at the beginning of this doctoral study to obtain perspectives from young people on the factors they felt influenced their identities and aspirations as they move through transnational spaces. I had been intrigued by this issue for many years of my teaching career and realised this was somewhat uncharted territory in my field. I began by reviewing the literature around identities, aspirations, social capital and international schooling and the interplay between them. I then constructed and conducted a small scale pilot study using four of my own students in my former place of work. Based on the experience and reflection of the pilot study, I went on to plan and conduct the main study and to write this doctoral thesis.

I wanted to give my students a voice; both for themselves and to improve my own practice. I interviewed 20 young people in my classroom on two occasions, using two methods to ensure validity. These were students of mine at my place of work. From the participants' 'treasures of insight' (Molloy 2015: 474), I decided that these young people's interview responses and narrative data could be categorised into two main themes: Relationships and International Privilege, with each of these main themes having their own three sub-themes: Home, Family and Friends and Travel, International Schooling and The Future. I concluded from the main study that this cohort of young people were optimistic about their futures, secure in their present selves and agentic about being able to be successful and in control of their lives. Their sense of self is grounded in strong familial relationships and they enjoy the privileges of their globalised and elite lifestyles. There are implications from this work in the areas of careers guidance and pastoral care for educators who work closely with students in these circumstances. A study on a larger scale could potentially shed further light on some on the issues raised using this one school as a case study.

My close personal involvement with the young people who so kindly gave up their time to speak with me throughout the course of the study has intensified my initial interest in the aspirations and identities of young people. I have grown and evolved both professionally and personally as a result of undertaking this doctoral degree. I 
have become a student again, and as a result I have a new empathy with my own students whom I teach and a renewed curiosity into how it is we all learn and evolve as individuals. We truly are all unique, each with our special narrative and in various stages of becoming. Everyone is capable of much more than they think.

It goes without saying that I have also developed optimal time management skills and a new appreciation for down time and the importance of relaxation and 'switching off'. As those of you reading this know all too well, an endeavour such as this requires persistence, optimism, focus, sacrifice, energy and passion in high abundance. I have also become very familiar with Microsoft Word!

I see my day to day work with young people through a new lens. In my teaching practice I have become more child-centred, attempting to see all issues from the perspective of the child and how I can best serve him or her. This has resulted in very interesting staff meeting experiences when colleagues discuss and debate policy, curriculum and discipline. However, I believe it is vital that all educators take all of their decisions with the first priority being the child's welfare and well-being in mind. I have also developed new thoughts into the teacher, the learner and the curriculum and the 'spaces in between' which affect our educational experiences. It has given me pause to reflect and to never underestimate the role of social situations for student learning. Learning is challenging, sometimes uncomfortable and should always raise more questions than it answers.

I have been kindly welcomed into the academic community when presenting my work at conferences and contributing to journals and on-line academic blogs. I have had articles published in both the National Institute for Career Education and Counselling Journal and the on-line journal 'The Bridge'. I also contributed to the British Educational Research Association's blog on Respecting Children and Young People. Feedback from peers and colleagues in the academic community has helped me to examine my research, writing and presentation style. Additionally, I have been fortunate to meet some extremely analytical and insightful people who have directed me to readings in education, politics and philosophy which have inspired my teaching practice. 
After having reflected on what the participants so generously shared in their interviews, I have re-examined my priorities in life and what constitutes my own sense of happiness and personal success. Issues such as empathy, community, charity, solidarity, acceptance, social justice and tolerance, which I hope were part of my character before the study, are now seen through a more informed and thoughtful lens. Perhaps most importantly, the doctoral experience has allowed my attitude to and practice of classroom teaching to grow and my views on education to evolve. I truly hope the students I presently teach and will teach in the future have experienced and will experience the benefits of this evolution. I encourage them to keep hoping, keep dreaming and keep desiring. 


\section{Appendices}

Table One: Issues and Themes from the Pilot Study

\begin{tabular}{|l|l|}
\hline Issues & Theme \\
\hline $\begin{array}{l}\text { Teachers, school atmosphere, school } \\
\text { presenters, appreciation of differences }\end{array}$ & $\begin{array}{l}\text { Schooling (Discussed in depth by all } \\
\text { participants) }\end{array}$ \\
\hline $\begin{array}{l}\text { Sports, media, home country, moving, } \\
\text { identity }\end{array}$ & $\begin{array}{l}\text { Identity (Discussed in depth by two of } \\
\text { four) }\end{array}$ \\
\hline Education and College, success, careers & The Future (Discussed in depth by all) \\
\hline Parents, family, adults & Family (Discussed in depth by all) \\
\hline $\begin{array}{l}\text { Friends, losing friends, making new } \\
\text { friends }\end{array}$ & $\begin{array}{l}\text { Friends (Discussed in depth by three of } \\
\text { four) }\end{array}$ \\
\hline
\end{tabular}

\section{Parental Consent Form}

Title of Study: An investigation into how a globalised lifestyle, international capital and an international schooling experience shape the identities and aspirations of young people.

Researcher: Jonathan Young

Doctorate of Education Student at the University of Leicester, UK.

Supervisor: Dr. Joan Smith, University of Leicester, UK.

\section{The Study}

Under the supervision and permission of Leicester University in the UK, I wish to carry out a study into what students feel influences their aspirations in an international school setting. I wish to interview the students on two occasions, for up to 30 minutes each interview. The students will be asked to collect up to 10 photographs over the course of their participation in the project. They will use these photographs as 
discussion springboards, explaining why they chose them and how what is in the photograph affects their aspirations and image of their future self.

\section{Risks}

There are no risks involved to your child in participating in this study.

\section{Confidentiality}

The information gathered from this study will be kept strictly confidential. Your child's real name will not be used in the report and all files, transcripts and data will be stored in a locked cabinet and no one except myself will have access to them. Your child's name will not be used and any identifying personal information will be avoided.

\section{Direct Benefits}

Your child will benefit from taking part in a research project which allows them the opportunity to reflect upon their future selves, analyse their schooling environment and critically ponder what and who influences their aspirations.

\section{Alternatives}

Your child is free to choose not to participate in this research study and to opt out of the study at any time of their, or even your choosing.

\section{Consent}

I have been given a copy of this consent form to keep.

PARTICIPATION IN THIS RESEARCH STUDY IS VOLUNTARY.

My child is free to decline to participate in this research study, or I may withdraw their participation at any point without penalty. Their decision whether or not to participate in this research study will have no influence on their present or future status at the school.

My child has my consent to participate in this 
educational research study into students perspectives to what influences their aspirations.

Parent/Guardian:

Date:

Contact Details Below:

Jonathan Young

Chemin du Vossegat 5

1180 Brussels, Belgium 
Table Two- The Participants of the Main Study (M-Male/F-Female)

\begin{tabular}{|c|c|c|c|c|c|c|}
\hline Name & $\begin{array}{l}\text { Sex } \\
M / F\end{array}$ & $\begin{array}{l}\text { Country of } \\
\text { Birth* }\end{array}$ & $\begin{array}{l}\text { Country on } \\
\text { Passport* }\end{array}$ & $\begin{array}{l}\text { Years } \\
\text { in } \\
\text { Present } \\
\text { School* }\end{array}$ & $\begin{array}{l}\text { First } \\
\text { Language* }\end{array}$ & $\begin{array}{l}\text { Parents' } \\
\text { Home } \\
\text { Countries* }\end{array}$ \\
\hline Anya & $\mathrm{F}$ & Poland & Poland & 2 & Polish & Poland (2) \\
\hline Allie & $\mathrm{F}$ & Belgium & $\begin{array}{l}\text { Belgium/South } \\
\text { Africa }\end{array}$ & 2 & French & $\begin{array}{l}\text { South Africa } \\
\text { and } \\
\text { Lebanon }\end{array}$ \\
\hline Melanie & $\mathrm{F}$ & UK & UK & 11 & English & $\begin{array}{l}\text { Ireland and } \\
\text { UK }\end{array}$ \\
\hline Minty & $\mathrm{F}$ & Switzerland & Switzerland & 5 & French & $\begin{array}{l}\text { Switzerland } \\
\text { and Iran }\end{array}$ \\
\hline Bobbi & $\mathrm{F}$ & Belgium & UK & 3 & English & $\begin{array}{l}\text { Ireland and } \\
\text { UK }\end{array}$ \\
\hline Mary & $\mathrm{F}$ & UK & $\begin{array}{l}\text { Canada/France/ } \\
\text { Germany } \\
\text { Belgium }\end{array}$ & 1 & French & $\begin{array}{l}\text { Canada and } \\
\text { France }\end{array}$ \\
\hline Gabby & $\mathrm{F}$ & USA & Ireland/USA & 3 & English & USA (2) \\
\hline Valerie & $\mathrm{F}$ & Belgium & Belgium & 8 & French & Belgium (2) \\
\hline Doreen & $\mathrm{F}$ & Norway & Norway & 3 & Norwegian & Norway (2) \\
\hline Sandra & $\mathrm{F}$ & Germany & Germany & 3 & German & $\begin{array}{l}\text { Germany } \\
(2)\end{array}$ \\
\hline Juan & $M$ & Spain & Spain & 2 & Spanish & Spain (2) \\
\hline Jaap & $M$ & $\begin{array}{l}\text { The } \\
\text { Netherlands }\end{array}$ & $\begin{array}{l}\text { The } \\
\text { Netherlands }\end{array}$ & 3 & Dutch & $\begin{array}{l}\text { The } \\
\text { Netherlands } \\
\text { (2) }\end{array}$ \\
\hline Karl & $M$ & Denmark & Denmark & 3 & Danish & $\begin{array}{l}\text { Denmark } \\
(2)\end{array}$ \\
\hline Felipe & $\mathrm{M}$ & Argentina & Argentina & 2 & Spanish & $\begin{array}{l}\text { Argentina } \\
(2)\end{array}$ \\
\hline
\end{tabular}




\begin{tabular}{|l|l|l|l|l|l|l|}
\hline Mel & M & China & France & 8 & French & $\begin{array}{l}\text { France and } \\
\text { Germany }\end{array}$ \\
\hline Micky & $\mathrm{M}$ & Belgium & France & 4 & French & $\begin{array}{l}\text { Italy and } \\
\text { France }\end{array}$ \\
\hline Hector & $\mathrm{M}$ & Uganda & Tanzania & 3 & English & Tanzania (2) \\
\hline Osawa & $\mathrm{M}$ & UK & Japan & 8 & Japanese & Japan (2) \\
\hline Johan & $\mathrm{M}$ & Sweden & Sweden & 4 & Swedish & Sweden (2) \\
\hline Louis & $\mathrm{M}$ & Belgium & Belgium & 11 & French & Belgium (2) \\
\hline
\end{tabular}

*I asked the participants to give me the above information at the beginning of their first interview.

Table Three: Issues and Themes from the Main Study

Themes within this table were mentioned by all of the participants in the Main Study.

\begin{tabular}{|l|l|}
\hline Issues & Themes \\
\hline Being happy with what you do, & Success \\
\hline $\begin{array}{l}\text { Parents, sisters, brothers, grandparents, } \\
\text { uncles, cousins }\end{array}$ & Family \\
\hline Friends & Friends \\
\hline Media & Identity \\
\hline $\begin{array}{l}\text { Horseback riding, swimming, harp, } \\
\text { tennis, judo, acrobatics, piano, volleyball, } \\
\text { gymnastics, skiing, ballet, golf, } \\
\text { skateboarding, acting, track and field, } \\
\text { choir, soccer, cross country, motorsports, } \\
\text { wakeboarding, sailing, basketball, } \\
\text { hockey, karate }\end{array}$ & Activity \\
\hline \begin{tabular}{l} 
Education, Perspectives \\
\hline
\end{tabular} & International Schooling Experiences \\
\hline
\end{tabular}


Transience

Table Four-Categories of Aspirations

\begin{tabular}{|l|l|l|}
\hline Type of Aspiration & Example & $\begin{array}{l}\text { Number of participants } \\
\text { expressing such an } \\
\text { aspiration }\end{array}$ \\
\hline Traditional and Long Term & $\begin{array}{l}\text { Educational and } \\
\text { Occupational }\end{array}$ & 16 \\
\hline $\begin{array}{l}\text { Locially Responsible and } \\
\text { Long Term }\end{array}$ & $\begin{array}{l}\text { Wanting to improve global } \\
\text { warming and global } \\
\text { politics }\end{array}$ & 2 \\
\hline $\begin{array}{l}\text { Personal and Medium } \\
\text { Term }\end{array}$ & $\begin{array}{l}\text { Expressing a hope to travel } \\
\text { and be near friends upon } \\
\text { finishing secondary school }\end{array}$ & 2 \\
\hline
\end{tabular}

Table Five- Categories of the Participants

\begin{tabular}{|l|l|l|l|l|}
\hline Type & $\begin{array}{l}\text { Local Student } \\
(2)\end{array}$ & $\begin{array}{l}\text { Locally Born } \\
\text { Foreigner (3) }\end{array}$ & $\begin{array}{l}\text { Ex-pat Veteran } \\
\text { (5) }\end{array}$ & $\begin{array}{l}\text { First Time Ex- } \\
\text { patriate (10) }\end{array}$ \\
\hline $\begin{array}{l}\text { Names of } \\
\text { Participants }\end{array}$ & Valerie, Louis & $\begin{array}{l}\text { Allie, Melanie, } \\
\text { Bobbi }\end{array}$ & $\begin{array}{l}\text { Minty, Mary, } \\
\text { Anya, Osawa, } \\
\text { Micky }\end{array}$ & $\begin{array}{l}\text { Gabby, Juan, } \\
\text { Mel, Doreen, } \\
\end{array}$ \\
& & $\begin{array}{l}\text { Sandra, Johan, } \\
\text { Karl, Hector, } \\
\text { Jaap, Felipe }\end{array}$ \\
\hline
\end{tabular}


Table Six -Other Themes mentioned by some but not all of the participants in the Main Study.

\begin{tabular}{|c|c|c|}
\hline Theme & $\begin{array}{l}\text { Number of Participants } \\
\text { who mentioned it }\end{array}$ & Names of participants \\
\hline Religion & 5 & $\begin{array}{l}\text { Johan, Gabby, Val, Max, } \\
\text { Hector }\end{array}$ \\
\hline Divorce & 2 & Sandra, Allie \\
\hline Media & 3 & Doreen, Hector, Jaap \\
\hline Adoption & 1 & Mel \\
\hline Birthdays & 2 & Johan, Minty \\
\hline Charity Work & 2 & Val, Bobbi \\
\hline Cultural Traditions & 3 & Anya, Jaap, Felipe \\
\hline Death & 2 & Val, Gabby \\
\hline Belonging in Belgium & 3 & Bobbi, Karl, Melanie \\
\hline $\begin{array}{l}\text { Belonging in International } \\
\text { Schools }\end{array}$ & 5 & $\begin{array}{l}\text { Melanie, Micky, Jaap, } \\
\text { Bobbi, Allie }\end{array}$ \\
\hline University & 7 & $\begin{array}{l}\text { Jaap, Micky, Felipe, Allie, } \\
\text { Mel, Louis, Val }\end{array}$ \\
\hline Career & 11 (6 girls and 5 boys) & $\begin{array}{l}\text { Minty (scientist), Anya } \\
\text { (vet), Karl (pilot), Gabby } \\
\text { (politics), Melanie (artist), } \\
\text { Sandra (doctor), Johan } \\
\text { (acting), Hector } \\
\text { (architect), Felipe } \\
\text { (engineer), Juan (banking), } \\
\text { Allie (lawyer) }\end{array}$ \\
\hline Global Responsibility & 2 & Minty, Gabby \\
\hline
\end{tabular}




\section{Further Evidence from the Participants' Interviews Regarding their Views on}

\section{International Schooling}

Sandra: ...I think it (international schooling) gives me a wider view on the world, also, and more opportunities for the future ... I know much more people from all over the world here, I will have a better chance and know more what I am doing now than before and I am also getting a better education...

Osawa: I think an international school gives you an ability to interact with kids from other countries so I think that's the good thing of having an international school so you can be more like (15 second pause) interact I think, interact with many other people not only people in your country so I think it's important to like interact with people in other countries and to learn with them...

Mel:...it gives us the language... and you meet a lot of people from a lot of different cultures...

Bobbi: it gives me so much freedom to meet to new people and see their culture or where they come from and people always move around, I think that is the sad part but I think you just have to accept it and new people come and people go but there will be some people who stay and that is good but I want to come back to what I said, there are so many cultures maybe you can be part of the culture maybe, you know a bit more about it and maybe it will help you to accept it and I think people are really accepted here because everybody is different no matter where they come from and this school is so accepting, accepting anyone who wants to come no matter where they are from or what their differences are... what I realise the difference is between an international school and a European School or just any other schools, when I first came here I was really British...my accent has changed, when I first came here everyone was like 'its soccer not football'...it is very Americanised...the students definitely do that...it is one of the weaker parts...

Gabby: it was really fast ...but my parents were really excited to come here, they didn't have to but they really wanted to but when they were asked if they wanted to they were really excited to give us the opportunity and they were mostly excited about the language, the aspects of travel and the culture so there are a lot of really great new 
experiences that we get here ... with all the young cousins, to miss being a part of their life but there are so many benefits that we are getting here that it balances in a way and we'll be back with them, we have the rest of our lives to spend with them so I am really grateful that we have gotten this opportunity... because living overseas isn't normal...

Anja: ...in America usually everybody's American you know in schools that are like country schools you would call them they have only local people that don't really have the chance to travel a lot, there are pros and cons to both I guess but in an international school you can meet a bunch of people, discover new cultures but also share yours... think it is an advantage because you can see a lot of people's perspectives or what they do and it is interesting because if you are like in a school with only like the same people, its kinda like how some people think being the same should not be allowed because it is really boring, so a state school has someone from the state but not like from China or Africa or different countries like that ...

Karl:...it definitely gives me a mix of the whole world, like the cultures of the whole world...it definitely lets me learn different languages...

Doreen: ...very many insights on culture, language and different opinions from like where they have been raised and how they have been raised and I have always been interested in culture because when I lived in Oslo there weren't many people from a lot of different countries...

Jaap:...it also brings in new cultures, like new things that I never knew about and it's good to see how much cultures are and how there's not racism and stuff like that, in my old school it could get a bit racist...

Hector:...it gives me a new way of thinking, like thinking and learning, like really good qualities...so it helps me grow more in education.

Felipe:.. a lot of opportunities really... I am a really lucky person because not a lot of people have this opportunity to learn the things we do in this school. 


\section{References}

Abbas, T. (2015) Book Review: The Muslims are Coming: Islamophobia, Extremism and The Domestic War on Terror, Sociology, DOI: 10.1177/0038038515573398.

Acemoglu, D. and Pischke, J-S. (2001) Changes in the Wage Structure, Family Income and Children's Education, European Economic Review, 45, 890-904.

Achor, S. (2010) The Happiness Advantage, New York: Crown Business.

Adami, R. (2014) Re-thinking Relations in Human Rights Education: The Politics of Narratives, Journal of Philosophy of Education, 48 (2), 293-307.

Adler, P. and Adler, P. (2012) How Many Qualitative Interviews is Enough?: Expert Voices and Early Career Reflections on Sampling and Cases in Qualitative Research, in S. Baker and R. Edwards (eds.) National Centre for Research Methods Review Paper: Economic and Social Research Council.

Aguiar, A. and Nogueira, M.A. (2012) Internationalisation Strategies of Brazilian Private Schools, International Studies in Sociology of Education, 22 (4), 353-368.

Ahmed, S. (2008) Sociable Happiness, Emotion, Space and Society, 1, 10-13. Ahmed, S. (2010) The Promise of Happiness, London: Duke University Press. Albert, D. and Steinberg, L. (2011) Judgment and Decision Making in Adolescence, Journal of Research on Adolescence, 21 (1), 211-224.

Aldridge, J. and Ala'I, K. (2013) Assessing Students' Views of School Climate: Developing and Validating the What's Happening in This School? (WHITS) Questionnaire, Improving Schools, 16, 47-66.

Alexander, C., Edwards, R. and Temple, B. (2007) Contesting Cultural Communities: Language, Ethnicity and Citizenship in Britain, Journal of Ethnic and Migration Studies, 33 (5), 783-800. 
Alexander, H. (2013) Caring and Agency: Noddings on Happiness in Education, Educational Philosophy and Theory, 45 (5), 488-493.

Ali, S. (2012) 'Visual Analysis', in C. Seale (ed.) Researching Society and Culture, $3^{\text {rd }}$ edition, London: Sage, pp. 283-301.

Alipio, C., Lu, M.C.W. and Yeoh, B.S.A. (2015) Asian Children and Transnational Migration, Children's Geographies, 13 (3), 255-262.

Allan, G. (2008) Friendship, Flexibility and Family, Personal Relationships, 15, 1-16. Allen, K. and Hollingworth, S. (2013) 'Sticky Subjects' or 'Cosmopolitan Creatives'? Social Class, Place and Urban Young People's Aspirations for Work in the Knowledge Economy, Urban Studies, 50, 499-517.

Allen, K. and Mendick, H. (2013) Keeping it Real? Social Class, Young People and 'Authenticity' in Reality TV, Sociology, 47, 460-476.

Allen, Q. (2012) Photographs and Stories: Ethics, Benefits, and Dilemmas of Using Participant Photography with Black Middle Class Male Youth, Qualitative Research, 12, 443-458.

Alvesson, M. and Ashcraft, K. L. (2012) "Interviews", in G. Symon and C. Cassell (eds.), Qualitative Organisational Research. London: Sage, pp. 239-257.

Amplify et al (2013) What WE Say We Need, A Report Looking at the Basic Items, Opportunities and Aspirations that are Important to Young People, London: Office of the Children's Commissioner.

Anders, J. (2012) The Link Between Household Income, University Applications and University Attendance, Fiscal Studies, 33 (2), 185-210.

Anders, J. and Micklewright, J. (2013) Teenagers' Expectations of Applying to University: How Do They Change? London: Institute of Education, University of London.

Antonsich, M. (2010) Searching for Belonging-An Analytical Framework, Geography Compass, 4 (6), 644-659. 
Appadurai, A. (2004) "The Capacity to Aspire: Culture and the Terms of Recognition", in R. Vijayendra and M. Walton (eds.) Culture and Public Action. Stanford: Stanford University Press, pp. 59-84.

Apple, M. (2001) Comparing Neo-liberal Projects and Inequality in Education, Comparative Education, 37 (4), 409-423.

Apple, M. (2011) Global Crises, Social Justice and Teacher Education, Journal of Teacher Education, 62, 222-234.

Apple, M. (2013) Can Education Change Society? New York: Routledge.

Archer, L., DeWitt, J., and Wong, B. (2013) Spheres of Influence: What Shapes Young People's Aspirations at Age 12/13 and What are the Implications for Educational Policy?, Journal of Education Policy, DOI: 10.1080/02680939.2013.790079.

Arnett, J.J. (2006) G. Stanley Halls Adolescence: Brilliance and Nonsense, History of Psychology, 9 (3), 186-197.

Arrington, K. (2000) Middle Grades Career Planning Programs, Journal of Career Development, 27, 103-109.

Arshad, R. (2012) "Commentary: Schools and Social Capital: Implications for Practice", in J. Allan and R. Catts (eds.), Social Capital, Children and Young People. Bristol: The Policy Press, pp. 199-208.

Ashley, L., Duberley, J., Sommerlad, H. and Scholarios, D. (2015) A Qualitative Evaluation of Non-Educational Barriers to the Elite Professions, London: Social Mobility and Child Poverty Commission.

Ashton, D., Brown, P., and Lauder, H. (2010) Skill Webs and International Human Resource Management: Lessons from A Study of The Global Skill Strategies of Transnational Companies, The International Journal of Human Resource Management, $21(6), 836-850$.

Aspires (2013) Young People's Science and Career Aspirations, Age 10-14, London: Department of Education and Professional Studies. 
Atherton, G., Cymbir,E., Roberts, K., Page, L. and Remedios, R. (2009) How Young People Formulate Their Views about the Future, Research Report DCSF-RR152, London: University of Westminster.

Ayalon, A. (2011) Teachers as Mentors: Models for Promoting Achievement with Disadvantaged and Underrepresented Students by Creating Community, Sterling, VA: Stylus.

Baggini, J. (2007) Welcome to Everytown: A Journey into the English Mind, London: Granta.

Bagnall, N. (2012) National or Global: The Mutable Concepts of Identity and Home for International School Students, Prospects, 42, 177-190.

Bagnoli, A. (2009) Beyond the Standard Interview: The Use of Graphic Elicitation and Arts-Based Methods, Qualitative Research, 9, 547-570.

Bailey, L. (2015a) The Experiences of Host Country Nationals in International Schools: A Case Study from Malaysia, Journal of Research in International Education, 14 (2), 8597.

Bailey, L. (2015b) Reskilled and 'Running Ahead': Teachers in an International School Talk About Their Work, Journal of Research in International Education, 14 (1), 3-15.

Bainbridge, D. (2009) Teenagers: A Natural History, London: Portobello.

Baker, W., Sammons, P., Siraj-Blatchford, I., Sylva, K., Melhuish, E.C. and Taggart, B. (2014) Aspirations, Education and Inequality from The Effective Provision of PreSchool, Primary and Secondary Education Project, Oxford Review of Education, 40 (5), $525-542$.

Bal, E. and Willems, R. (2014) Introduction: Aspiring Migrants, Local Crises and the Imagination of Futures 'Away from Home', Identities: Global Studies in Culture and Power, 21 (3), 249-258.

Ball, S. (2013) Foucault, Power and Education, London: Routledge. 
Ball, S. (2015) Education, Governance and The Tyranny of Numbers, Journal of Education Policy, 30 (3), 299-301.

Ballet, J., Biggeri, M. and Comim, F. (2011) “Children's Agency and the Capability Approach: A Conceptual Framework", in M. Biggeri, J. Ballet and F. Comim (eds.), Children and the Capability Approach. Basingstoke, UK: Palgrave MacMilllian, pp. 2245.

Barbalet, J. (2014) Globalization and Cosmopolitanism: Continuity and Disjuncture, Contemporary and Historical, Journal of Sociology, 50, 199-212.

Barni, D., Ranieri, S., Scabini, E. and Rosnati, R. (2011) Value Transmission in the Family: Do Adolescents Accept the Values Their Parents Want to Transmit?, Journal of Moral Education, 40 (1), 105-121.

Basit, T. (2003) Manual or Electronic? The Role of Coding in Qualitative Data Analysis, Educational Research, 45, (2), 143-154.

Basit, T. (2014) Educational Capital and Generational Aspirations Amongst British Asians, British Educational Research Journal, 8, 1-4.

Batchelor, D. (2006) Becoming What You Want To Be, London Review of Education, 4 (3), 225-238.

Bates, J. (2013) Administrator Perceptions of Transition Programs in International Secondary Schools, Journal of Research in International Education, 12, 85-102.

Bates, R. (2011) “Introduction", in R. Bates (ed.) Schooling Internationally: Globalisation, Internationalisation and The Future for International Schools. Oxon: Routledge, pp. 1-20.

Bates, R. (2012) Is Global Citizenship Possible, and Can International Schools Provide It, Journal of Research in International Education, 11 (3), 262-274.

Baumeister, R. and Leary, M. (1995) The Need to Belong: Desire for Interpersonal Attachments as a Fundamental Human Motivation, Psychological Bulletin, 117, (3), 497-529. 
Bayramoglu, G. and Sahin, M. (2015) Positive Psychological Capacity and Its Impacts on Success, Journal of Advanced Management Science, 3 (2), 154-157.

Beal, S. and Crockett, L. (2013) Adolescents' Occupational and Educational Goals: A Test of Reciprocal Relations, Journal of Applied Developmental Psychology, 34, 219229.

Beaty-O'Ferrall, M.E., Green, A. and Hanna, F. (2010) Classroom Management Strategies for Difficult Students: Promoting Change Through Relationships, Middle School Journal, 41 (4), 4-11.

Beavis, C. (2013) Young People, New Media and Education: Participation and Possibilities, Social Alternatives, 32 (2), 39-44.

Beck, U. and Beck-Gernsheim, E. (2002) Individualization, London: Sage.

Belfi, B., Gielen, S., De Fraine, B., Verschueren, K. and Meredith, C. (2015) SchoolBased Social Capital: The Missing Link Between Schools' Socioeconomic Composition and Collective Teacher Efficacy, Teaching and Teacher Education, 45, 33-44.

Belk, R.W. (1985) Materialism: Trait Aspects of Living in The Material World, Journal of Consumer Research, 12, 265-280.

Beneito-Montagut, R. (2011) Ethnography Goes Online: Towards a User-Centred Methodology to Research Interpersonal Communication on the Internet, Qualitative Research, 11 (6), 716-735.

Bennett, J. (2011) Conference Workshop: Developing Intercultural Competence For International Education Faculty and Staff, San Francisco: A.I.E.A.

Berbary, L. (2013) Too Good at Fitting In: Methodological Consequences and Ethical Adjustments, International Journal of Qualitative Studies in Education, DOI: 10.1080/09518398.2013.820856.

Berger, R. (2015) Now I See It, Now I Don't: Researcher's Position and Reflexivity in Qualitative Research, Qualitative Research, 15 (2), 219-234. 
Berngruber, A. (2015) 'Generation Boomerang' in Germany? Returning to the Parental Home in Young Adulthood, Journal of Youth Studies, 18 (10), 1274-1290.

Bernstein-Yamashiro, B. and Noam, G.G. (2013) Teacher-Student Relationships: A Growing Field of Study, New Directions for Youth Development, 137, 15-26.

Bessant, J. and Watts, R.W. (2014) 'Cruel Optimism': A Southern Theory Perspective in The European Union's Youth Strategy, 2008-2012, International Journal of Adolescence and Youth, 19 (S1), 125-140.

Biddle, E. (2010) Meeting a Patient as a Singular Event, Aporia, 2 (3), 18-23.

Bienengraber, T. (2014) Educating Competencies for Democracy, Journal of Moral Education, 43 (4), 536-539.

Biesta, G. (2014) "Who Knows?: On the Ongoing Need to Ask Critical Questions About The Turn Towards Evidence in Education and Related Fields", in K.B. Peterson, D. Reimer and A. Qvortrup (eds.), Evidence and Evidence Based Education in Denmark. Copenhagen: Aarhus University Department of Education, pp.19-26.

Biesta, G. and Tedder, M. (2006) How is Agency Possible? Towards an Ecological Understanding of Agency-As-Achievement, Learning Lives, Working Paper 5.

Billig, M. (1992) Talking of the Royal Family, London: Routledge.

Billig, M. (1995) Banal Nationalism, London: Sage.

Biswas, S. (2002) Whither the Nation State? National and State Identity in the Face of Fragmentation and Globalisation, Global Society, 16 (2), 175-198.

Blakemore, S.J. and Mills, K.L. (2014) Is Adolescence a Sensitive Period for Sociocultural Processing?, Annual Review of Psychology, 65, 9.1-9.21.

Blanden, J. and MacMillan, L. (2014) Education and Intergenerational Mobility: Help or Hindrance?, London: Centre for Analysis and Social Exclusion.

Blaxter, L., Hughes, C. and Tight, M. (2010) How to Research, New York: Open University Press. 
Block, D. (2013) The Structure and Agency Dilemma in Identity and Intercultural Communication Research, Language and Intercultural Communication, 13 (2), 126147.

Blum, L. (2013) Political Identity and Moral Education: A Response to Jonathan Haidt's The Righteous Mind, Journal of Moral Education, 42 (3), 298-315.

Blum, L. (2014) Three Educational Values for a Multicultural Society: Difference Recognition, National Cohesion and Equality, Journal of Moral Education, 43 (3), 332334.

Blunt, A. and Dowling, R. (2006) Home, London: Routledge.

Bok, J. (2010) The Capacity to Aspire to Higher Education: 'It's Like Making Them Do a Play Without a Script', Critical Studies in Education, 51 (2), 163-178.

Borgen, W. and Hiebert, B. (2006) Career Guidance and Counselling for Youth: What Adolescents and Young Adults are Telling Us, International Journal Advising Counselling, 28, 389-400.

Bourdieu, P. (1977) Outline of a Theory of Practice, Cambridge: Cambridge University Press.

Bourdieu, P. (1984) Distinction: A Social Critique of the Judgement of Taste, London: Routledge.

Bourdieu, P. (1985) The Social Space and The Genesis of Groups, Theory and Society, 14 (6), 723-744.

Bourdieu, P. (1986) "The Forms of Capital" in J.G. Richardson (ed.), Handbook for the Theory and Research for the Sociology of Education. New York: Greenwood Press, pp. 241-258.

Bourdieu, P. (1990a) The Logic of Practice, Stanford: Stanford University Press. Bourdieu, P. (1990b) Photography: A Middle Brow Art, Cambridge: Polity Press. Bourdieu, P. (2000) Pascalian Meditations, Stanford, CA: Stanford University Press. 
Bourdieu, P. (2005) The Social Structures of the Economy, Cambridge: Polity Press.

Bowker, A. (2004) Predicting Friendship Stability During Early Adolescence, Journal of Early Adolescence, 24 (2), 85-112.

Bowles, S. and Gintis, H. (1975) The Problem with Human Capital Theory-A Marxian Critique, The American Economic Review, 65 (2), 74-82.

Boyask, R. (2013) Theorising the Democratic Potential of Privatised Schools Through the Case of Free Schools, ACCESS: Critical Perspectives on Communication, Cultural and Policy Studies, 1\&2, 11-26.

Boyden, J. (2013) 'We're Not Going to Suffer Like This in The Mud': Educational Aspirations, Social Mobility and Independent Child Migration Among Populations Living in Poverty, Compare: A Journal of Comparative and International Education, $\mathbf{4 3}$ (5), 580-600.

Bradshaw, R. (2014) Democratic Teaching: An Incomplete Job Description, Democracy and Education, 22 (2), 1-5.

Bray, M. and Yamato, Y. (2003) Comparative Education in a Microcosm: Methodological Insights from The International Schools Sector in Hong Kong, International Review of Education, 49 (1-2), 51-73.

Briggs, A. and Coleman, M. (2007) Research Methods in Educational Leadership and Management, London: Sage.

British Educational Research Association (2011) Ethical Guidelines for Educational Research, London: B.E.R.A.

Brown, G. (2011) Emotional Geographies of Young People's Aspirations for Adult Life, Children's Geographies, 9 (1), 7-22.

Brown, P., Lauder, H. and Ashton, D. (2010) The Global Auction: The Broken Promises of Education, Jobs and Incomes, Oxford: Oxford University Press.

Brubaker, R. and Cooper, F. (2000) Beyond 'Identity', Theory and Society, 29, 1-47. 
Bruhlmeier, A. (2010) Head, Heart and Hand: Education in The Spirit of Pestalozzi, London: Sophia Books.

Brummitt, N. and Keeling, A. (2013) "Charting the Growth of International Schools", in R. Pearce (ed.), International Education and Schools: Moving Beyond the First Forty Years. London: Bloomsbury, pp. 25-36.

Bryant, J. and Ellard, J. (2015) Hope As a Form of Agency in The Future Thinking of Disenfranchised Young People, Journal of Youth Studies, 18 (4), 485-499.

Bryk, A. and Schneider, B. (2002) Trust in Schools: A Core Resource for School Improvement, New York: Russell Sage Foundation.

Bryman, A. (2012) Social Research Methods, Oxford: Oxford University Press.

Bunkse, E. (2004) Geography and The Art of Life, Baltimore, MD: The John Hopkins University Press.

Bunnell, T. (2005) Perspectives on International Schools and The Nature and Extent of Local Community Contact, Journal of Research in International Education, 4, 43-63.

Bunnell, T. (2006) The Growing Momentum and Legitimacy Behind an Alliance for International Education, Journal of Research in International Education, 5, 155-176.

Bunnell, T. (2008) The International Baccalaureate in England and Wales: The Alternative Paths For the Future, The Curriculum Journal, 19 (3), 151-160.

Bunnell, T. (2010a) The Momentum Behind The International Primary Curriculum in Schools in England, Journal of Curriculum Studies, 42 (4), 471-486.

Bunnell, T. (2010b) The International Baccalaureate and A Framework for Class Consciousness: The Potential Outcomes of A 'Class-For-Itself', Discourse: Studies in The Cultural Politics of Education, 31 (3), 351-362.

Bunnell, T. (2011) The International Baccalaureate Middle Years Programme After 30 Years: A Critical Inquiry, Journal of Research in International Education, 10, 261-274. 
Bunnell, T. (2015a) Teachers in International Schools: A Global Educational 'Precariat'?, Globalisation, Societies and Education, DOI: 10.1080/14767724.2015.1068163.

Bunnell, T. (2015b) The Rise and Decline of The International Baccalaureate Diploma Programme in The United Kingdom, Oxford Review of Education, 41 (3), 387-403.

Bunnell, T., Fertig, M. and James, C. (2015) The Institutionalisation of International Schools: An Illustration and Development of An Analytical Framework, Paper Presented at the British Educational, Leadership, Management and Administration Society (BELMAS) Annual Conference, Wokefield Park, Reading, July 2015.

Bunnell, T., Fertig, M. and James, C. (2016) What is International About International Schools?: An Institutional Legitimacy Perspective, To Be Published in Oxford Review of Education (Preprint).

Burgess, H., Sieminski, S., and Arthur, L. (2006) Achieving Your Doctorate in Education, London: Sage.

Burridge, P. (2014) Understanding Teachers' Pedagogical Choice: A Sociological Framework Combining The Work of Bourdieu and Giddens, Educational Studies, 40 (5), 571-589.

Busher, H. (2012) Students as Expert Witnesses of Teaching and Learning, Management in Education, 26 (3), 113-119.

Busher, H. and Watling, R. (2003) Preparing for Research in Theory and Practice: Validity and Reliability, Leicester: University of Leicester.

Cahill, K. (2011) What Class Are You In? A Study of Social Class, School, Choice and Identity, The Boolean, 26-30.

Caletrio, J. (2012) Global Elites, Privilege and Mobilities in Post-Organised Capitalism, Theory, Culture and Society, 29, 135-149.

Calhoun, C. (1997) Nationalism, Buckingham: Open University Press.

Cambridge, J. and Thompson, J.J. (2004) Internationalism and Globalisation as Contexts for International Education, Compare, 34 (2), 161-175. 
Campbell, C. (2015) The Socioeconomic Consequences of Dropping Out of High School: Evidence From an Analysis of Siblings, Social Science Research, 51, 108-118.

Cantle, T. (2011) Cohesion and Integration: From 'Multi' to 'Inter' Culturalism, Montreal: Symposium International sur L'interculturalisme.

Cantle, T. (2012) Interculturalism: For the Era of Globalisation, Cohesion and Diversity, Political Insight, 3 (3), 38-41.

Caputo, J. (2013) Truth: Philosophy in Transit, London: Penguin.

Carmo, R.M., Cantante, F. and de Almeida Alves, N. (2014) Time Projections: Youth and Precarious Employment, Time and Society, 23 (3), 337-357.

Carney, J., Niles, S. and Trusty, J. (2005) Education-Career Planning and Middle School Counsellors, Professional School Counselling, 9 (2), 136-144.

Carr, S. (2014) Book Review: Interpersonal Relationships in Education: An Overview of Contemporary Research, Journal of Research in International Education, 13, 76-77.

Carrier, A., Louvet, E., Chauvin, B. and Rohmer, O. (2014) The Primacy of Agency Over Competence in Status Perception, Social Psychology, 45 (5), 347-356.

Carter, T. and Gilovich, T. (2012) I Am What I Do, Not What I Have: The Differential Centrality of Experiential and Material Purchases to the Self, Journal of Personality and Social Psychology, 102 (6), 1304-1317.

Castex, G. and Kogan-Dechter, E. (2014) The Changing Roles of Education and Ability in Wage Determination, Journal of Labour Economics, 32 (4), 685-710.

Caviedes, A. (2015) An Emerging 'European' News Portrayal of Immigration?, Journal of Ethnic and Migration Studies, 41 (6), 897-917.

Cebulla, A. and Tomaszewski, W. (2013) The Demise of Certainty: Shifts in Aspirations and Achievement at the Turn of the Century, International Journal of Adolescence and Youth, 18 (3), 141-157. 
Charmaz, K. (2012) How Many Qualitative Interviews is Enough?: Expert Voices and Early Career Reflections on Sampling and Cases in Qualitative Research, in S. Baker and R. Edwards (eds.) National Centre for Research Methods Review Paper: Economic and Social Research Council.

Charmaz, K. (2014) Grounded Theory in Global Perspective: Reviews by International Researchers, Qualitative Inquiry, 20, 1074-1084.

Chase, S.E. (1995) "Taking Narrative Seriously: Consequences for Method and Theory in Interview Studies", in R. Josselson and A. Lieblich (eds.), Interpreting Evidence: The Narrative Study of Lives. Thousand Oaks, CA: Sage, pp. 1-26.

Choi, J.K. (2015) Identity and Language: Korean Speaking Korean, Korean-American Speaking Korean and English?, Language and Intercultural Communication, 15 (2), 240266.

Chow, A., Krahn, H.J. and Galambos, N.L. (2014) Developmental Trajectories of Work Values and Job Entitlement Beliefs in The Transition to Adulthood, Developmental Psychology, 50 (4), 1102-1115.

Church, A., Katigbak, M., Locke, K., Zhang, H., Shen, J., Jesus Vargas-Flores, J., IbanezReyes, J., Tanaka-Matsumi, J., Curtis, G., Cabrera, H., Mastor, K., Alvarez, J., Ortiz, F., Slmon, J. and Ching, C. (2012) Need Satisfaction and Well-Being: Testing SelfDetermination Theory in Eight Cultures, Journal of Cross Cultural Psychology, published online 8 November 2012, 1-28.

Clavin, P. (2005) Defining Transnationalism, Contemporary European History, 14 (4), 421-439.

Clifton, J., Thompson, S., and Thorley, C. (2014) Winning the Global Race?: Jobs, Skills and the Importance of Vocational Education, London: Institute for Public Policy Research.

Coats, C. (2015) Thinking Through the Photographic Encounter: Engaging with the Camera as Nomadic Weapon, International Journal of Education and The Arts, 15 (9), $1-23$. 
Coffey, A. (2013) Relationships, The Key to Successful Transition from Primary to Secondary School?, Improving Schools, 16, 261-271.

Coffey, J. and Farrugia, D. (2013) Unpacking the Black Box: The Problem of Agency in the Sociology of Youth, Journal of Youth Studies, DOI:

10.1080/13676261.2013.830707.

Cohen, J. (2013) The Private Life, London: Granta.

Cohen, L., Manion, L., and Morrison, K. (2011) Research Methods in Education, London: Routledge.

Coleman, J.S. (1988) Social Capital in the Creation of Human Capital, American Journal of Sociology, 94, Supplement: Organizations and Institutions: Sociological and Economic Approaches to the Analysis of Social Structure, S95-S120.

Commission on Social Mobility and Child Poverty Commission (2014) Elitist Britain?, London: U.K. Government.

Cook, D.T. (2015) A Politics of Becoming: When 'Child' is Not Enough, Childhood, 22 (1), 3-5.

Cook-Sather, A. (2009) "I Am Not Afraid to Listen"-Prospective Teachers Learning from Students, Theory into Practice, 48 (3), 176-183.

Corcoran, T. (2014) Are the Kids Alright? Relating to Representations of Youth, International Journal of Adolescence and Youth, DOI: 10.1080/02673843.2014.881296. Cordingley, P. (2015) The Contribution of Research to Teachers' Professional Learning and Development, Oxford Review of Education, 41 (2), 234-252.

Cottrell-Studemeyer, C. (2015) Geographies of Flexible Citizenship, Geography Compass, 9/10, 565-576.

Crawford, C. (2014) The Link Between Secondary School Characteristics and University Participation and Outcomes, University of Warwick: Department for Education. 
Cremin, H., Mason, C., and Busher, H. (2011) Problematising Pupil Voice Using Visual Methods: Findings From a Study of Disaffected Pupils in an Urban Secondary School, British Educational Research Journal, 37 (4), 585-603.

Crocetti, E., Erentaite, R. and Zukauskiene, R. (2014) Youth Development and Civic Engagement in Adolescence, Journal of Youth and Adolescence, 43, 1818-1828.

Crocetti, E., Rubini, M., Luyckx, K. and Meeus, W. (2008) Identity Formation in Early and Middle Adolescents From Various Ethnic Groups: From Three Dimensions to Five Statuses, Journal of Youth and Adolescence, 37, 983-996.

Croghan, R., Griffin, C., Hunter, J., and Phoenix, A. (2008) Young People's Constructs of the Self: Notes on the Use of Analysis of the Photo-Elicitation Methods, International Journal of Social Research Methodology, 11 (4), 345-356.

Cronin, A. (2014) Between Friends: Making Emotions Intersubjectively, Emotion, Space and Society, 10, 71-78.

Cross, M. (2013) Young People and the Course of Ordinariness, British Journal of Guidance and Counselling, 41 (1), 89-90.

Crow, L. (2013) The Photograph, Qualitative Inquiry, DOI: 10.1177/1077800413505550.

Cuiting, L., and Kerpelman, J. (2007) Parental Influences on Young Women's Certainty about Their Career Aspirations, Sex Roles, 56, 105-115.

Dallavis, C. (2013) Qualifying Sociopolitical Consciousness: Complicating Culturally Responsive Pedagogy for Faith-Based Schools, Education and Urban Society, 45, 266284.

Davidson, E. (2008) Marketing the Self: The Politics of Aspiration Among Middle Class Silicon Valley Youth, Environment and Planning, 40, 2814-2830.

Davidson, J., Dottin Jr., J., Penna, S., and Robertson, S. (2009) Visual Sources and the Qualitative Dissertation: Ethics, Evidence, and the Politics of Academia-Moving 
Innovation in Higher Education from the Centre to the Margins, International Journal of Education and the Arts, 10 (27), 1-40.

Davies, P., Qiu, T. and Davies, N.M. (2014) Cultural and Human Capital, Information and Higher Education Choices, Journal of Education Policy, 29 (6), 804-825.

Deardorff. D. (2011) Assessing Intercultural Competence, New Directions for Institutional Research, 149, 65-79.

Deleuze, G. (1995) Negotiations: 1972-1990, New York: Columbia University Press.

Deleuze, G. and Guattari, F. (1987) A Thousand Plateaus, London: Bloomsbury.

Deveney, B. (2005) An Investigation into Aspects of Thai Culture and Its Impact on Thai Students in an International School in Thailand, Journal of Research in International Education, 4 (2), 153-171.

de Vries, R. and Rentfrow, J. (2016) A Winning Personality: The Effects of Background on Personality and Earnings, London: The Sutton Trust.

Dewaard, J. (2015) Beyond Group-Threat: Temporal Dynamics of International Migration and Linkages to Anti-Foreigner Sentiment, Journal of Ethnic and Migration Studies, 41 (7), 1041-1067.

DiAngelo, R. and Sensoy, O. (2014) Leaning In: A Student's Guide to Engaging Constructively with Social Justice Content, Radical Pedagogy, 11 (1), 1-15.

Diener, E. (1984) Subjective Well-Being, Psychological Bulletin, 95 (3), 542-575.

Dildar, S.M., UI Hassan, N., Ali, G. and Sher Juni, M. (2015) English Language as Culture, Class and Power: Explaining the English as a Medium of Education in the Education System of Pakistan, International Journal of Research, 2 (2), 1-10.

Dittmar, H., Bond, R. and Hurst, M. (2014) The Relationship Between Materialism and Personal Well-Being: A Meta-Analysis, Journal of Personality and Social Psychology, 107 (5), 879-924.

Dodson, K. (2015) Globalization and Protest Expansion, Social Problems, 62, 15-39. 
Doherty, C., Luke, A., Shield, P. and Hincksman, C. (2012) Choosing Your Niche: The Social Ecology of The International Baccalaureate Diploma in Australia, International Studies in Sociology of Education, 22 (4), 311-332.

Dolby, N. (2012) Afterword: A Research Agenda for International Education, International Studies in Sociology of Education, 22 (4), 369-374.

Dolby, N. and Rahman, A. (2008) Research in International Education, Review of Educational Research, 78 (3), 676-726.

Domenech-Betoret, F. and Gomez-Artiga, A. (2014) The Relationship Among Students' and Teachers' Thinking Styles, Psychological Needs and Motivation, Learning and Individual Differences, 29, 89-97.

Doncaster, K. and Thorne, L. (2000) Reflection and Planning: Essential Elements of Professional Doctorates, Reflective Practice, 1 (3), 391-399.

Donnelly, M. (2014) The Road to Oxbridge: Schools and Elite University Choices, British Journal of Educational Studies, 62 (1), 57-72.

Dorling, D. (2010) The Myth of Inherited Inequality, Fabian Review, 122 (1), 19-21.

Dorling, D. (2011) Injustice, Bristol: The Policy Press.

Duberley, J., Johnson, P. and Cassell, C. (2012) “Philosophies Underpinning Qualitative Research", in G. Symon and C. Cassell (eds.), Qualitative Organisational Research. London: Sage, pp. 15-34.

du Bois, J.W. (1991) Transcription Design Principles for Spoken Discourse Research, Pragmatics, 1, 71-76.

Duff, P. (2012) "Issues of Identity", in A. Mackey and S. Gass (eds.), The Routledge Handbook of Second Language Acquisition. London: Routledge, pp. 410-426.

Dufur, M.J., Parcel, T.L., and Troutman, K.P. (2010) Does Capital at Home Matter More Than Capital at School? Social Capital Effects on Academic Achievement, Research in Social Stratification and Mobility, DOI: 10.1016/j.rssm.2012.08.002. 
Dugonjic, L. (2014) 'A Miniature League of Nations': Inquiry into The Social Origins of The International School, 1924-1930, Paedagogica Historica: International Journal of the History of Education, 50 (1-2), 138-150.

Dupriez, V., Monseur, C., Campenhoudt, M. and Lafontaine, D. (2012) Social Inequalities of Post-Secondary Educational Aspiration: Influence of Social Background, School Composition and Institutional Context, European Educational Research Journal, 11 (4), 504-519.

Eccles, J. (1999) The Development of Children Ages 6-14, The Future of Children, 9 (2), 30-44.

Eccles, J. (2009) Who Am I and What Am I Going to Do With My Life? Personal and Collective Identities as Motivators of Action, Educational Psychologist, 44 (2), 78-89.

Edwards, R. and Gillies, V. (2012) Farewell to Family? Notes on an Argument for Retaining the Concept, The Policy Press, 1 (1), 63-69.

Eidse, F. and Sichel, N. (2004) "Introduction", in F. Eidse and N. Sichel (eds.), Unrooted Childhoods: Memoirs of Growing Up Global. London: Nicholas Brearley Publishing, pp. 1-6.

Eglinton, K. (2013) Between the Personal and the Professional: Ethical Challenges When Using Visual Ethnography to Understand Young People's Use of Popular Visual Material Culture, Young, 21, 253-271.

Elgar, F.J. and Aitken, N. (2010) Income Inequality, Trust and Homicide in 33 Countries, European Journal of Public Health, 21 (2), 241-246.

Elliott, A. and Urry, J. (2010) Mobile Lives, London: Routledge.

Erden, S. and Ummet, D. (2014) Examination of High School Students' Learned Resourcefulness: A Review of Gender, Parental Attitudes and Values, International Online Journal of Educational Studies, 6 (1), 72-82.

Erel, U. (2010) Migrating Cultural Capital: Bourdieu in Migration Studies, Sociology, 44, 642-660. 
Ergen, A., Baykan, B.G. and Turan, S. G. (2015) Effect of Materialism and

Environmental Knowledge on Environmental Consciousness Among High School

Students: A Study Conducted in Istanbul Province, International Journal of Human

Science, 12 (1), 511-526.

Erickson, L., McDonald, S. and Elder, G. (2009) Informal Mentors in Education:

Complementary or Compensatory Resources?, Sociology of Education, 82, 344-367.

Erikson, E.H. (1962) Youth: Fidelity and Diversity, Daedalus, 91 (1), 5-27.

European Commission (2014) Horizon 2020: Work Programme 2014-2015, Brussels: European Commission.

European Youth Press (2014) Ideas for a Better Europe: EYE 2014 Report, Brussels:

European Parliament.

Ezra, R. (2003) Culture, Language and Personality in the Context of the Internationally Mobile Child, Journal of Research in International Education, 2, 123-149.

Ezra, R.(2007) Caught between Cultures: A Study of Factors Influencing Israeli Parents' Decisions to Enrol Their Children at an International School, Journal of Research in International Education. 6, 259-286.

Faas, D. (2009) Reconsidering Identity: The Ethnic and Political Dimensions of Hybridity Among Majority and Turkish Youth in Germany and England, The British Journal of Sociology, 60 (2), 299-320.

Faas, D., Hajisoteriou, C. and Anegelides, P. (2014) Intercultural Education in Europe: Policies, Practices and Trends, British Educational Research Journal, 40 (2), 300-318.

Fail, H., Thompson, J., and Walker, G. (2004) Belonging, Identity and Third Culture Kids: Life Histories of Former International School Students, Journal of Research in International Education, 3, 319-338.

Farmer, G. (2001) Longitudinal Exploration of the Caste Theory of Educational Aspirations, Children and Schools, 23 (3), 160-170.

Farrell, A. (2005) Ethical Research with Children, New York: The Open University Press. 
Farrugia, D. (2013) Young People and Structural Inequality: Beyond the Middle Ground, Journal of Youth Studies, 16 (5), 679-693.

Ferrante, F. (2009) Education, Aspirations and Life Satisfaction, KYKLOS, 62 (4), 542562.

Ferrare, J.J. and Apple, M. W. (2015) Field Theory and Educational Practice: Bourdieu and The Pedagogic Qualities of Local Field Positions in Educational Contexts, Cambridge Journal of Education, 45 (1), 43-59.

Field, J. (2005) Social Capital and Lifelong Learning, Bristol: The Polity Press.

Fielding, M. (2012) Education as if People Matter: John MacMurray, Community and the Struggle for Democracy, Oxford Review of Education, 38 (6), 675-692.

Findlay, A.M., King, R., Smith, F.A., Geddes, A and Skeldon, R. (2012) World Class? An Investigation of Globalization, Difference, and International Student Mobility, Transactions of the Institute of British Geographers, 37 (1), 118-131.

Finlay, A.K., Wray-Lake, L., Warren, M. and Maggs, J. (2014) Anticipating Their Future: Adolescent Values For the Future Predict Adult Behaviors, International Journal of Behavioral Development, DOI: 10.1177/0165125414544231.

Flaherty, M.G. (2012) Age and Agency: Time Work Across the Life Course, Time and Society, 22 (2), 237-253.

Flanagan, C. (2014) Teaching a Larger 'Sense of Community', Analyses of Social Issues and Public Policy, 14 (1), 423-425.

Fletcher, A. (2005) Meaningful Student Involvement: Guide to Students as Partners in School Change, Olympia, WA: Human Links Foundation.

Floersch, J., Longhofer, J., Kranke, D., and Townsend, L. (2010) Integrating Thematic, Grounded Theory and Narrative Analysis: A Case Study of Adolescent Psychotropic Treatment, Qualitative Social Work, 9, 407-425. 
Flouri, E. and Panourgia, C. (2012) Do Primary School Children's Career Aspirations Matter? The Relationship Between Family Poverty, Career Aspirations, and Emotional and Behavioural Problems, London: Centre for Longitudinal Studies.

Flouri, E., Tsivrikos, D., Akhtar, R. and Midouhas, E. (2015) Neighbourhood, School and Family Determinants of Children's Aspirations in Primary School, Journal of Vocational Behavior, 87, 71-79.

Forbes, J. and Lingard, B. (2015) Assured Optimism in a Scottish Girls' School: Habitus and The (Re) Production of Global Privilege, British Journal of Sociology of Education, 36 (1), 116-136.

Foresight (2013) Future Identities: Changing Identities in the UK: The Next Ten Years, London: The Government Office for Science.

Foucault, M. (2003) Abnormal: Lectures at the College de France 1974-1975, London: Verso.

Fram, S. (2013) The Constant Comparative Analysis Method Outside of Grounded Theory, The Qualitative Report, 18 (1), 1-25.

France, A. and Haddon, E. (2014) Exploring the Epistemological Fallacy: Subjectivity and Class in The Lives of Young People, Young, 22, 305-321.

Frelin, A. and Grannas, J. (2015) Direct and Indirect Educational Relationships: Developing a Typology for The Contribution of Different Categories of School Staff in Relation to Students' Educational Experiences, Improving Schools, 18 (1), 56-68.

Friedman, S. (2012) Cultural Omnivores or Culturally Homeless? Exploring the Shifting Cultural Identities of the Upwardly Mobile, Poetics, 40, 467-489.

Friedman, S. (2013) The Price of the Ticket: Rethinking the Experience of Social Mobility, Sociology, DOI: 10.1177/0038038513490355.

Frost, M. (2007) Texas Students' College Expectations: Does High School Racial Composition Matter?, Sociology of Education, 80, 43-66. 
Furlong, M.J., Whipple, A.D., St. Jean, G., Simental, J. Soliz, A. and Punthuna, S. (2003) Multiple Contexts of School Engagement: Moving Toward a Unifying Framework for Educational Research and Practice, The California School Psychologist, 8, 99-113.

Gadamer, H. (2013) Truth and Method, London: Bloomsbury.

Gale, K. (2013) Action Research and the Assemblage: Engaging Deleuzian Pedagogy and Inquiry Beyond the Contraints of the Individual and the Group in Education Settings, International Journal of Qualitative Studies in Education, http://dx.doi.org/10.1080/09518398.2013.805447.

Gale, T. and Parker, S. (2015) Calculating Student Aspiration: Bourdieu, Spatiality and The Politics of Recognition, Cambridge Journal of Education, 45 (1), 81-96.

Garcia, P.R.J.M., Restubog, S.L.D., Bordia, P., Bordia, S. and Roxas, R.E.O. (2015) Career Optimism: The Roles of Contextual Support and Career Decision-Making Self-Efficacy, Journal of Vocational Behavior, 88, 10-18.

Garg, R., Kauppi, C., Lewko, J. and Urajnik, D. (2002) A Structural Model of Educational Aspirations, Journal of Career Development, 29, 87-108.

Gaztambide-Fernandez, R. and Howard, A. (2014) Social Justice, Deferred Complicity and the Moral Plight of the Wealthy, Democracy and Education, 21 (1), 1-4.

Gee, J.P. (1999) Introduction to Discourse Analysis: Theory and Method, London: Routledge.

Gee, J.P. (2000) Identity as an Analytic Lens for Research in Education, Review of Research in Education, 25, 99-125.

Gemici, S., Lim, P. and Karmel, T. (2013) The Impact of Schools on Young People's Transition to University, Adelaide: NCVER.

Ghosh, S. (2015) Learning From Community: Agenda for Citizenship Education, Education, Citizenship and Social Justice, 10 (1), 21-36.

Gibbs, P. (2015) Happiness and Education: Troubling Students for Their Own Contentment, Time and Society, 24 (1), 54-70. 
Giddens, A. (1984) The Constitution of Society, Los Angeles: University of California Press.

Giddens, A. (1991) Modernity and Self Identity, Stanford CA: Stanford University Press. Gilding, M. (2010) Reflexivity Over and Above Convention: The New Orthodoxy in the Sociology of Personal Life, Formerly Sociology of the Family, The British Journal of Sociology, 61 (4), 757-777.

Ginevra, M.C., Nota, L., Soresi, S., Shogren, K., Wehmeyer, M., and Little, T. (2013) A Cross Cultural Comparison of the Self-Determination Construct in Italian and American Adolescents, International Journal of Adolescence and Youth, DOI:

10.1080/02673843.2013.808159.

Gitlin, A. (2008) Cultivating the Qualitative Research Borderlands: Educational Poetics and the Politics of Inclusivity, International Journal of Qualitative Studies in Education, $21(6), 627-645$.

Glaser, B. (1965) The Constant Comparative Method of Qualitative Analysis, Social Problems, 12 (4), 436-445.

Glaser, B. and Holton, J. (2007) Remodeling Grounded Theory, Historical Social Research, 19, 47-68.

Glassman, M. (2011) Is Education Ripe for A Paradigm Shift? The Case for The Capability Approach, Education as Change, 15 (1), 161-174.

Glassman, M. and Patton, R. (2014) Capability Through Participatory Democracy: Sen, Freire and Dewey, Educational Philosophy and Theory, 46 (12), 1353-1365.

Goffman, E. (1983) The Interaction Order: American Sociological Association, 1982 Presidential Address, American Sociological Association, 48 (1), 1-17.

Goldin, N., Patel, P. and Perry, K. (2014) The Global Youth Wellbeing Index, Washington: Centre for Strategic and International Studies.

Goodson, I., Biesta, G., Tedder, M. and Adair, N. (2010) Narrative Learning, London: Routledge. 
Gorard, S. (2010) Education Can Compensate for Society-A Bit, British Journal of Educational Studies, 58 (1), 47-65.

Gorard, S. (2013) Research Design, London: Sage.

Gottfredson, L. (1981) Circumscription and Compromise: A Developmental Theory of Occupational Aspirations, Journal of Counseling Psychology Monograph, 28 (6), 545579.

Grace, M., Keys, D., Hart, A. and Keys, B. (2011) Achieving (Extra)Ordinary Aspirations: A Research Project Exploring The Role That The Step Ahead Program Has Played in the Lives of the Young People Affected By Homelessness, Melbourne: Victoria University.

Gracia, P. (2015) Parent-Child Leisure Activities and Cultural Capital in The United Kingdom: The Gendered Effects of Education and Social Class, Social Science Research, $52,290-302$.

Grayling, A.C. (2013) Friendship, London: University Press.

Green, E. (2014) The Negotiation and Articulation of Identity, Position and Ethos in Joint Church Academies, Research Papers in Education, 29 (3), 285-299.

Griffiths, M. (2014) Educational Relationships: Rousseau, Wollstonecraft and Social Justice, Journal of Philosophy of Education, 48 (2), 339-354.

Griffiths, T.G. and Arnove, R.F. (2015) World Culture in The Capitalist World-System in Transition, Globalisation, Societies and Education, 13 (1), 88-108.

Grimshaw, T. and Sears, C. (2008) Where Am I From? Where Do I Belong? : The Negotiation and Maintenance of Identity by International School Students, Journal of Research in International Education, 7, 259-278.

Grinberg, S.M. (2013) “Researching The Pedagogical Apparatus (Dispostif): An Ethnography of The Molar, Molecular and Desire in Contexts of Extreme Urban Poverty", in R. Coleman and J. Ringrose (eds.), Deleuze and Research Methodologies. Edinburgh: Edinburgh University Press, pp. 201-218. 
Gutman, L. and Akerman, R. (2008) Determinants of Aspirations, London: Centre for Research on the Wider Benefits of Learning Institute of Education.

Guy, G. and Beaman, K.V. (2003) Global Orientation and Sociolinguistic Accommodation as Factors in Cultural Assimilation, International Journal of the Humanities, 1, 993-1010.

Habermas, T. and Hatiboglu, N. (2014) Contextualizing the Self: The Emergence of a Biographical Understanding in Adolescence, New Directions for Child and Adolescent Development, 145, 29-41.

Hacohen, C. (2012) "The Norm is a Flux of Change": Teachers Experiences in International Schools, Educational Psychology in Practice: Theory, Research and Practice in Educational Psychology, 28 (2), 113-126.

Hadfield-Hill, S. and Horton, J. (2014) Children's Experiences of Participating in Research: Emotional Moments Together?, Children's Geographies, 12 (2), 135-153.

Hadjar, A. and Aeschlimann, B. (2015) Gender Stereotypes and Gendered Vocational Aspirations Among Swiss Secondary School Students, Educational Research, 57 (1), 2242.

Hafez, F. (2014) Shifting Borders: Islamophobia as Common Ground for Building PanEuropean Right Ring Unity, Patterns of Prejudice, 48 (5), 479-499.

Haidt, J. (2012) The Righteous Mind, London: Penguin.

Hall, S. and Appleyard, L. (2011) Trans-local Academic Credentials and the (Re)Production of Financial Elites, Globalisation, Societies and Education, 9 (2), 247264.

Hall, S., Massey, D. and Rustin, M. (2013) After Neoliberalism? The Kilburn Manifesto, Soundings, 53, 1-19.

Han, K.J. (2015) The Impact of the Radical Right-Wing Parties on The Positions of Mainstream Parties Regarding Multiculturalism, West European Politics, 38 (3), 557576. 
Han, S. (2015) Social Capital and Subjective Happiness: Which Contexts Matter?, Journal of Happiness Studies, 16, 241-255.

Hannerz, U. (1992) Cultural Complexity: Studies in The Social Organisation of Meaning, New York: Columbia University Press.

Hansen, M.N. (2014) Self-Made Wealth or Family Wealth?: Changes in Intergenerational Wealth Mobility, Social Forces, 93 (2), 457-481.

Harper, D. (2002) Talking About Pictures: A Case for Photo Elicitation, Visual Studies, $17(1), 13-26$.

Harper, D. (2003) "Reimagining Visual Methods: Galileo to Neuromancer", in N. Denzin and Y. Lincoln (eds.), Collecting and Interpreting Qualitative Materials. Thousand Oaks, CA: Sage, pp. 176-198.

Harper, S. and Kuh, G. (2007) Myths and Misconceptions About Using Qualitative Methods in Assessment, New Directions for Institutional Research, 136, 5-14.

Hart, C.S. (2012a) Aspirations, Education and Social Justice: Applying Sen and Bourdieu, London: Bloomsbury.

Hart, C.S. (2012b) Aspirations, Education and Social Justice, Research: News from the British Educational Research Association, 117, 34-35.

Harteveld, E., Van Der Burg, W., Dahlberg, S. and Kokkonen, A. (2015) The Gender Gap in Populist Radical-Right Voting: Examining The Demand Side in Western and Eastern Europe, Patterns of Prejudice, 49 (1-2), 103-134.

Harvey, L., Allen, K. and Mendick, H. (2015) Extraordinary Acts and Ordinary Pleasures: Rhetorics of Inequality in Young People's Talk about Celebrity, Discourse and Society, DOI: $10.1177 / 0957926515576636$.

Hasanen, M.M., Al-Kandari, A.A., and Al-Sharoufi, H. (2014) The Role of English Language and International Media as Agents of Cultural Globalisation and Their Impact on Identity Formation in Kuwait, Globalisation, Societies and Education, 12 (4), 542563. 
Hattie, J. (2012) Visible Learning, London: Routledge.

Hauser, R. and Anderson, D.K. (1991) Post-High School Plans and Aspirations of Black and White High School Seniors: 1976-1986, Sociology of Education, 64, 263-277.

Havighurst, R. (1953) Human Development and Education, New York: David McKay.

Hayden, M. (2011) Transnational Spaces of Education: The Growth of the International School, Globalisation, Societies and Education, 9 (2), 211-224.

Hayden, M. and Thompson, J.J. (2000) Being International: Student and Teacher Perceptions from International Schools, Oxford Review of Education, 26 (1), 107-123.

Hayden, M. and Thompson, J.J. (2013) "International Schools: Antecedents, Current Issues and Metaphors for the Future", in R. Pearce (ed.), International Education in Schools: Moving Beyond the First Forty Years. London: Bloomsbury, pp. 3-23.

Head, G. (2014) From My Heart: Transforming Lives Through Values, Journal of Moral Education, 43 (4), 543-545.

Heckman, J.J., Stixrud, J. and Urzua, S. (2006) The Effects of Cognitive and NonCognitive Abilities on Labour Market Outcomes and Social Behaviour, Journal of Labour Economics, 24 (3), 411-482.

Heggli, G., Haukanes, H. and Tjomsland, M. (2013) Fearing the Future? Young People Envisioning their Working Lives in the Czech Republic, Norway and Tunisia, Journal of Youth Studies, 16 (7), 916-931.

Hegna, K. (2014) Changing Educational Aspirations in the Choice of and Transition to Post-Compulsory Schooling-A Three Wave Longitudinal Study of Oslo Youth, Journal of Youth Studies, 17 (5), 592-613.

Held, D., McGrew, A., Goldblatt, D. and Perraton, J. (1999) Global Transformations: Politics, Economics and Culture, Cambridge: Polity Press.

Hemming, P. and Madge, N. (2011) Researching Children, Youth and Religion: Identity, Complexity and Agency, Childhood, 19, 38-50. 
Henderson, S., Holland, J., McGrellis, S., Sharpe, S. and Thomson, R. (2012) Storying Qualitative Longitudinal Research: Sequence, Voice and Motif, Qualitative Research, 12, 16-34.

Herrmann, R. and Brewer, M. (2004) “Identities and Institutions: Becoming European in the EU", in R. Herrmann, T. Risse and M. Brewer (eds.), Transnational Identities: Becoming European in the EU. Oxford: Rowman and Littlefield Publishers, pp. 1-25. Heseltine, M. (2012) No Stone Left Unturned in Pursuit of Growth, London: Department for Business, Innovation and Skills.

Hiatt, C., Laursen, B., Mooney, K.S. and Rubin, K.H. (2015) Forms of Friendship: A Person-Centred Assessment of The Quality, Stability and Outcomes of Different Types of Adolescent Friends, Personality and Individual Differences, 77, 149-155.

Hill, I. (2007) Multicultural and International Education: Never the Twain Shall Meet?, International Review of Education, 53 (3), 245-264.

Hill, I. (2012) Evolution of Education for International Mindedness, Journal of Research in International Education, 11, 245-262.

Hill, I. (2014) Internationally Minded Schools as Cultural Artefacts: Implications for School Leadership, Journal of Research in International Education, 13, 175-189.

Hill, N.E. and Wang, M. (2015) From Middle School to College: Developing Aspirations, Promoting Engagement and Indirect Pathways from Parenting to Post High School Enrolment, Developmental Psychology, 51 (2), 224-235.

Hollenbeck, A.F. (2015) The Familiar Observer: Seeing Beyond The Expected in Educational Research, International Journal of Research and Method in Education, 38 (2), 149-165.

Hooley, T., Matheson, J. and Watts, A.G. (2014) Advancing Ambitions: The Role of Career Guidance in Supporting Social Mobility, London: The Sutton Trust. 
Hooley, T., Watts, A.G. and Andrews, D. (2015) Teachers and Careers: The Role of School Teachers in Delivering Career and Employability Learning, University of Derby: International Centre for Guidance Studies.

Hopfenbeck, T. (2013) Students' Voice, Aspirations, and Perspectives: International Reflections and Comparisons, London Review of Education, 11 (2), 179-183.

Horton, J. (2008) A 'Sense of Failure'? Everydayness and Research Ethics, Children's Geographies, 6 (4), 363-383.

Hoskins, K. and Barker, B. (2014) Education and Social Mobility: Dreams of Success, London: Institute of Education Press.

Howard, A., Polimeno, A. and Wheeler, B. (2014) Negotiating Privilege and Identity in Educational Contexts, London: Routledge.

Howard, K., Ferrari, L., Nota, L., Solberg, S. and Soresi, S. (2009) The Relation of Cultural Context and Social Relationships to Career Development in Middle School, Journal of Vocational Behavior, 75, 100-108.

Howell, K. (2013) An Introduction to The Philosophy of Methodology, London: Sage. Hrycak, J. (2015) Home and Away: An Inquiry Into Home-Based and Overseas Teacher Perceptions Regarding International Schools, Journal of Research in International Education, 14 (1), 29-43.

Hughes, J., Campbell, A., Lolliot, S., Hewstone, M. and Gallagher, T. (2013) Inter-Group Contact at School and Social Attitudes: Evidence from Northern Ireland, Oxford Review of Education, 39, (6), 761-779.

Huschke, S. (2014) Fragile Fabric: Illegality Knowledge, Social Capital and HealthSeeking of Undocumented Latin American Migrants in Berlin, Journal of Ethnic and Migration Studies, 40 (12), 2010-2029.

Hutchinson, J. and Kettlewell, K. (2015) Education to Employment: Complicated Transitions in a Changing World, Educational Research, 57 (2), 113-120. 
Iannelli, C. (2013) The Role of the School Curriculum in Social Mobility, British Journal of Sociology of Education, 34 (5-6), 907-928.

Ibanez, B.P. (2014) Living as A Creative Activity-An Introduction to John Dewey's Theory of Experience, Pragmatism Today, 5 (2), 13-18.

Igarashi, H. (2015) Privileged Japanese Transnational Families in Hawaii as Lifestyle Migrants, Global Networks, 15 (1), 99-117.

Iglic, H. (2014) The Crumbling or Strengthening of Social Capital? The Economic Crisis' Impact on Social Networks and Interpersonal Trust in Slovenia, Druzboslovne Razprave, 77, 7-26.

Illeris, K. (1999) How We Learn, Oxon: Roskilde.

Inglis, D. (2014) Cosmopolitans and Cosmopolitanism: Between and Beyond Sociology and Political Philosophy, Journal of Sociology, 50, 99-114.

IPSOS MORI (2014) Who is Generation Next?, London: IPSOS Mori Social Research Institute.

Jabal, E. (2013) Institutional Identity and School-Community Matters: 'Encapsulated' and 'Inclusive' Lessons for Engagement From Two International Schools in Hong Kong, Journal of Research in International Education, 12 (1), 3-21.

Jackson, A. Y. (2013) "Data as Machine: A Deleuzian Becoming", in R. Coleman and J. Ringrose (eds.), Deleuze and Research Methodologies. Edinburgh: Edinburgh University Press, pp. 111-124.

Jackson, L. (2014) Respect for Others Must Begin in The Classroom, Research Intelligence, 125, 12-13.

Jager, J., Yuen, C.X., Putnick, D.L., Hendricks, C. and Bornstein, M.H. (2015) AdolescentPeer Relationships, Separation and Detachment from Parents and Internalizing and Externalizing Behaviors: Linkages and Interactions, Journal of Early Adolescence, 35 (4), 511-537. 
James, D. (2015) How Bourdieu Bites Back: Recognizing Misrecognition in Education and Educational Research, Cambridge Journal of Education, 45 (1), 97-112.

James, O. (2013) "Foreword", in J. Wild (ed.), Exploiting Childhood: How Fast Food, Material Obsession and Porn Culture are Creating New Forms of Child Abuse. London: Jessica Kingsley Publishers, pp. 11-13.

Jamieson, L. and Milne, S. (2012) Children and Young People's Relationships, Relational Processes and Social Change: Reading Across Worlds, Children's Geographies, 10 (3), 265-278.

Jantzer, A., Stalides, D. and Rottinghaus, P. (2009) An Exploration of Social Cognitive Mechanisms, Gender, and Vocational Identity Among Eighth Graders, Journal of Career Development, 36, 114-138.

Jennings, J.L., Deming, D., Jencks, C., Lopuch, M. and Scheuler, B.E. (2015) Do Differences in School Quality Matter More Than We Thought? New Evidence on Educational Opportunity in the Twenty-First Century, Sociology of Education, 88 (1), $56-82$.

Jensen, L. (2011) Navigating Local and Global Worlds: Opportunities and Risks for Adolescent Cultural Identity Development, Psychological Studies, 56 (1), 62-70. Jensen, N.R. and Kjeldsen, C.C. (2014) "The Schism Between Evidence-Based Practice, Professional Ethics and Managerialism-Exemplified by Social Pedagogy", in K.B. Peterson, D. Reimer and A. Qvortrup (eds.), Evidence and Evidence Based Education in Denmark. Copenhagen: Aarhus University Department of Education, pp. 27-51. Jerrim, J. (2013) Family Background and Access to 'High Status' Universities, London: The Sutton Trust.

Johnson, D. (1994) Research Methods in Educational Management, Harlow: Longman. Johnson, P., Boyer, M. and Brown, S. (2011) Vital Interests: Cultivating Global Competence in the International Studies Classroom, Globalisation, Societies and Education, 9 (3-4), 503-519. 
Jones, B. and Ficklin, L. (2012) To Walk in Their Shoes: Recognising the Expression of Empathy as a Research Reality, Emotion, Space and Society, 5, 103-112.

Jones, G. (2014) Where's The Capital? A Geographical Essay, The British Journal of Sociology, 65 (4), 721-735.

Jones, J. (2011) Book Review: Schooling Internationally: Globalisation, Internationalism, and the Future for International Schools, Journal of Research in International Education, 10, 311-313.

Jones, O. (2014) The Establishment: And How They Get Away With It, London: Penguin. Kahneman, D. (2011) Thinking, Fast and Slow, London: Penguin.

Kalita, U. (2014) Occupational Aspiration and School Facilities of Secondary Stage Students: A Study, The Clarion, 3 (1), 118-123.

Kanan, H. and Baker, A.(2006) Influence of International Schools on the Perception of Local Students' Individual and Collective Identities, Career Aspirations and Choice of University, Journal of Research in International Education, 5, 251-268.

Karim, S. (2012) The Co-Existence of Globalism and Tribalism: A Review of the Literature, Journal of Research in International Education, 11, 137-151.

Kashima, Y., Koval, P. and Kashima, E. (2011) Reconsidering Culture and Self, Psychological Studies, 56 (1), 12-22.

Kautz, T., Heckman, J.J., Diris, R., ter Weel, B. and Borghans, L. (2014) Fostering and Measuring Skills: Improving Cognitive and Non-Cognitive Skills to Promote Lifetime Success, Cambridge, MA: National Bureau of Economic Research.

Keddie, A. (2014a) Schooling, Social Cohesion and 'Britishness', British Educational Research Association, 12, 1-4.

Keddie, A. (2014b) Political Justice, Schooling and Issues of Group Identity, Educational Philosophy and Theory, 46 (3), 311-323.

Keister, L. A. (2014) The One Percent, Annual Review of Sociology, 40, 347-367. 
Keller, S. (2013) Partiality, Oxford: Princeton University Press.

Kenway, J. and Fahey, J. (2014) Staying Ahead of the Game: The Globalising Practices of Elite Schools, Globalisation, Societies and Education, 12 (2), 177-195.

Kenway, J. and Fahey, J. (2015) The Gift Economy of Elite Schooling: The Changing Contours and Contradictions of Privileged Benefaction, British Journal of Sociology of Education, 36 (1), 95-115.

Kenway, J. and Hickey-Moody, A. (2011) Life Chances, Lifestyle and Everyday Aspirational Strategies and Tactics, Critical Studies in Education, 52 (2), 151-163.

Kenway, J. and Howard, A. (2013) New Directions for Research on Elites and Elite Education: Methodological Challenges, International Journal of Qualitative Studies in Education, 26 (9), 1210-1212.

Kenway, J. and Koh, A. (2013) The Elite School as 'Cognitive Machine' and 'Social Paradise': Developing Transnational Capitals for the National 'Field of Power', Journal of Sociology, 49, 272-290.

Kenway, J. and Koh, A. (2015) Sociological Silhouettes of Elite Schooling, British Journal of Sociology of Education, 36 (1), 1-10.

Khan, S.R. (2012) The Sociology of Elites, Annual Review of Sociology, 38, 361-377. Khattab, N. (2015) Students' Aspirations, Expectations, and School Achievement: What Really Matters? British Educational Research Journal, DOI: 10.1002/berj.3171.

Kinginger, C. (2015) Student Mobility and Identity Related Language Learning, Intercultural Education, 26 (1), 6-15.

Kintrea, K., St. Clair, R., and Houston, M. (2011) The Influence of Parents, Places and Poverty on Educational Attitudes and Aspirations, York: The Joseph Rowntree Foundation.

Kintrea, K., St. Clair, R. and Houston, M. (2015) Shaped by Place? Young People's Aspirations in Disadvantaged Neighborhoods, Journal of Youth Studies, 18 (5), 666684. 
Kirk, C., Lewis-Moss, R., Nilsen, C., and Colvin, D. (2011) The Role of Parent Expectations on Adolescent Educational Aspirations, Educational Studies, 37 (1), 89-99.

Kisida, B., Greene, J.P., and Bowen, D.H. (2014) Creating Cultural Consumers: The Dynamics of Cultural Capital Acquisition, Sociology of Education, 87, 281-294.

Klimstra, T., Hale, W., Raaijmakers, Q., Branje, S. and Meeus, W. (2010) Identity Formation in Adolescence: Change or Stability?, Journal of Youth and Adolescence, 39, 150-162.

Klimstra, T., Luyckx, K. and Meeus, W. (2012) Personal Identity in Belgium and The Netherlands, New Directions for Child and Adolescent Development, 138, 19-34.

Klug, H.J.P. and Maier, G.W. (2015) Linking Goal Progress and Subjective Well-Being: A Meta-Analysis, Journal of Happiness Studies, 16, 37-65.

Kochan, F. (2002) "Examining the Organizational and Human Dimensions of Mentoring: A Textual Data Analysis", in F. Kochan (ed.), The Organizational and Human Dimensions of Successful Mentoring Programs and Relationships. Greenwich, CT: Information Age, pp. 269-286.

Kochan, F. (2013) Analyzing the Relationships Between Culture and Mentoring, Mentoring and Tutoring: Partnership in Learning, 21 (4), 412-430.

Koh, A. and Kenway, J. (2012) Cultivating National Leaders in an Elite School: Deploying the Transnational in the National Interest, International Studies in Sociology of Education, 22 (4), 333-351.

Koh, S.Y. (2015) How and Why Race Matters: Malaysian-Chinese Transnational Migrants Interpreting and Practising Bumiputera-Differentiated Citizenship, Journal of Ethnic and Migration Studies, 41 (3), 531-550.

Kolb, S. (2012) Grounded Theory and The Constant Comparative Method: Valid Research Strategies for Educators, Journal of Emerging Trends in Educational Research and Policy Studies, 3 (1), 83-86. 
Kort, W. and Gharbi, E. (2011) Call Centers Performance: An Application of Structuration Theory, IBIMA, DOI: 10.5171/2011.606307.

Kraftl, P. (2013) Beyond 'Voice', Beyond 'Agency', Beyond 'Politics'? Hybrid Childhoods and Some Critical Reflections on Children's Emotional Geographies, Emotion, Space and Society, 9, 13-23.

Krahn, H. and Galambos, N. (2014) Work Values and Beliefs of 'Generation X' and 'Generation Y', Journal of Youth Studies, 17 (1), 92-112.

Kraus, M.W., Piff, P., Mendoza-Denton, R., Rheinschmidt, M.L. and Keltner, D. (2012) Social Class, Solipsism and Contextualism: How The Rich Are Different From The Poor, Psychological Review, 119 (3), 546-572.

Kristjansson, K. (2010) The Self and its Emotions, New York: Cambridge University Press.

Kuh, G. D., and Andreas, R. E. (1991) It's About Time: Using Qualitative Methods in Student Life Studies, Journal of College Student Development, 32 (5), 397-405.

Kuo, B.C.H. (2014) Coping, Acculturation and Psychological Adaptation Among Migrants: A Theoretical and Empirical Review and Synthesis of the Literature, Health Psychology and Behavioral Medicine: An Open Access Journal, 2 (1), 16-33.

Lagattuta, K.H. (2014) Linking Past, Present, and Future: Children's Ability to Connect Mental States and Emotions Across Time, Child Development Perspectives, 8 (2), 90-95. Lampert, M. (2010) Learning Teaching In, From and For Practice: What Do We Mean?, Journal of Teacher Education, 61, 21-34.

Lampert, M. (2012) Improving Teaching and Teachers: "A Generative Dance"?, Journal of Teacher Education, 63, 361-367.

Lamsal, M. (2012) The Structuration Approach of Anthony Giddens, Himalayan Journal of Sociology and Anthropology, 5, 111-122.

Langford, M. (2013) Book Review: Internationalizing Teacher Education in the United States, Journal of Research in International Education, 12, 103-112. 
Larkin, C. (2013) Enacting Children's Citizenship: Developing Understandings of how Children Enact Themselves as Citizens Through Actions and Acts of Citizenship, Childhood, published online March 14, 2013.

Law, B. (1996) "Careers Work in Schools", in A.G. Watts, B. Law, J. Killeen, J.M. Kidd and R. Hawthorn (eds.), Rethinking Careers Education and Guidance: Theory, Practice and Policy, London: Routledge, pp. 95-111.

Layard, R. (2003) Happiness: Has Social Science a Clue?, London: London School of Economics Lionel Robbins Memorial Lectures 2002/3.

Leat, D., Reid, A. and Lofthouse, R. (2015) Teachers' Experiences of Engagement with and In Educational Research: What Can Be Learned from Teachers' Views?, Oxford Review of Education, 41 (2), 270-286.

Lee, E., and Kramer, R. (2013) Out With the Old, In With the New? Habitus and Social Mobility at Selective Colleges, Sociology of Education, 86, 18-35.

Leighton, R. (2013) "Citizenship Education for Children of the Elite in England", in P. Cunningham (ed.), Identities and Citizenship Education: Controversy, Crisis and Challenges. London: Cice, pp. 419-428.

Leininger, L.J. and Kalil, A. (2014) Economic Strain and Children's Behaviour in The Aftermath of the Great Recession, Journal of Marriage and Family, 76, 998-1010. Leonard, M. and McKnight, M. (2015) Look and Tell: Using Photo-Elicitation Methods with Teenagers, Children's Geographies, 13 (6), 629-642.

Leonavicius, V. and Ozolinciute, E. (2015) Gap Year Students in Lithuania: The Value Orientations of Children From Wealthy Social Groups, International Studies in Sociology of Education, 25 (1), 38-62.

Letki, N. and Mierina, I. (2015) Getting Support in Polarized Societies: Income, Social Networks and Socioeconomic Context, Social Science Research, 49, 217-233. 
Liebenberg, L., Ungar, M. and Theron, L. (2013) Using Video Observation and Photo Elicitation Interviews to Understand Obscured Processes in the Lives of Youth Resilience, Childhood, DOI: 10.1177/0907568213496652.

Lindley, J. and Machin, S. (2012) The Quest for More and More Education: Implications for Social Mobility, Fiscal Studies, 33 (2), 265-286.

Littler, J. (2013) Meritocracy as Plutocracy: The Marketing of 'Equality' Under Neoliberalism, New Formations, 80/81, 52-72.

Liu, L. (2014) A Search For a Place to Call Home: Negotiation of Home, Identity and Senses of Belonging Among New Migrants from the People's Republic of China to New Zealand, Emotion, Space and Society, 10, 18-26.

Lucas, K. (2001) The Social Construction of Mentoring Roles, Mentoring and Tutoring: Partnership and Learning, 9 (1), 23-47.

Lucas-Molina, B., Williamson, A.A., Pulido, R. and Perez-Albeniz, A. (2015) Effects of Teacher-Student Relationships on Peer Harassment: A Multilevel Study, Psychology in The Schools, 52 (3), 298-315.

Lundy, L. (2007) 'Voice' is Not Enough: Conceptualising Article 12 of the United Nations Convention on the Rights of the Child, British Educational Research Journal, 33 (6), 927-942.

Luthar, S.S. (2013) The Problem With Rich Kids, (www.psychologytoday.com) online, accessed 19 January 2015.

Luthar, S.S, Barkin, S.H. and Crossman, E.J. (2013) "I Can Therefore I Must": Fragility in The Upper Middle Classes, Developmental and Psychopathology $25^{\text {th }}$ Anniversary Special Issue, 25, 1529-1549.

Lyman, E.L. and Luthar, S.S. (2014) Further Evidence on The 'Costs of Privilege': Protectionism in High-Achieving Youth at Socioeconomic Extremes, Psychology in The Schools, 51 (9), 913-930. 
Lyubomirsky, S. (2001) Why Are Some People Happier Than Others? The Role of Cognitive and Motivational Processes in Well-Being, American Psychologist, 56 (3), 239-249.

Maalouf, A. (2000) In the Name of Identity, New York: Penguin.

MacDonald, J. (2013) “Moving on From the 1960's: A New Model of Diploma for Our Global Citizens", in M. Hayden and J. Thompson (eds.) Taking the Diploma Programme Forward. Woodbridge, UK: John Catt Educational Ltd, pp. 52-64.

Machin, D. (2014) Professional Educator or Professional Manager? The Contested Role of the For-Profit International School Principal, Journal of Research in International Education, DOI: 10.1177/1475240914521347.

MacKenzie, P. (2009) The Attraction of International Schools for Japanese Parents Living in Japan, Journal of Research in International Education, 8, 326-346.

MacLure, M. (2013) “Classification or Wonder? Coding as an Analytic Practice in Qualitative Research", in R. Coleman and J. Ringrose (eds.), Deleuze and Research Methodologies. Edinburgh: Edinburgh University Press, pp. 164-183.

MacMillan, L, Tyler, C. and Vignoles, A. (2013) Who Gets the Top Jobs? The Role of Family Background and Networks in Recent Graduates' Access to High Status Professions, London: Department of Quantitative Social Science.

MacMillan, L. and Vignoles, A. (2013) Mapping the Occupational Destinations of New Graduates: Research Report, London: Social Mobility and Child Poverty Commission. MacMurray, J. (2012) Learning to Be Human, Oxford Review of Education, 38 (6), 661674.

Malanchuk, O., Messersmith, E.E., and Eccles, J.S. (2010) The Ontogeny of Career Identities in Adolescence, New Directions for Child and Adolescent Development, 130, 97-110. 
Malin, H., Reilly, T., Quinn, B. and Moran, S. (2013) Adolescent Purpose Development: Exploring Empathy, Discovering Roles, Shifting Priorities, and Creating Pathways, Journal of Research on Adolescence, DOI: 10.1111/jora.12051.

Malin, H., Tirri, K. and Liauw, I. (2015) Adolescent Moral Motivations for Civic Engagement: Clues to the Political Gender Gap? Journal of Moral Education, 44 (1), $34-$ 50.

Mann, A., Massey, D., Glover, P., Kashefpadkel, E. and Dawkins, J. (2013) Nothing in Common: The Career Aspirations of Young Britons Mapped Against Projected Labour Market Demand (2010-2020), London: Education and Employers Taskforce.

Marsh, H. (2012) Relationships for Learning: Using Pupil Voice to Define Teacher-Pupil Relationships that Enhance Pupil Engagement, Management in Education, 26 (3), 161163.

Marteleto, L. and Andrade, F. (2013) The Educational Achievement of Brazilian Adolescents: Cultural Capital and the interaction between Families and Schools, Sociology of Education, DOI: 10.1177/0038040713494223.

Martin, A., and Dowson, M. (2009) Interpersonal Relationships, Motivation, Engagement and Achievement: Yields for Theory, Current Issues and Educational Practice, Review of Educational Research, 79, 327-365.

Martin, F. (2012) Thinking Differently About Difference: Think Global Think Piece, (http://think-global.org.uk/resources/item/7118) online, accessed 11 April 2015.

Martinez, M.A., Hetterschijt, C. and Iglesias, M.J. (2015) The European Schools: Perspectives of Parents as Participants in a Learning Community, Journal of Research in International Education, 14 (1), 44-60.

Mary, A. (2013) Re-Evaluating the Concept of Adulthood and the Framework of Transition, Journal of Youth Studies, DOI: 10.1080/13676261.2013.853872. 
Mau, S., Gulzau, F., Laube, L. and Zaun, N. (2015) The Global Mobility Divide: How Visa Policies Have Evolved Over Time, Journal of Ethnic and Migration Studies, 41 (8), $1192-$ 1213.

Maxwell, C. and Aggleton, P. (2013) Top Girls: Young Women and Independent Schools, Swindon: UK Economic and Social Research Council.

Mazzei, L. (2013) “Desire Undone: Productions of Privilege, Power and Voice" in R. Coleman and J. Ringrose (eds.), Deleuze and Research Methodologies. Edinburgh: Edinburgh University Press, pp. 96-110.

Mazzoni, V. and Harcourt, D. S. (2014) An International Experience of Research with Children: Moving Forward on the Idea of Children's Participation, Qualitative Research, $14(2), 252-268$.

McClure, L., Yonezawa, S., and Jones, M. (2010) Can School Structures Improve Teacher-Student Relationships? The Relationship Between Advisory Programs, Personalization and Students' Academic Achievement, Education Policy Analysis Archive, 18, (17), 1-21.

McDevitt, T., Hess, C., Leesatayakun, M., Sheehan, E. and Kaufeld, K. (2013) A Cross Sectional Study of Career Aspirations in Thai Children in an International School in Bangkok, Journal of Career Development, 40 (6), 531-550.

McDonald, S., Erickson, L. and Gatlin, D. (2009) “Mentoring in Context: A Sociological Approach to the Study of Mentoring Relationships", M. Keel (ed.), Mentoring: Program Development, Relationships, and Outcomes. New York: Nova Science Publishers.

McGregor, G. (2013) Beyond ' $Y$ ' and Other Stereotypes: Exploring the Experience of Youth in The $21^{\text {st }}$ Century, Social Alternatives, 32 (2), 3-5.

McIntyre, D. (2004) “Perspectives on Classroom Consultation", in M. Arnot, D. Mclntyre, D. Pedder and D. Reay (eds.), Consultation in The Classroom: Developing Dialogue About Teaching and Learning. Cambridge, UK: Pearson, pp.85-90. 
McIntyre, D., Pedder, D., and Ruddick, J. (2005) Pupil Voice: Comfortable and Uncomfortable Learning for Teachers, Research Papers in Education, 20 (2), 149-168.

McLachlan, D. (2007) Global Nomads in an International School: Families in Transition, Journal of Research in International Education, 6, 233-249.

McLaughlin, C. and Gray, J. (2015) “Adolescent Well-Being and The Relational School”, in C. McLaughlin (ed.), The Connected School: A Design for Well-Being. London: Pearson, pp. 1-7.

McLeod, D. and Burrows, R. (2014) Home and Away: Family Matters in the Lives of Young Transnational Couples, Journal of Sociology, 50, 368-382.

McNess, E., Arthur, L. and Crossley, M. (2015) 'Ethnographic Dazzle' and The Construction of The 'Other': Revisiting Dimensions of Insider and Outsider Research for International and Comparative Education, Compare: A Journal of Comparative and International Education, 45 (2), 295-316.

Mead, M. (1973) Coming of Age in Samoa, New York: Harper Collins.

Mee, K. and Wright, S. (2009) Geographies of Belonging, Environment and Planning A, 41, 772-779.

Mellor, J., Ingram, N., Abrahams, J. and Beedell, P. (2014) Class Matters in the Interview Setting? Positionality, Situatedness and Class, British Educational Research Journal, 40 (1), 135-149.

Mendick, H., Allen, K. and Harvey, L. (2015) 'We Can Get Everything We Want If We Try Hard': Young People, Celebrity, Hard Work, British Journal of Educational Studies, DOI: 10.1080/00071005.2014.1002382.

Merricks, T. (1999) Endurance, Psychological Continuity and the Importance of Personal Identity, Philosophy and Phenomenological Research, 59, 983-997.

Merry, M. (2015) The Conundrum of Religious Schools in Twenty-First-Century Europe, Comparative Education, 51 (1), 133-156. 
Merry, M. and de Ruyter, D. (2011) The Relevance of Cosmopolitanism for Moral Education, Journal of Moral Education, 40 (1), 1-18.

Messelink, H.E., Van Maele, J. and Spencer-Oatey, H. (2015) Intercultural Competencies: What Students in Study and Placement Mobility Should Be Learning, Intercultural Education, 26 (1), 62-72.

Michalos, A.C. (2008) Education, Happiness and Well-Being, Social Indicators Research, 87 (3), 347-366.

Middle Years of Schooling Association (M.Y.S.A.) (2008) M.Y.S.A. Position Paper: Middle Schooling: People, Practices and Places, Brisbane: M.Y.S.A.

Miller, J. and Das, R. (2011) Culture and the Role of Choice in Agency, Journal of Personality and Social Psychology, 101 (1), 46-61.

Miller, W. (1997) The Anatomy of Disgust, Cambridge, MA: Harvard University Press. Mincu, M.E. (2015) Teacher Quality and School Improvement: What is the Role of Research?, Oxford Review of Education, 41 (2), 253-269.

Minoura, Y. (1992) A Sensitive Period for the Incorporation of a Cultural Meaning System: A Study of Japanese Children Growing up in the United States, Ethos, 20 (3), 304-339.

Miravet, L. and Garcia, O. (2013) The Role of Teachers' Shared Values and Objectives in Promoting Intercultural and Inclusive School Cultures: A Case Study, International Journal of Qualitative Studies in Education, 26 (10), 1373-1386.

Mitchell, C. (2011) Doing Visual Research, London: Sage.

Molloy, C. (2015) Getting By or Getting In? Grappling with Access and Affect in Qualitative Research Projects Involving Vulnerable Human Subjects, Qualitative Inquiry, 21 (5), 467-476.

Moogan, Y.J. (2011) An Analysis of School Pupils' (With Low Social Economic Status) Perceptions of University, Regarding Programs of Study, Educational Studies, 37 (1), 114. 
Morgan, J. (2015) Emptiness and the Education of Emotions, Educational Philosophy and Theory: Incorporating ACCESS, 47 (3), 291-304.

Morrison, K. (2013) Interviewing Children in Uncomfortable Settings: 10 Lessons for Effective Practice, Educational Studies, 39 (3), 320-337.

Moulton, V., Flouri, E., Joshi, H. and Sullivan, A. (2015) The Role of Aspirations in Young People's Emotional and Behavioural Problems, British Educational Research Journal, 41 (6), 925-946.

Murdock, E., Hirt, F.S., and Ferring, D. (2014) Salience of Nationality in Students' Spontaneous Self-Concept: A Comparative Study of a Nationally Homogeneous and a Heterogeneous School Context, Journal of Research in International Education, 13, 119-134.

Murphy-Graham, E. and Lample, J. (2014) Learning to Trust: Examining the Connections Between Trust and Capabilities Friendly Pedagogy Through Case Studies from Honduras and Uganda, International Journal of Educational Development, 36, 51 62.

Murray, J. (2014) Evidence of a Transnational Capitalist Class-For-Itself: The Determinants of PAC Activity Among Foreign Firms in the Global Fortune 400, 20002006, Global Networks, 14 (2), 230-250.

Murris, K. (2013) The Epistemic Challenge of Hearing Child's Voice, Studies in Philosophy and Education, 32 (3), 245-259.

Murris, K. (2015) Listening-As-Usual: A Response to Michael Hand, Studies in Philosophy and Education, 34, 331-335.

Myers, J. (2010) Exploring Adolescents' Thinking about Globalisation in an International Education Program, Journal of Research in International Education, 9, 153-167.

Nash, P. and Schlosser, A. (2015) Working With Schools in Identifying and Overcoming Emotional Barriers to Learning, Educational Studies, 41 (1-2), 143-155. 
Nayak, A. (2010) Race, Affect and Emotion: Young People, Racism and Graffiti in The Postcolonial English Suburbs, Environment and Planning A, 42, 2370-2392.

Negru-Subtirica, O., Pop, E.I. and Crocetti, E. (2015) Developmental Trajectories and Reciprocal Associations Between Career Adaptability and Vocational Identity: A Three Wave Longitudinal Study with Adolescents, Journal of Vocational Behavior, 88, 131142.

Nelson, P. (2013) The Inquiry of Care, Educational Theory, 63 (4), 351-367.

Nette, J and Hayden, M. (2007) Globally Mobile Children: The Sense of Belonging, Educational Studies, 33 (4), 435-444.

Newby, P. (2010) Research Methods for Education, London: Pearson.

Newman, J.L., Dantzler, J. and Coleman, A. N. (2015) Science in Action: How Middle School Students are Changing Their World Through STEM Service-Learning Projects, Theory into Practice, 54, 47-54.

Ng, V. (2012) The Decision to Send Local Children to International Schools in Hong Kong: Local Parents' Perspectives, Asia Pacific Education Review, 13, 121-136.

N.H.S. England (2008) Children and Young People Positive Practice Guide, London: Department of Health.

N.H.S. England (2015) Future in Mind: Promoting, Protecting and Improving Our Children and Young People's Mental Health and Wellbeing, London: Department of Health.

Nilsson, M., Ejlertsson, G., Andersson, I. and Blomqvist, K. (2015) Caring as a Salutogenic Aspect in Teachers' Lives, Teaching and Teacher Education, 46, 51-61.

Noam, G., Malti, T. and Karcher, M. (2014) “Mentoring Relationships in Developmental Perspective", in D. Dubois and M. Karcher (eds.), Handbook of Youth Mentoring. London: Sage, pp. 99-115.

Noble, G. (2013) 'It is Home But It is Not Home': Habitus, Field and The Migrant, Journal of Sociology, 49, 341-356. 
Noddings, N. (2012) The Caring Relation in Teaching, Oxford Review of Education, 38 (6), 771-781.

Nordstrom, S.N. (2015) Not So Innocent Anymore: Making Recording Devices Matter in Qualitative Interviews, Qualitative Inquiry, 21 (4), 388-401.

Ochieng, B. (2010) "You Know What I Mean:" The Ethical and Methodological Dilemmas and Challenges for Black Researchers Interviewing Black Families, Qualitative Health Research, 20, 1725-1735.

O'Connor, M.K., Netting, F., and Thomas, M. (2008) Grounded Theory: Managing the Challenge for Those Facing Institutional Review Board Oversight, Qualitative Inquiry, $14,28-45$.

Odland, G. and Ruzicka, M. (2009) An Investigation into Teacher Turnover in International Schools, Journal of Research in International Education, 8, 5-29.

O’Donnell, A. (2014) Another Relationship to Failure: Reflections on Beckett and Education, Journal of Philosophy of Education, 48 (2), 260-275.

O'Leary, J. (2013) Advancing Access and Admissions, London: The Sutton Trust.

Ong, A. (1996) Cultural Citizenship and Subject Making: Immigrants Negotiate Racial and Cultural Boundaries in The United States, Current Anthropology, 37 (5), 737-762.

Onwuengbuzie, A. and Leech, N. (2007) Sampling Designs in Qualitative Research: Making the Sampling Process More Public, The Qualitative Report, 12 (2), 238-254.

Oosterhoff, B., Metzger, A. and Babskie, E. (2015) What Do Citizens Have to Do? Parents' and Adolescents' Messages About Civic Duty, Journal of Adolescent Research, 30 (3), 365-389.

Oosterlaken, I. (2015) Economic Complexity and Human Development: How Economic Diversification and Social Networks Affect Human Agency and Welfare, Journal of Human Development and Capabilities: A Multi-Disciplinary Journal for People-Centred Development, 16 (1), 156-157. 
O’Reilly, K. (2012) International Migration and Social Theory, Basingstoke: Palgrave Macmillan.

Orthner, D., Jones-Sanpei, H., Akos, P. and Rose, R. (2013) Improving Middle School Student Engagement Through Career-Relevant Instruction in the Core Curriculum, The Journal of Educational Research, 106 (1), 27-38.

Orthner, D., Jones-Sanpei, H., Hair, E.C., Moore, K.A., Day, R.D. and Kaye, K. (2009) Marital and Parental Relationship Quality and Educational Outcome for Youth, Marriage and Family Review, 45 (2-3), 249-269.

Osborne, S. and Guenther, J. (2013) Red Dirt Thinking on Aspiration and Success, The Australian Journal of Indigenous Education, 42 (2), 88-99.

O’Tuathaigh, G. (2014) “The Great Departure Lounge: An Historical Perspective on Irish Emigration" in E. Mannion (ed.), Mr. Tuke's Fund: Connemara Emigration in the 1880's. Clifden: Clifden 2012 Heritage Committee, pp. 7-11.

Oxfam (2014) Even It Up: Time to End Extreme Inequality, Boston: Oxfam.

Passy, R. (2013) Surviving and Flourishing in a Neoliberal World: Primary Trainees Talking, British Educational Research Journal, 39 (6), 1060-1075.

Patterson, J. (2015) Moynihan and The Single-Parent Family, Education Next, 15 (2), 110.

Pearce, R. (2005) Developing a Model of Identity as a Means of Monitoring NewlyRelocated Students in International Schools, Doctoral Thesis, University of Bath.

Pearce, R. (2011) When Borders Overlap: Composite Identities in Children in International Schools, Journal of Research in International Education, 10, 154-173.

Pearce, R. (2013a) “Introduction", in R. Pearce (ed.), International Education in Schools: Moving Beyond the First Forty Years. London: Bloomsbury, pp. xii-xx.

Pearce, R. (2013b) "Student Diversity: The Core Challenge to International Schools", in R. Pearce (ed.), International Education in Schools: Moving Beyond the First Forty Years. London: Bloomsbury, pp.61-83. 
Peiro-Velert, C., Escarti, A. and Trigueros, C. (2014) Assessing Adolescents' Appraisal of Significant Adults' Goal-Involving Criteria for Judging Their Success in Physical Education and Sport Settings: A Missing Link in the Socialization Process, European Journal of Human Movement, 32, 186-211.

Pendergast, D. and Main, K. (2013) The Middle Years of Schooling Association's Representations of Young Adolescents: Particularising The Adolescent, Social Alternatives, 32 (2), 25-30.

Pendery, D.R. (2015) The Taiwanese Student Happiness Initiative: Fulfilling Lives and Success in The Future, Journal of Social Change, 7 (1), 1-12.

Perry, J. (2013) A Review of "Interculturalism: The New Era of Cohesion and Diversity" by Ted Cantle, International Journal of Housing Policy, 13 (2), 220-222.

Peters, R. (1966) Ethics and Education, London: George Allen and Unwin.

Peterson, A.D.C. (1987) Schools Across Frontiers: The Story of The International Baccalaureate and The United World Colleges, La Salle, IL: Open Court.

Piff, P., Kraus, M.W., Cote, S., Hayden Cheng, B. and Keltner, D. (2010) Having Less, Giving More: The Influence of Social Class on Prosocial Behaviour, Journal of Personality and Social Psychology, 99 (5), 771-784.

Pike, M. (2009) The Emmanuel Schools Foundation: Sponsoring and Leading Transformation at England's Most Improved Academy, Management in Education, 23 (3), 139-143.

Pimlott-Wilson, H. (2011) The Role of Familial Habitus in Shaping Children's Views of Their Future Employment, Children's Geographies, 9 (1), 111-118.

Pittman, F. (1985) Children of the Rich, Family Process, 24 (4), 461-472.

Pizzorno, M.C., Benozzo, A. and Carey, N. (2015) Narrating Career, Positioning Identity and Constructing Gender in An Italian Adolescent's Personal Narratives, Journal of Vocational Behaviour, 88, 195-204. 
Plummer, K. (1983) Documents of Life: An Introduction to The Problems and Literature of a Humanistic Method, London: Allen and Unwin.

Polkinghorne, D. (1988) Narrative Knowing and the Human Sciences, Albany: State University of New York Press.

Pollock, D. and Van Reken, R. (1999) Third Culture Kid Experience: Growing Up Among Worlds, Yarmouth, MA: Intercultural Press.

Poore, P. (2005) School Culture: The Space Between the Bars; The Silence Between the Notes, Journal of Research in International Education, 4, 351-361.

Power, S., Brown, P., Allouch, A., and Tholen, G. (2013) Self, Career and Nationhood: The Contrasting Aspirations of British and French Elite Graduates, The British Journal of Sociology, 64 (4), 578-596.

Prince, D. (2013) What About Place? Considering the Role of Physical Environment on Youth Imagining of Future Possible Selves, Journal of Youth Studies, DOI: 10.1080/13676261.2013.836591.

Pring, R. (2000) The False Dualism of Educational Research, Journal of Philosophy of Education, 34 (2), 247-260.

P.S.H.E. Association (2015) Teacher Guidance: Preparing to Teach About Mental Health and Emotional Well-Being, London, Department for Education.

Putnam, R. (1993) Making Democracy Work: Civic Traditions in Modern Italy, Princeton: Princeton University.

Pyyry, N. (2015) 'Sensing with' Photography and 'Thinking With' Photographs in Research into Teenage Girls' Hanging Out, Children's Geographies, 13 (2), 149-163.

Quaglia, R.J. and Cobb, C.D. (1996) Toward a Theory of Student Aspirations, Journal of Research in Rural Education, 12, 127-132.

Rachjman, J. (1985) Michel Foucault: The Freedom of Philosophy, New York: Columbia University Press. 
Raco, M. (2009) From Expectations to Aspirations: State Modernisation, Urban Policy and The Existential Policies of Welfare in the UK, Political Geography, 28 (7), 436-444. Rampino, T. and Taylor, M. (2012) Educational Aspirations and Attitudes Over The Business Cycle, Essex: Institute for Social and Economic Research.

Rao, N., Morris, P. and Sayed, Y. (2015) Aspirations, Differences and Inequalities: Educational Opportunities and Transitions, Compare: A Journal of Comparative and International Education, 45 (1), 1-4.

Rao, N., Sayed, Y. and Morris, P. (2014) Knowledges, Identities and Aspirations: Implications For Learning, Compare: A Journal of Comparative and International Education, 44 (6), 849-851.

Rappleye, J. (2015) Revisiting the Metaphor of The Island: Challenging 'World Culture' From an Island Misunderstood, Globalisation, Societies and Education, 13 (1), 58-87.

Raz, J. (1989) Liberating Duties, Law and Philosophy, 8 (1), 3-21.

Resnik, J. (2008) "The Construction of the Global Worker Through International Education", in J. Resnik (ed.), The Production of Educational Knowledge in the Global Era. Rotterdam: Sense Publishers, pp. 147-167.

Resnik, J. (2012) Sociology of International Education-An Emerging Field of Research, International Studies in Sociology of Education, 22 (4), 291-310.

Rey, T. (2004) Marketing the Goods of Salvation: Bourdieu on Religion, Religion, 34 (4), 331-343.

Reyna, V.F. and Farley, F. (2006) Risk and Rationality in Adolescent Decision Making: Implications for Theory, Practice and Public Policy, Psychological Science in The Public Interest, 7 (1), 1-44.

Richins, M.L. and Chaplin, L.N. (2015) Material Parenting: How the Use of Goods in Parenting Fosters Materialism in the Next Generation, Journal of Consumer Research, $41(6), 1333-1357$. 
Richter, M. and Nollert, M. (2014) Transnational Networks and Transcultural Belonging: A Study of the Spanish Second Generation in Switzerland, Global Networks, 14 (4), 458-476.

Riddle, S. (2013) Youth as Rhizome: Music, Machines and Multiplicities, Social Alternatives, 32 (2), 45-48.

Roberts, B. (2012) Reflection on What is Implied by 'International' with Reference to International Education and International Schools, International Schools Journal, 31, (2), 69-76.

Robinson, C. and Taylor, C. (2013) Student Voice as a Contested Practice: Power and Participation in Two Student Voice Projects, Improving Schools, 16, 32-46.

Robinson, W. (2005) Gramsci and Globalisation: From Nation-State to Transnational Hegemony, Critical Review of International, Social and Political Philosophy, 8 (4), 559574.

Robinson, W. and Harris, J. (2000) Towards a Global Ruling Class? Globalization and The Transnational Capitalist Class, Science and Society, 64 (1), 11-54.

Rose, J., and Baird, J. (2013) Aspirations in An Austerity State: Young People's Hopes and Goals for the Future, London Review of Education, 11 (2), 157-173.

Ross, A. (2009) Disengagement from Education Among 14-16 Year Olds, London: National Centre for Social Research.

Rudnev, M. (2014) Value Adaptation Among Intra-European Migrants: Role of Country of Birth and Country of Residence, Journal of Cross-Cultural Psychology, 45, 16261642.

Rutherford, T. (2013) Emotional Well-Being and Discrepancies Between Child and Parent Educational Expectations and Aspirations in Middle and High School, International Journal of Adolescence and Youth, DOI: 10.1080/02673843.2013/767742. 
Rutherford, T. (2015) Emotional Well-Being and Discrepancies Between Child and Parent Educational Expectations and Aspirations in Middle and High School, International Journal of Adolescence and Youth, 20 (1), 69-85.

Ryan, R. and Deci, E. (2012) “Overview of Self-Determination Theory: An Organismic Dialectical Perspective", in R. Ryan (ed.), The Oxford Handbook of Human Motivation. Oxford: Oxford University Press, pp. 3-33.

Sahlberg, P. (2004) Teaching and Globalisation, Managing Global Transitions, 2 (1), 6583.

Said, E. (2001) Reflections on Exile and Other Literary and Cultural Essays, London: Granta Books.

Samuel, F.A. (2015) Human Fulfilment and Education: A Critique of Dewey's Philosophy of Education, Religion and Education, 42 (1), 99-117.

Sanchez-Marti, A. and Ramirez-Iniguez, A. (2012) Inclusive Education: An Examination of School Relationships and Student Interactions, Intercultural Education, 23 (6), 491500 .

Sandberg-Thoma, S.E., Snyder, A.R. and Jang, B.J. (2015) Exiting and Returning to the Parental Home for Boomerang Kids, Journal of Marriage and Family, 77, 806-818.

Sanderse W. (2013) The Meaning of Role Modelling in Moral and Character Education, Journal of Moral Education, 42 (1), 28-42.

Sarantakos, S. (1998) Social Research, Basingstoke: Macmillan. Schoon, I., and Polek, E. (2011) Teenage Career Aspirations and Adult Career Attainment: The Role of Gender, Social Background and General Cognitive Ability, International Journal of Behavioral Development, 35, 210-217.

Savage, M., Devine, F., Cunningham, N., Taylor, M., Li, Y., Hjellbrekke, J., Le Roux, B., Friedman, S. and Miles, A. (2013) A New Model of Social Class? Findings from the BBC's Great British Class Survey Experiment, Sociology, 47 (2), 219-250. 
Sawitri, D. R. and Creed, P. A. (2015) Perceived Career Congruence Between Adolescents and Their Parents as a Moderator Between Goal Orientation and Career Aspirations, Personality and Individual Differences, http://dx.doi.org/10.1016/i.paid.2014.12.061.

Sawitri, D.R., Creed, P.A. and Zimmer-Gembeck, M.J. (2015) Longitudinal Relations of Parental Influences and Adolescent Career Aspirations and Actions in a Collectivist Society, Journal of Research on Adolescence, 25 (3), 551-563.

Schachter, E. and Rich, Y. (2011) Identity Education: A Conceptual Framework for Educational Researchers and Practitioners, Educational Psychologist, 46 (4), 222-238.

Schoon, I. and Parsons, S. (2002) Teenage Aspirations for Future Careers and Occupational Outcomes, Journal of Vocational Behavior, 60, 262-288.

Schoon, I. and Polek, E. (2011) Teenage Career Aspirations and Adult Career Attainment: The Role of Gender, Social Background and General Cognitive Ability, International Journal of Behavioral Development, 35, 210-217.

Scott, Z. and Serek, J. (2015) Ethnic Majority and Minority Youths' Ascription of Responsibility for Solving Current Social Issues: Links to Civic Participation, Journal of Adolescent Research, 30 (2), 180-212.

Sears, C. (2011) Integrating Multiple Identities: Narrative in the Formation of Maintenance of the Self in International School Students, Journal of Research in International Education, 10, 71-86.

Sears, C. (2012) Negotiating identity in English-medium Settings: Agency, Resistance and Appropriation Among Speakers of Other Languages in an International School, Journal of Research in International Education, 11, 117-136.

Seery, A. (2010) Education, The Formation of Self and The World of Web 2.0, London Review of Education, 8 (1), 63-73.

Seligman, M. (2011) Flourish, London: Nicholas Brealey Publishing. 
Sellar S. (2013) Hoping For the Best in Education: Globalisation, Social Imaginaries and Young People, Social Alternatives, 32 (2), 31-38.

Sellar, S. and Gale, T. (2011) Mobility, Aspiration, Voice: A New Structure of Feeling for Student Equity in Higher Education, Critical Studies in Education, 52, 115-134.

Sen, A. (1985) Well-Being, Agency and Freedom: The Dewey Lectures 1984, The Journal of Philosophy, 102 (4), 169-221.

Sen, A. (2008) The Idea of Justice, Journal of Human Development, 9 (3), 331-342.

Senior, J. (2014) All Joy and No Fun, New York, Harper Collins.

Senland, A. (2015) The Neuroscience of Human Relationships: Attachment and The Developing Social Brain, Journal of Moral Education, 44 (1), 116-119.

Serracant, P. (2015) The Impact of The Economic Crisis on Youth Trajectories: A Case Study From Southern Europe, Young, 23 (1), 39-58.

Settersen Jr., R. and Ray, B. (2010) What's Going on with Young People Today? The Long and Twisting Path to Adulthood, The Future of Children, 20 (1), 19-41.

Shaheen, F. and Gul, F. (2014) Socioeconomic Status and Achievement: A Survey Study of Students at Secondary Level, International Journal of Educational Studies, 1 (3), 163167.

Sheldon, K. and Schuler, J. (2011) Wanting, Having and Needing: Integrating Motive Disposition Theory and Self-Determination Theory, Journal of Personality and Social Psychology, 101 (5), 1106-1123.

Sheng, X. (2014) Parental Expectations Relating to Children's Higher Education in Urban China: Cultural Capital and Social Class, Journal of Sociology, 50 (4), 560-576.

Shevellar, L. (2015) From Bearers of Problems to Bearers of Culture: Developing Community in the Community Development Classroom, International Journal of Qualitative Studies in Education, 28 (4), 457-475. 
Shin, D.C. (2015) How People Perceive and Appraise the Quality of Their Lives: Recent Advances in the Study of Happiness and Wellbeing, Irvine, CA: Centre for The Study of Democracy.

Shoffner, M.F., Newsome, D., Minton, C.A.B. and Morris, C.A.W. (2015) A Qualitative Exploration of the STEM Career-Related Outcome Expectations of Young Adolescents, Journal of Career Development, 42 (2), 102-116.

Sichel, N. (2004) "Going Home", in F. Eidse and N. Sichel (eds.), Unrooted Childhoods: Memoirs of Growing Up Global. London: Nicholas Brearley Publishing, pp. 185-198.

Sidhu, J.K. and Foo, K.H. (2015) Materialism: The Road to Happiness and Life Satisfaction Among Singaporeans, The Journal of Happiness and Well-Being, 3 (1), 7792.

Sigalas, E. (2010) The Role of Personal Benefits in Public Support for the EU: Learning From the Erasmus Students, West European Politics, 33 (6), 1341-1361.

Sihvonen, J. (2015) Media Consumption and The Identity Projects of The Young, Young, 23 (2), 171-189.

Sikora, J. and Biddle, N. (2015) How Gendered is Ambition? Educational and Occupational Plans of Indigenous Youth in Australia, International Journal of Educational Development, 42, 1-13.

Silova, I. and Rappleye, J. (2015) Beyond The World Culture Debate in Comparative Education: Critiques, Alternatives and A Noisy Conversation, Globalisation, Societies and Education, 13 (1), 1-7.

Silverman, D. (2004) Interpreting Qualitative Data: Methods for Analysing Talk, Text and Interaction, London: Sage.

Sinclair, S., McKendrick, J.H., and Scott, G. (2010) Failing Young People? Education and Aspirations in a Deprived Community, Education, Citizenship and Social Justice, 5 (5), 420. 
Skeggs, B. (2014) Values Beyond Value? Is Anything Beyond The Logic of Capital?, The British Journal of Sociology, 65 (1), 1-20.

Sklair, L. (2001) The Transnational Capitalist Class, Oxford: Blackwell.

Skrbis, Z., Western, M., Tranter B., Hogan, D., Coates, R., Smith, J., Hewitt, B. and Mayall, M. (2011) Expecting the Unexpected: Young People's Expectations About Marriage and Family, Journal of Sociology, 48 (1), 63-83.

Skrbis, Z. and Woodward, I. (2007) The Ambivalence of Ordinary Cosmopolitanism: Investigating the Limits of Cosmopolitan Openness, The Sociological Review, 55 (4), 730-747.

Skrbis, Z., Woodward, I. and Bean, C. (2013) Seeds of Cosmopolitan Future? Young People and Their Aspirations For Future Mobility, Journal of Youth Studies, DOI: 10.1080/13676261.2013.834314.

Sloane-Seale, A. (2012) Teachers as Mentors: Models for Promoting Achievement with Disadvantaged and Underrepresented Students by Creating Community, Canadian Journal of University Continuing Education, 38 (1), 1-3.

Smith, A. (1991) National Identity, London: Penguin.

Smith, C. (2009) Souls in Transition, Oxford: Oxford University Press.

Smith, E., Gidlow, B., and Steel, G. (2012) Engaging Adolescent Participants in Academic Research: The Use of Photo-Elicitation Interviews to Evaluate School-Based Outdoor Education Programmes, Qualitative Research, 12, 367-387.

Smith, J. (2014) Gendered Trends in Student Teachers' Professional Aspirations, Educational Management Administration and Leadership, DOI: 10.1177/1741143214543200.

Smith, R. (2008) The Long Slide to Happiness, Journal of Philosophy of Education, 42 (34), 559-573.

Smyth, J. (2012) Doing Research on Student Voice in Australia, Management in Education, 26 (3), 153-154. 
Smyth, J. and Wrigley, T. (2013) Living on the Edge: Rethinking Poverty, Class and Schooling, New York: Peter Lang Publishing Inc.

Sohl, S. and Arensmeier, C. (2015) The School's Role in Youths' Political Efficacy: Can School Provide a Compensatory Boost to Students' Political Efficacy?, Research Papers in Education, 30 (2), 133-163.

Song, J. (2013) For Whom The Bell Tolls: Globalisation, Social Class and South Korea's International Schools, Globalisation, Societies and Education, 11 (1), 136-159.

South, S. and Haynie, D. (2004) Friendship Networks of Mobile Adolescents, Social Forces, 83 (1), 315-350.

Soutter, A.K., O'Steen, B. and Gilmore, A. (2014) The Student Well-Being Model: A Conceptual Framework for the Development of Student Well-Being Indicators, International Journal of Adolescence and Youth, 19 (4), 496-520.

Soutter, M. (2014) The Moral Work of Teaching and Teacher Education: Preparing and Supporting Practitioners, Journal of Moral Education, 43 (4), 532-534.

Speder, Z. and Murinko, L. (2013) Perceptions of the Ages and Markers of Adulthood: Are Conceptions of Adulthood Universal and Unisex? Ages and Social Markers in 25 European Countries, Social Forces, 92 (3), 873-898.

Stahl, G. (2014) The Affront of the Aspiration Agenda: White Working Class Male Narratives of 'Ordinariness' in Neoliberal Times, Masculinities and Social Change, 3 (2), 88-119.

Staller, K.M. (2015) Qualitative Analysis: The Art of Building Bridging Relationships, Qualitative Social Work, 14 (2), 145-153.

Stauder, J. (2014) Friendship Networks and The Social Structure of Opportunities for Contact and Interaction, Social Science Research, 48, 234-250.

St. Clair, R. and Benjamin, A. (2011) Performing Desires: The Dilemma of Aspirations and Educational Attainment, British Educational Research Journal, 37 (3), 501-517. 
St. Clair, R., Kintrea, K., and Houston, M. (2013) Silver Bullet or Red Herring? New Evidence on The Place of Aspirations in Education, Oxford Review of Education, DOI: 10.1080/03054985.2013.854201.

Sternberg, R. (2001) Why Schools Should Teach for Wisdom: The Balance Theory of Wisdom in Educational Settings, Educational Psychologist, 36 (4), 227-245.

Stockfelt, S. (2015) Capital, Agency, Family and The Diaspora: An Exploration of Boys' Aspirations Towards Higher Education in Urban Jamaica, Compare: A Journal of Comparative and International Education, 45 (1), 5-25.

St. Pierre, E.A. and Jackson, A.Y. (2014) Qualitative Data Analysis After Coding, Qualitative Inquiry, 20 (6), 715-719.

Strajn, D. (2014) Educating for Democratic Consciousness: Counter-Hegemonic Possibilities, International Review of Education, 60, 587-589.

Strand, S. and Winston, J. (2008) Educational Aspirations in Inner City Schools, Educational Studies, 34 (4), 249-267.

Stutchbury, K. and Fox, A. (2009) Ethics in Educational Research: Introducing a Methodological Tool for Effective Ethical Analysis, Cambridge Journal of Education, 39 (4), 489-504.

Subedi, B. (2013) Photographic Images of Refugee Spatial Encounters: Pedagogy of Displacement, Qualitative Research in Education, 2 (3), 277-301.

Swalwell, K. (2013) "With Great Power Comes Great Responsibility": Privileged Students' Conceptions of Justice-Oriented Citizenship, Democracy and Education, 21 (1), 1-11.

Swartz, T., Kim, M., Uno, M., Mortimer, J., and O'Brien, K. (2011) Safety Nets and Scaffolds: Parental Support in the Transition to Adulthood, Journal of Marriage and Family, 73 (2), 414-429.

Sweetland, S.R. (1996) Human Capital Theory: Foundations of a Field of Inquiry, Review of Educational Research, 66 (3), 341-359. 
Sweetman, P. (2003) Twenty First Century Dis-ease? Habitual Reflexivity or The Reflexive Habitus, The Sociological Review, 51 (4), 529-549.

Symon, G. and Cassell, C. (2012) "Assessing Qualitative Research", in G. Symon and C. Cassell (eds.), Qualitative Organisational Research. London: Sage, pp. 204-223.

Takayama, K. (2015) Provincialising The World Culture Theory Debate: Critical Insights From a Margin, Globalisation, Societies and Education, 13 (1), 34-57.

Tarc, P. and Tarc, A.M. (2015) Elite International Schools in The Global South: Transnational Space, Class Relationships and the 'Middling' International Schoolteacher, British Journal of Sociology of Education, 36 (1), 34-52.

Tate, N. (2012) Challenges and Pitfalls Facing International Education in a PostInternational World, Journal of Research in International Education, 11 (3), 205-217. Taylor, J. (2012) Think Again, London: Continuum.

Taysum, A. (2011) The Value of Educational Research, Debate Paper: Doctoral U.K. Summer Study School.

Teney, C., Devleeshouwer, P. and Hanquinet, L. (2013) Educational Aspirations Among Ethnic Minority Youth in Brussels: Does The Perception of Ethnic Discrimination in The Labour Market Matter? A Mixed Methods Approach, Ethnicities, 13 (5), 584-606.

Tenney, E.R., Logg, J.M. and Moore, D.A. (2015) (Too) Optimistic About Optimism: The Belief That Optimism Improves Performance, Journal of Personality and Social Psychology, 108 (3), 377-399.

Tesch, R. (1990) Qualitative Research: Analysis Types and Software, London: Falmer Press.

The Prince's Trust (2014) Youth Index 2014, London: The Prince's Trust.

The Sutton Trust (2014) Mobility Manifesto, London: The Sutton Trust.

Thomas, G. (2013) How to Do Your Research Project, London: Sage. 
Thomas, L. (2015) “Design for Learning: Using Design Principles to Transform School”, in C. McLaughlin (ed.), The Connected School: A Design for Well-Being. London: Pearson, pp. 43-51.

Thompson, R. (2012) Changing Societies, Changing Childhood: Studying the Impact of Globalisation on Child Development, Child Development Perspectives, 2, 187-192.

Thornton, A., Pickering, E., Peters, M., Leathwood, C., Hollingworth, S. and Mansaray, A. (2014) School and College-Level Strategies to Raise Aspirations of High-Achieving Disadvantaged Pupils to Pursue Higher Education Investigation-Research Report, London: Department for Education.

Tietze, S. (2012) "Researching Your Own Organisation", in G. Symon and C. Cassell (eds.), Qualitative Organisational Research. London: Sage, pp. 53-71.

Timmermans, J. (2010) “Changing our Minds", in J.H.F. Meyer, R. Land and C. Baillie (eds.), Threshold Concepts and Transformational Learning. Rotterdam: Sense, pp. 3-19.

Tinnfalt, A., Jensen, J. and Eriksson, C. (2015) What Characterises a Good Family? Giving Voice to Adolescents, International Journal of Adolescence and Youth, 20 (4), 429-441.

Tomlinson, C.A. (2015) Teaching for Excellence in Academically Diverse Classrooms, Society, DOI: 10.1007/s12115-015-9888-0.

Turok, I., Kintrea, K., St. Clair, R., and Benjamin, A. (2009) Shaping Educational Attitudes and Aspirations: The Influence of Parents, Place and Poverty: Stage 1 Report. University of Glasgow, York: Joseph Rowntree Foundation.

Twine, F.W. and Gardener, B. (2013) "Introduction", in F.W. Twine and B. Gardener (eds.), Geographies of Privilege. London: Routledge, pp.1-10.

Tyler, I. (2008) 'Chav Mum, Chav Scum', Feminist Media Studies, 8 (1), 17-34.

U.K.C.E.S. (2012) The Youth Employment Challenge, London: U.K. Commission for Employment and Skills. 
U.K.C.E.S. (2014) Precarious Futures? Youth Unemployment in an International Context, London: U.K. Commission for Employment and Skills.

Ule, M., Zivoder, A. and du Bois-Reymond, M. (2015) 'Simply the Best for My Children': Patterns of Parental Involvement in Education, International Journal of Qualitative Studies in Education, 28 (3), 329-348.

University of Leicester (2012a) Social Science Research 4: Qualitative Research and Analysis, Leicester: College of Social Science.

University of Leicester (2012b) Research Concerning Children and Young People, (http://www2.le.ac.uk/institution/committees/research-ethics/research-concerningchildren-and-young-people-guidelines) online, accessed 17 August 2012.

Unterhalter, E., Ladwig, J. and Jeffrey, C. (2014) Aspirations, Education and Social Justice: Applying Sen and Bourdieu, British Journal of Sociology of Education, 35 (1), 133-145.

Van Bochove, M., Burgers, J., Geurts, A., de Koster, W. and van der Waal, J. (2015) Questioning Ethnic Identity: Interviewer Effects in Research About Immigrants' SelfDefinition and Feelings of Belonging, Journal of Cross-Cultural Psychology, 46 (5), $652-$ 666.

Van Den Bouwhuijsen, H. (1995) What Makes Human Differences into Cultural Differences? Philosophica, 55 (1), 87-116.

Van Houtte, M. and Stevens, P. A. J. (2010) School Ethnic Composition and Aspirations of Immigrant Students in Belgium, British Educational Research Journal, 36 (2), 209237.

Van Maele, D. and Van Haute, M. (2011) The Quality of School Life: Teacher-Student Trust Relationships and The Organisational School Context, Social Indicators Research, $100,85-100$.

Van Oord, L. (2008) After Culture: Intergroup Encounters in Education, Journal of Research in International Education, 7, 131-147. 
Van Oord, L. and Corn, K. (2013) Learning how to Swallow the World: Engaging with Human Difference in Culturally Diverse Classrooms, Journal of Research in International Education, published online 21 March 2013.

Van Tubergen, F. and Volker, B. (2014) Inequality in Access to Social Capital in the Netherlands, Sociology, DOI: 10.1177/0038038514543294.

Vasques de Miranda, G. (2007) Plural School, Estudos Avancados, 21 (60), 61-74.

Veenhoven, R. (1994) Is Happiness a Trait?, Social Indicators Research, 32 (2), 101-160.

Velliaris, D.M. and Willis, C.R. (2014) International Family Profiles and Parental School Choice in Tokyo, Journal of Research in International Education, 13 (3), 235-247.

Veness, A. (1993) Neither Homed Nor Homeless: Contested Definitions and the Personal Worlds of the Poor, Political Geography, 12 (4), 319-340.

Vera-Estay, E., Dooley, J.J. and Beauchamp, M.H. (2015) Cognitive Underpinnings of Moral Reasoning in Adolescence: The Contribution of Executive Functions, Journal of Moral Education, 44 (1), 17-33.

Vertovec, S. (2010) Toward Post-Multiculturalism? Changing Communities, Conditions and Contexts of Diversity, International Social Science Journal, 61 (199), 83-95.

Vidovich, L. and Yap, M. (2008) "Local Dynamics in Expanding School Choice in Singapore", in M. Forsey, S. Davies and G. Walford (eds.), The Globalisation of School Choice?. Oxford: Symposium, pp. 209-226.

Vieluf, S., Hochweber, J., Klieme, E. and Kunter, M. (2015) Who Has a Good Relationship with Teachers? A Comparison of Comprehensive Education Systems with Education Systems Using Between-School Tracking, Oxford Review of Education, 41 (1), 3-25.

Vorhaus, J. (2014) Function and Functional Explanation in Social Capital Theory: A Philosophical Appraisal, Studies in Philosophy and Education, 33, 185-199.

Vornanen, R., Torronen, M. and Niemela, P. (2009) Insecurity of Young People: The Meaning of Insecurity as Defined by 13-17 Year Old Finns, Young, 17, 399-419. 
Vuolo, M., Mortimer, J. and Staff, J. (2013) Adolescent Precursors of Pathways from School to Work, Journal of Research on Adolescence, 24 (1), 145-162.

Wacquant, L. (2011) Habitus as Topic and Tool: Reflections on Becoming a Prizefighter, Qualitative Research in Psychology, 8 (1), 81-92.

Wacquant, L. (2014) Putting Habitus in Its Place: Rejoinder to The Symposium, Body and Society, 20 (2), 118-139.

Walsh, J. (2014) From Nations of Immigrants to States of Transience: Temporary Migration in Canada and Australia, International Sociology, 29, 584-606.

Waters, J. and Brooks, R. (2011) International/Transnational Spaces of Education, Globalisation, Societies and Education, 9 (2), 155-160.

Waytz, A., Hershfield, H.E. and Tamir, D.I. (2015) Mental Simulation and Meaning in Life, Journal of Personality and Social Psychology, 108 (2), 336-355.

Weenink, D. (2007) Cosmopolitan and Established Resources of Power in the Education Arena, International Sociology, 22 (4), 492-516.

Weenink, D. (2008) Cosmopolitanism as a Form of Capital: Parents Preparing their Children for a Globalising World, Sociology, 42, 1089-1106.

Weis, L. (2014) A Comment on Class Productions in Elite Secondary Schools in TwentyFirst-Century Global Context, Globalisation, Societies and Education, 12 (2), 309-320.

Wentzel, K. (2012) "Teacher-Student Relationships and Adolescent Competence at School", in T. Wubbels et al (eds.), Interpersonal Relationships in Education. Rotterdam: Sense Publishers, pp. 19-36.

Wentzel, K., Barry, C., and Caldwell, K. (2004) Friendships in Middle School: Influences on Motivation and School Adjustment, Journal of Educational Psychology, 96, (2), 195203.

Wertsch, J.V. (1993) Voices of the Mind, Cambridge, MA: Harvard University Press. 
Weston, R. and Qu, L. (2013) Working Out Relationships, Melbourne: Australian Institute of Family Studies.

White, E., Mistry, R. and Chow, K. (2013) How Do Teachers Talk About Economic Inequality? The Complexity of Teaching at A Socioeconomic Integrated Elementary School, Analyses of Social Issues and Public Policy, 13 (1), 370-394.

Whitehead, J. (2008) Using a Living Theory Methodology in Improving Practice and Generating Educational Knowledge in Living Theories, Educational Journal of Living Theories, 1 (1), 103-126.

Wicht, A. and Ludwig-Mayerhofer, W. (2014) The Impact of Neighbourhoods and Schools on Young People's Occupational Aspirations, Journal of Vocational Behaviour, 85, 298-308.

Wigerfelt, B. and Wigerfelt, A.S. (2015) Anti-Gypsyism in Sweden: Roma's and Travellers' Experiences of Bias-Motivated Crime, Internet Journal of Criminology, (www.internetjournalofcriminology.com) online, accessed 20 February 2015.

Wiles, J. (2008) Sense of Home in a Transnational Social Space: New Zealanders in London, Global Networks, 1, 116-137.

Wilkinson, D. and Wilkinson, V. (2013) "The Pestalozzi Influence on International Education", in R. Pearce (ed.), International Education in Schools: Moving Beyond the First Forty Years. London: Bloomsbury, pp. 107-117.

Wilkinson, R. and Pickett, K. (2010) The Spirit Level: Why Equality is Better for Everyone, London: Penguin.

Williams, C. (2007) Research Methods, Journal of Business and Economic Research, 5 (3), 65-71.

Williams, F. (2005) A Good Enough Life: Developing the Grounds for a Political Ethic of Care, Soundings, 30, 17-32. 
Williams, W.R. and Carter, K.A. (2014) Disadvantage and Privilege in Our Schools: How Teachers, Psychologists and Policy Makers Can Do Better, Analyses of Social Issues and Public Policy, 14 (1), 415-418.

Williamson, H. (2014) Radicalisation to Retreat: Responses of the Young to Austerity Europe, International Journal of Adolescence and Youth, 19 (S1), 5-18.

Wiltgren, L. (2013) Youth Using National Symbols in Constructing Identities, Journal of Youth Studies, DOI: 10.1080/13676261.2013.815706.

Wolgemuth, J.R., Erdil-Moody, Z., Opsal, T., Cross, J.E., Kaanta, T., Dickmann, E.M. and Colomer, S. (2015) Participants' Experiences of the Qualitative Interview: Considering the Importance of Research Paradigms, Qualitative Research, 15 (3), 351-372.

World Health Organisation (2012) Social Determinants of Health and Well-Being among Young People: Health Behaviour in School Aged Children (HBSC) Study: International Report from the 2009/2010 Survey, Copenhagen: World Health Organisation.

Wrench, A., Hammond, C., McCallum, F., and Price, D. (2012) Inspire to Aspire: Raising Aspirational Outcomes Through a Student Well-Being Curricular Focus, International Journal of Inclusive Education, DOI: 10.1080/13603116.2012.718804.

Xie, C.J. (2015) The Effect of Privilege on Students' Constructions of Social Responsibility: A Case Study at Westville Boys' High School, Independent Study Project (ISP) Collection, Paper 2035. http://digitalcollections.sit.edu/isp collection/2035.

Xu, X. and Payne, S. (2013) Quantity, Quality and Satisfaction with Mentoring: What Matters Most?, Journal of Career Development, DOI: 10.1177/0894845313515946.

Yanow, D., Ybema, S. and van Hulst, M. (2012) “Practising Organisational Ethnography", in G. Symon and C. Cassell (eds.), Qualitative Organisational Research. London: Sage, pp. 331-350.

Yardley, L. (2000) Dilemmas in Qualitative Health Research, Psychology and Health, 15 (2), 215-228. 
Yeager, D. and Bundick, M. (2009) The Role of Purposeful Work Goals in Promoting Meaning in Life and in Schoolwork During Adolescence, Journal of Adolescent Research, 24, 423-451.

Yemini, M. (2012) Internationalization Assessment in Schools: Theoretical Contributions and Practical Implications, Journal of Research in International Education, 11, 152-164.

Yi, J. and Jung, G. (2015) Debating Multicultural Korea: Media Discourse on Migrants and Minorities in South Korea, Journal of Ethnic and Migration Studies, 41 (6), 9851013.

Yosso, T. (2005) Whose Culture Has Capital? A Critical Race Theory Discussion of Community Cultural Wealth, Race, Ethnicity and Education, 8 (1), 69-91.

Young, J. (2014) 'The Whole World is My Home': An Investigation into How A Globalised Lifestyle, International Capital and An International Schooling Experience Influence the Identities and Aspirations of Young People, Journal of The National Institute for Career Education and Counselling, 32, 35-42.

Yuval-Davis, N. (2006) Belonging and The Politics of Belonging, Patterns of Prejudice, 40 (3), 197-214.

Zembylas, M. (2012) Transnationalism, Migration and Emotions: Implications for Education, Globalisation, Societies and Education, 10 (2), 163-179.

Zhang, Y. and Guo, Y. (2015) Becoming Transnational: Exploring Multiple Identities of Students in a Mandarin-English Bilingual Programme in Canada, Globalisation, Societies and Education, 13 (2), 210-229.

Zhang, Y. and McGrath, I. (2009) Teacher-Student relationships in an International Baccalaureate School in China, Journal of Research in International Education, 8, 164190. 
Zick, A., Kupper, B. and Hovermann, A. (2011) Intolerance, Prejudice and

Discrimination: A European Report, Berlin: Nora Langenbacher Friedrich-Ebert-Stiftung Forum.

Ziller, C. (2015) Ethnic Diversity, Economic and Cultural Contexts, and Social Trust:

Cross Sectional and Longitudinal Evidence from European Regions 2002-2010, Social Forces, 93 (3), 1211-1240.

Zipin, L., Sellar, S., Brennan, M. and Gale, T. (2013) Educating for Futures in Marginalized Regions: A Sociological Framework for Rethinking and Researching Aspirations, Educational Philosophy and Theory: Incorporating ACCESS, DOI: 10.1080/00131857.2013.839376.

Zyngier, D. (2014) Living on The Edge: Rethinking Poverty, Class and Schooling, International Studies in Sociology of Education, DOI: 10.1080/09620214.2014.969926. 